\title{
Chronobiology's progress. Part I, season's appreciations 2004-2005: time-, frequency-, phase-, variable-, individual-, age- and site-specific chronomics
}

\author{
Franz Halberg ${ }^{1}$, Germaine Cornélissen ${ }^{1}$, George Katinas $^{1}$, Levan Tvildiani $^{2}$, Marina Gigolashvili ${ }^{3}$, \\ Ketevan Janashia ${ }^{4}$, Tim Toba ${ }^{1}$, Miguel Revilla ${ }^{5}$, Philip Regal ${ }^{1}$, Robert B. Sothern ${ }^{1}$, Hans W. Wendt ${ }^{1}$, \\ Zhengrong Wang ${ }^{6}$, Michal Zeman ${ }^{7}$, Rita Jozsa ${ }^{8}$, R.B. Singh ${ }^{9}$, Gen Mitsutake ${ }^{10}$, Sergei M. Chibisov ${ }^{11}$, Jong \\ Lee $^{1}$, Dan Holley ${ }^{12}$, James E. Holte ${ }^{1}$, Robert P. Sonkowsky ${ }^{1}$, Othild Schwartzkopff ${ }^{1}$, Patrick Delmore ${ }^{13}$, \\ Kuniaki Otsuka $^{10}$, Earl E. Bakken ${ }^{14}$, Jerzy Czaplicki ${ }^{15}$ and the International BIOCOS Group
}

${ }^{1}$ Halberg Chronobiology Center, University of Minnesota, Minneapolis, MN, USA

${ }^{2}$ Department of Internal Medicine, Tbilisi State Medical University, Tbilisi, Georgia

${ }^{3}$ Georgian National Astrophysical Observatory, Tbilisi, Georgia

${ }^{4}$ Ministry of Labour, Health and Social Affairs of Georgia, Tbilisi, Georgia

${ }^{5}$ University of Valladolid, Spain

${ }^{6}$ Sichuan University, Chengdu, Sichuan, China

${ }^{7}$ Department of Animal Physiology, Comenius University, Bratislava, Slovakia

${ }^{8}$ University Pecs, Pecs, Hungary

${ }^{9}$ Nutrition and Heart Centre, Halberg Hospital \& Research Institute, Moradabad, India

${ }^{10}$ Tokyo Women's Medical University, Medical Center East, Tokyo, Japan

${ }^{11}$ People's Friendship University of Russia, Moscow, Russia

${ }^{12}$ San Jose State University, San Jose, CA, USA

${ }^{13}$ Medtronic Inc., Fridley, MN, USA

${ }^{14}$ North Hawaii Community Hospital Inc., Kamuela, HI, USA

${ }^{15}$ Institut de Pharmacologie et de Biologie Structurale CNRS, Université Paul Sabatier, Toulouse, France

Received $22^{\text {nd }}$ December 2005.

Published online $20^{\text {th }}$ January 2006.

\begin{abstract}
Summary
New components of transdisciplinary spectra or known components in new variables in us, matching those around us, are being mapped. Their hardly trivial interactions associated with the good and bad around us - from religiosity to crime and war - are being rendered measurable, for the eventual development of countermeasures to the diseases of societies and nations. Internal cycles not only underlie life itself and underlie our evolving genetics at all levels of organization; they also constitute the essential control and reference information in all transdisciplinary science. In preparing for travel to Mars and other missions in space that may take more than a year, let us do what is immediately practicable. Transyears may have very small amplitudes yet are associated with sudden cardiac death in some terrestrial locations; if they should play a role in these electrical incidents of the heart, among others like myocardial infarction and stroke, they will jeopardize lengthy missions in extraterrestrial space, away from hospitals.

The likelihood of stroke or cardiac death can be immediately reduced by chronobiologically assessing blood pressure and heart rate variability and by optimizing the efficacy of timed treatment rather than relying on an unacceptable and often inaccurate spotcheck and treating by convenience rather than pertinence. Needed are: detection of nocturnal abnormality when medication may no longer be effective (or is too effective) neither seen during office visits by day; detection of circadian hyperamplitude-tension (CHAT) associated with a risk of stroke and kidney disease greater than other risks
\end{abstract}


(including "hypertension" when all risks are assessed concomitantly); detection of CHAT as high risk among normotensives who may not need anti-hypertensive medication; individualized inferential statistical testing to determine whether a drug or non-drug intervention such as autogenic training (relaxation) is effective and for how long (detecting any initial and later success or failure), some of which conditions otherwise are not found without chronobiology; individualization of treatment timing, since the same dose of the same medication can further lower the subject's blood pressure average and circadian amplitude when the timing of daily administration is optimized, as ascertained by sequential testing and parameter tests.

Thus, we save lives by monitoring and assessing, and if need be treating, vascular disease risk through chronobiologically interpreted 24-hour or preferably longer (24-hour/7-day) blood pressure and heart rate variability. Abnormalities in the variability of blood pressure and heart rate, impossible to find during a conventional office visit (the latter aiming at the fiction of a "true" blood pressure), can raise cardiovascular disease risk in the next six years from $4 \%$ to $100 \%$.

Keywords: chronobioethics - gliding spectra - blood pressure - heart rate - travel to Mars

- Dedicated to Alejandro Zaffaroni, who came as a pleasant surprise with flowers and more. May a marker-guided preventive chronotherapy of elevations of the risks of diseases not only of individuals but also of societies and nations eventually evolve.

\section{INTRODUCTION}

Chronomics maps the dynamics of organisms' interactions with their environment near and far broadly (Halberg et al. 2003a), rather than merely standardizing lighting, the availability of food and daily routines (in studies on behavior in time in the proximal habitat niche) (Halberg 1969). We found and mapped additional near-matching cycles in and around us (Halberg et al. 2004aI, cI, dI and gI), as anticipated from earlier experience, namely our prior finding of a geophysical counterpart for the biological week and of several sociological, psychological, physiological, pathological and epidemiological near-matches for the geophysical half-year and counterparts for the solar circacissemiannual [cis (= on the near side of) 0.5 -year length] and circatransannual [trans (= beyond) oneyear length], circadecadal and circamultidecadal systems (Halberg et al. 2000a). In most cases, new biomedical counterparts for known physical cycles are again detected, characterized by both time- and space-specificity, the latter probably related to local terrestrial and/or atmospheric effects. Vice versa,

Franz Halberg, Halberg Chronobiology Center, University of Minnesota, Mayo Mail Code 8609,420 Delaware St. S.E., Minneapolis, MN 55455, USA

욜 +1 (612) $624.6976,624.3144$ or 626.5404

且 +1 (612) 624.9989

$\square$ halbe001@umn.edu the presence of consistent biological counterparts reinforced the intermittent detection and estimation with CIs (95\% confidence intervals) of components in physics that have been neglected spectral lines, such as neartransyears, because of their changes in frequency and amplitude, their splitting and/or disappearing and/or reappearing and/or rejoining, described by the name of the mythological king of the wind as "aeolian", a noun and adjective also applicable to the behavior of physical variables (Chibisov et al. 2005I, Sonkowsky et al. 2005aI,bI).

In 1938, Alexander Leonidovich Chizhevsky rhetorically asked: “... can we study an organism outside its cosmoterrestrial environment?" $\mathrm{He}$ answered in the negative, since the living organism does not exist in isolation, and all its functions are in a permanent relation with its environment (...pouvons-nous étudier l'organisme en dehors du milieu cosmo-tellurique? La réponse est négative, car l'organisme vivant n'a pas d'existence isolée et toutes ses fonctions sont en relation permanente avec ce milieu) (Chizhevsky 1938).

In 2006, we have learned from studies of humans in isolation from society in caves for many months (Halberg 1968, Halberg et al. 1998) and in bunkers (Wever 1979) for shorter spans that we may respond more clearly to our remote or manipulated physical environment after subtraction of the social environment (Halberg 1968). Both the question (Chizhevsky 1938, Brown 1960) and the answers have to be formulated in terms of a spectrum of cycles, seen and unseen, around and in us. Internal cycles not only underlie life itself and constitute our evolving genetics at all levels of 


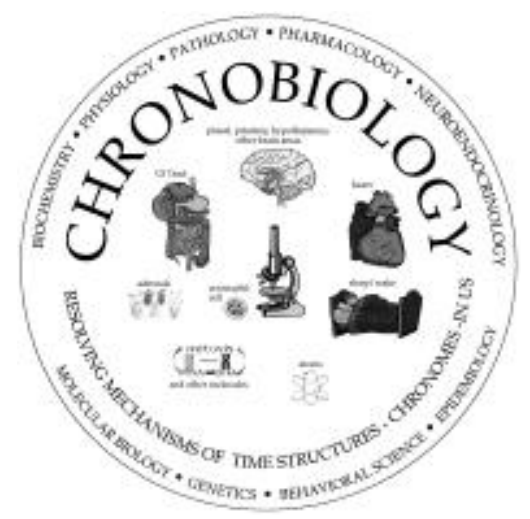

Fig. 1a. The senior author's endeavors that led him to chronobiology are described by invitation elsewhere and are available on the Internet (Halberg et al. 2003a); they constitute a figurative microscopy in time started with counts of circulating blood eosinophil cells (Halberg and Visscher 1950) under a real microscope, initiated in 1948, in developing a bioassay for corticosteroids at Harvard University (Halberg 1952); by 1950 in Minnesota, genetic differences in the extent of within-day changes in count and the rhythm in abnormal discharges detected by electroencephalography in patients with convulsive disorders, with Rudolf Engel (Halberg et al. 1952), led eventually to maps of cycles in the metabolism of the cell, the adrenal-hypothalamicpituitary-pineal network, and to organismic cycles, including the hours of changing resistance (Halberg et al. 1955a) and from there to a chrono-physiology, -pathology, -pharmacology and -toxicology (Halberg 1969). These studies were all carried out in an environment rendered as standardized as possible, yet originally only with respect to the availability of food, lighting and routines in the proximal habitat niche (Cornélissen and Halberg 1994, cf. Luce 1970, Reinberg and Smolensky 1983, Pauly and Scheving 1987, Touitou and Haus 1992, Chibisov 2005, Halberg et al. 2005bI, Refinetti 2006).

organization; they also constitute the essential control and reference information in all science. In preparing for travel to Mars and other missions in space that may take more than a year, let us do what is immediately practicable. Let us optimize more than circadian cycles. Transyears may have very small amplitudes yet may also be associated with sudden cardiac death (SCD) in some terrestrial locations and if they should play a role in these and/or other "incidents" of the heart, they may jeopardize lengthy missions in extraterrestrial space, away from hospitals. This optimization of transyears is the more important since transyear amplitudes can be manipulated by drugs (Watanabe et al. 2004aI). As to basics, from Francesco Redi's omne vivum e vivo, we arrive, if not at omnis cyclus e cyclo, then at a more cautious multi cycli maiores interni biologici e cycli externi. New components of transdisciplinary spectra or known components in new variables in us, matching those around us, are being mapped. Their hardly trivial interactions associated with the good and bad around us - from religiosity to crime and war - are being rendered measurable, for the eventual development of countermeasures to the diseases of societies and nations.

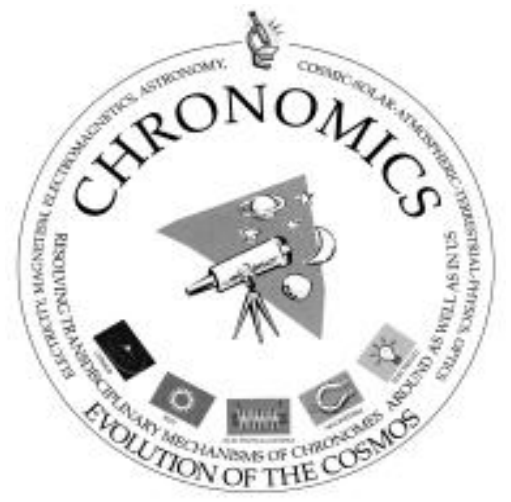

Fig. 1b. Chronomics, of much broader scope, a figurative telescopy, transdisciplinarily examines variables as they change in and around us, with focus on the dynamics of associations, with methods illustrated by the transition from the time-macroscopic displays in Fig. 2a of Julius Bartels, then a leader in inferential statistics (1936; cf. 1959), to the macro-microscopy of Figs $2 \mathrm{~b}, 3,9$ (and Figs $10-15$ in Halberg et al. 2006) facilitated by modern computers and satellites.

\section{PREAMBLE}

The analogies of a figurative microscope and telescope, Figs 1a (Halberg 1969, Halberg et al. 2003a) and 1b (Halberg et al. 2001a, 2003b), introduce findings that led to the development of new endeavors, that are presented in most of over 3000 published titles listed on a special website (http://franzhalberg.com; cf. http://www.msi.umn. edu/ halberg/). The authors from several continents in the bibliography (Halberg et al. 2006) deserve the credit for contributions summarized herein, but stand on the shoulders of many more in the bibliography on the website, among others (Huntington 1915, 1938).

\section{METHOD}

\section{Overview}

A special methodology (Halberg 1969, Cornélissen and Halberg 2005aI) qualifies a phenomenon as a cycle or, as evidence accumulates concerning its replicated occurrence, as a rhythm; it led to the quantitative and objective desiderata of a consensus reached at an international conference in Moscow on Oct. 11, 2005 by physicists meeting with physicians and other biomedical scientists 


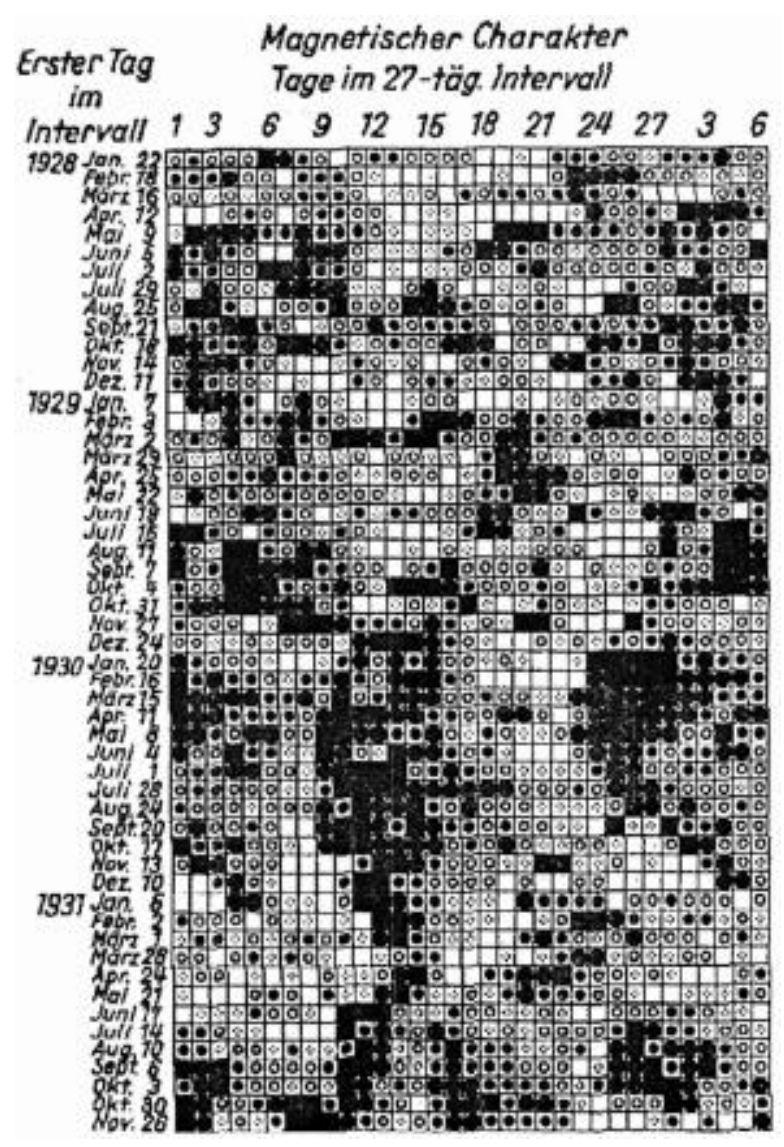

Fig.2a. Geomagnetic "behavior day" chart of Bartels (1936). Time - macroscopic "evidence" (Nachweis) of the 27-day solar rotation (reflected) in daily values of geomagnetic activity stacked along a partly replicated 27-day scale.The record reads like a book: The date of the first day in each row is indicated on the left, each successive row beginning 27 days later; at the end of each row, the first 6 days of the next row have been repeated to emphasize the continuity of the series. For reference, the days in each row are numbered 1-27. "The symbols were chosen so that there are in all about as many dark as light symbols on the chart" (Bartels 1936, 1953). "Every discussion of the physical causes of periodicities in geophysical and cosmical phenomena must be preceded by statistical studies testing the significance and reliability of these periodicities. This statistical viewpoint in the application of harmonic analysis was introduced by A. Schuster" (1906), who also deserves credit for recognizing the "quasi-persistence" of quasi-periodic variables, with "quasi-periodic" now being a homesteaded term (Farkas 1994). In a 1953 presentation, Bartels proposed the investigation of periodicities with his harmonic dial by focus on daily as well as yearly, half-yearly and 27-day changes as signatures of the solar rotation and/or geomagnetics. But periodograms on mechanical desk computers had already revealed free-running biological rhythms. In an era of satellites and electronic computers, the presence of circa-rhythms (discussed with Bartels in 1953) based on biological data analyzed by Schuster's periodogram becomes apparent in spectra by physicists (Shapiro 1967, Fraser-Smith 1972, Delouis and Mayaud 1975) and biologists alike (Halberg 1968, Halberg et al. 2003c and d, Halberg et al. 2005hI, cf. Mikulecky 1993, 1994a, 1997). The built-in biological periods in Fig. $2 b$ in organisms that were present perhaps 500 million years ago, reinforce findings on physical variables that go back, instead of for millions of years, only for a thousand or a few hundred years such as the aurora or the sunspot or for hardly more than 100 years, such as a geomagnetic index and for much shorter spans in the case of physical "newcomers" to science like the solar wind speed or proton content or coronal mass ejection.

(Chibisov 2005). This inferential statistical method consists of a combination of computer programs and time structural (chronomic) maps; the maps allow for the anticipation of certain transdisciplinary components and thus should enhance the sensitivity of tests of the statistical significance of a cycle, with qualifications by the added available evidence and other circumstances such as gaps in time series.

The larger the number of earlier demonstrations of a rhythm, the lesser is the need for the otherwise indispensable correction for multiple testing of the results from spectral analyses. The transdisciplinary anticipation and corroboration is of particular importance for relatively short time-series with nonsinusoidal components that cover less than 5 cycles of an investigated oscillation (Halberg et al. 1981).

When the time series are much longer (and decades-long series continue to accumulate), new components emerge. We find interesting, environmentally resonant physiological behavior in moving spectral windows (gliding or pergressive when successive intervals overlap rather than being fractionated, i.e., non-overlapping, the latter to lessen correlation). 


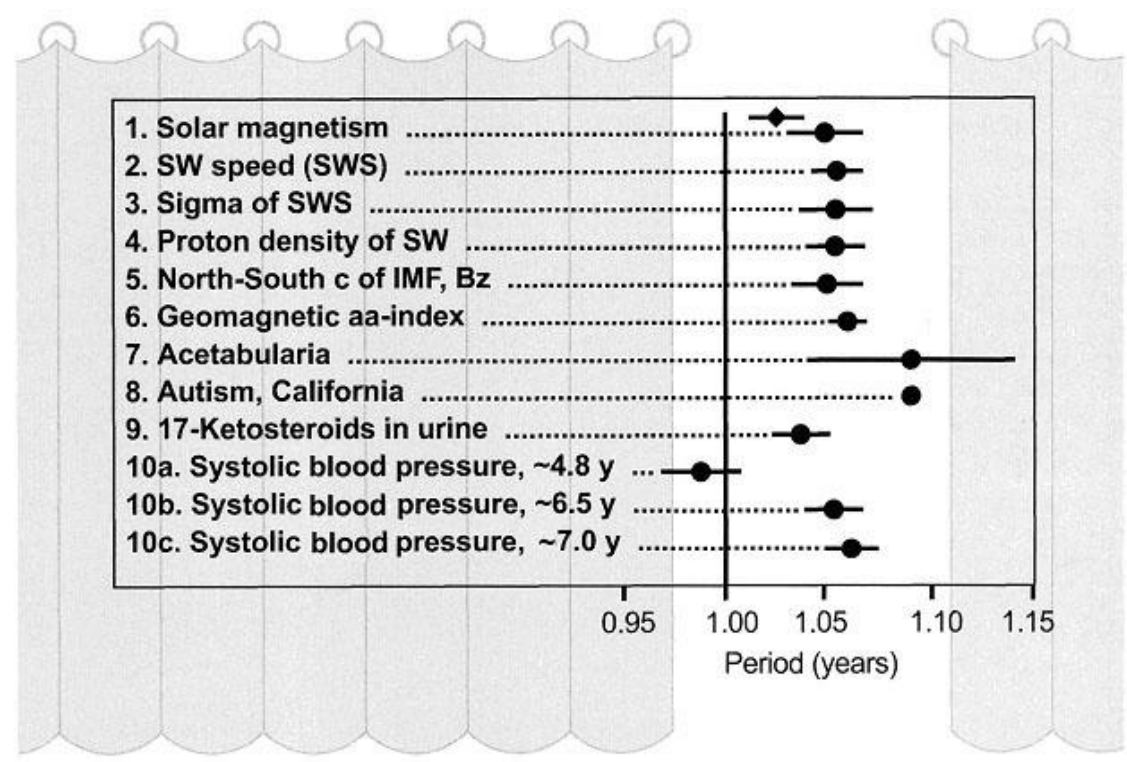

Fig.2b. Near-transyears around (1-6) and in (7-10) organism(s)*. It is indispensable to specify the calendar span and thereby also the length of a time series upon which the resolution of a (set of) spectral component(s) (c) with period(s) $(\tau)$ rests. Thus, based on a series of $\sim 4.5$ years, one finds a component of systolic blood pressure (10a) with a $\tau$ of a year since its $95 \%$ confidence interval (CI) overlaps the exact 1-year period. In row $10 \mathrm{~b}$ below, based on an about 6.5 -year record, the resolution of a neartransyear (with a $\tau$ between 1.0 and 1.2 years and a CI overlapping neither of these lengths) becomes possible, perhaps as a function of age. In another case (RBS), examined over decades as a function of age (not shown), transyears become more prominent with age (Halberg et al. 2004hI and 2006: Figs 12 and 13). A still longer record will have to confirm that during an even longer span at a still later age, as in FH, Fig. 3, there will be only transyears and no component with a CI of $\tau$ overlapping the calendar year length. As to mechanisms, it seems pertinent that the only endocrine record covering 15 years of observation of an adult's 17-ketosteroid excretion reveals globally no yearly component, only a near- and two fartransyears, the latter not shown.

The finding of mutually reinforcing physical and biological near-transyears, defined by 1.00 year $(\mathrm{y})<\tau<1.20 \mathrm{y}$, is the message of this graph, drawn with a curtain of uncertainty indicating the uncertainties of aeolians. These near-transyears in us, acquired by evolution, reinforce the reality of those around us from which they likely derive. We all stacked data in the past over a year and other $\tau$ s such as a day; yet whenever possible, we should get an estimate of the period involved before stacking! This was a sine qua non well over 50 years ago for circadians and has become one for circannuals and in particular for aeolians, such as the near-transyear, here depicted as calendar-time-location- and series-length-dependent neartransyears (Halberg et al. 2004dI).

*As separate components and probably not as sidelobes of circannual variation (not stemming from amplitude and/or phase modulation by components with a lower frequency). Circles = period lengths (point estimations); horizontal lines crossing circles $=95 \%$ confidence intervals $(\mathrm{Cls})$ of spectral components (when the zero-amplitude assumption was rejected nonlinearly.

From www noaa.gov 1: Stanford data from May 1975 - Apr 2002 (27 y) /Diamond: longer record of 37 y with added Stanford data (up to 2004) and including other data from Crimea starting in 1968; when data were available from both sites, Stanford and Crimea, they were avaraged; total record length from 1968 to 2004; 6: 131 y (1868 - 1998), From OMNI2 (1963 - 2003) (ftp://nssdcftp.gsfc.nasa.gov/spacecraft_data/omni) 2-4: SW = Solar wind. Sigma = Standard deviation, 5: Bz $=$ North - South component of Interplanetary Magnetic Field (IMF), From BIOCOS 7: Oxygen production (1980-1994), 8: Quarterly incidence, 10.5 y (1994-2004), 9: Daily excretion for 15 y of urinary steroidal metabolites (17 - ketosteroids, $\mathrm{CH}$, Oct 1948 - Oct 1963), 10: Half-hourly records from a man (GSK). 70 y old at start of measurements from Mar 1998 to Feb 2003 (a): to Dec 2004 (b), and to Apr 2005 (c). An initially lacking near-transyear appears with lengthening of series and/or age.

When cautiously interpreted with aligned global windows, the procedures constitute useful tools; they were previously illustrated for analyzing tree rings (Nintcheu-Fata et al. 2003), thereafter Wolf's relative sunspot numbers as a gauge of solar activity and the number of marriages and divorces in Japan during the past century (Katinas et al.
2005dI), illustrating broad applications. Major components in these and other decades- or even centuries-long time series show changes in period length and relative prominence over time. Particularly in the case of non-stationary time series, gliding spectra examine changes in time structure beyond a specific spectral component. 


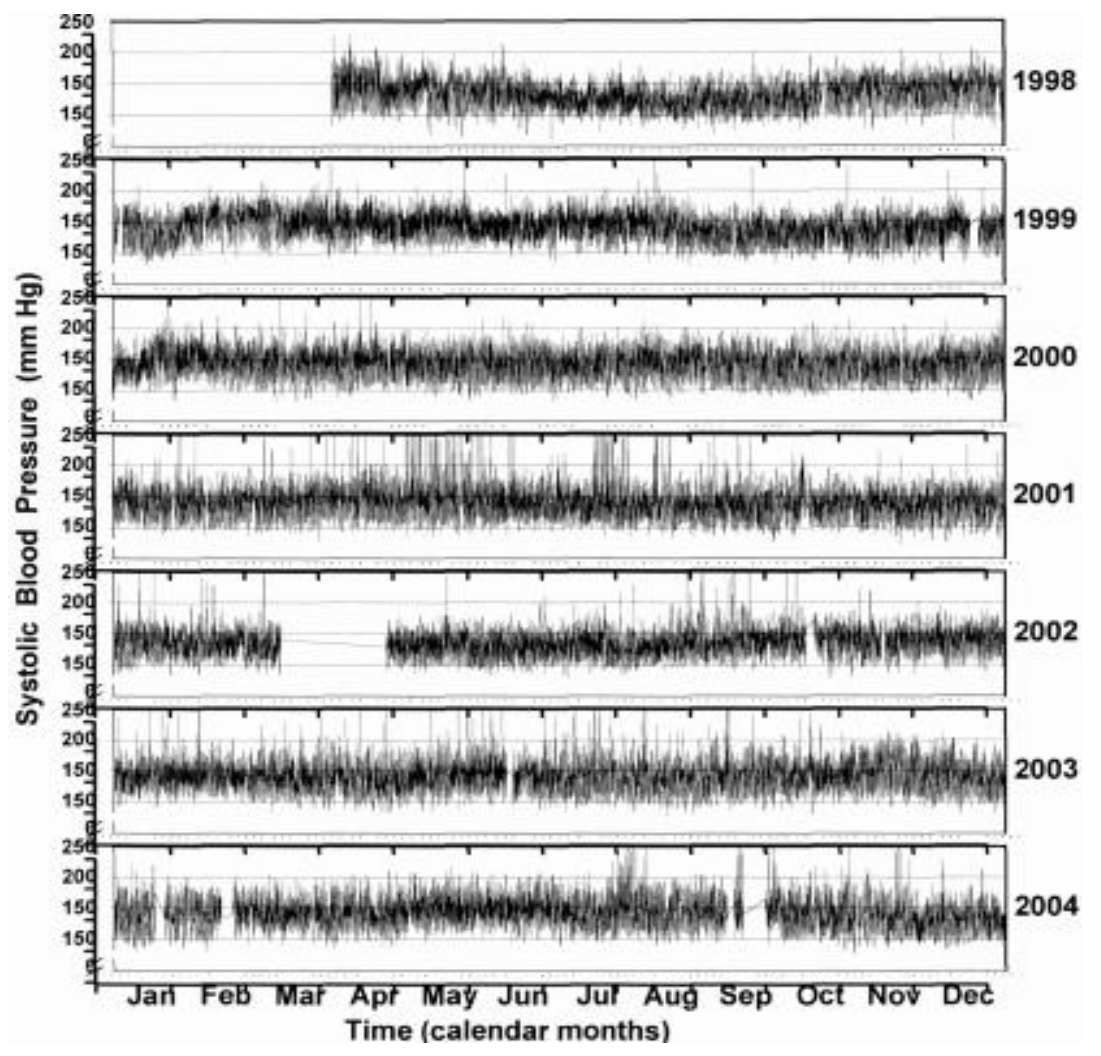

Fig. 2c. The variability of treated (Rx) systolic MESOR-hypertension complicated by circadian hyper-amplitude tension, briefly CHAT*. Chronogram of GSK's, a MESOR- and intermittently circadian hyper-amplitude-tensive man's, automatic systolic blood pressure (BP) measurements, made half-hourly by wearable recorders, for the first year with a Colin ABPM and thereafter with a TM-2421, produced by A\&D, Tokyo; recording was begun on the day after arrival in Minneapolis (MN, USA) after crossing 9 time zones (from East to West) from St-Petersburg (Russia) on March 30, 1998, at 72 years of age. GSK had been diagnosed with "hypertension" in 1959. His treatment in Russia was repeatedly adjusted but only after occasional spotchecks. After the beginning of automatic half-hourly around the clock monitoring, Rx changes were instituted many times (Katinas et al. 2005dI), mainly not in the kind of drugs or their dose, but in changing the timing of medication. This general view of the chronogram shows many spikes, consisting of several consecutive gradually increasing and then decreasing values that because of this pattern are not likely instrumental- or movement-related measurement artifacts and which could not be detected without systematic monitoring. For indispensable complementary assessment of dynamics see, e.g. Fig. 2 d.

* Half- hourly records (with gaps) of the blood pressure of a 72 year-old man at the start of observations. Original data ( $\mathrm{N}=90326)$ of G.S.K. on different Rx. Rx at start: Diltiazem $90 \mathrm{mg}$ at $\sim$ 06:00, 15:00, many adjustments of Rx during 7 years (Katinas et al. 2005bI).

\section{Aeolian (noun and adjective)}

Elsewhere, we introduced the term "aeolian" (Sonkowsky et al. 2005bI) to describe cycles (or rhythms, when they are sufficiently replicated) that wax and wane, abruptly or gradually, so that they change in amplitude and/or frequency, to the point of being undetected, but reappearing, splitting and/or (re)joining, providing in time series of sufficient length, a spectral band, if not line, with a relatively narrow 95\% confidence interval (CI), computed nonlinearly according to Marquardt (1963). The nomenclature for periodic, almostperiodic, quasi-periodic and other variables is welldefined in mathematical terms (Besicovitch 1954, Levitan and Zhikov 1982, Farkas 1994); but differential equations for almost- or quasi-periodic functions are not invariably applied to these waxing and waning periodicities, labeled quasi-periodic and quasi-persistent by Bartels, who provided timemacroscopic displays such as that in Fig. 2a (Bartels 1936, 1959) that can complement the displays of a computer era, Figs $2 \mathrm{~b}-\mathrm{e}, 3 \mathrm{a}-\mathrm{e}$.

We have avoided terminology that is mathematically homesteaded (Besicovitch 1954, Levitan and Zhikov 1982, Farkas 1994) or narrowly specific and/or that has only partial relevance, such as "quasi-persistent", "fleeting" or "evanescent" (Sonkowsky et al. 2005bI). Instead, we have used more intuitive terminology, respecting the etymology from mythology and the traditions representing, over the centuries, the god Aeolus. "Mid-term" for periods between 1 and 3 years (Mendoza et al. in press) and "quasibiannual" (Ivanov and Obridko, 2001, 2002) do not 
set limits for the periods involved. The limits which were set very tentatively (Halberg et al. 2005fI) will have to be specified for time series length and calendar location. Yet they are an attempt to introduce at least for biology a set of specified conditions that are not only a description like a periodicity, but specifically refer to changes from detection to failure to detect, from a line to a split and again to rejoining, from fading to increasing again in amplitude, while gliding in period or changing abruptly in both period and amplitude. Such points can now be better documented in gliding spectra, Figs 3a-f, implying specifically the sine qua non of time-, frequency-, and amplitudespecificity of the findings to be described as "aeolian". We make our own associations with these rhythmic phenomena. In the Odyssey (10.177) Aeolus, king of the winds, ties them up in a bag, trying to provide a tranquil voyage for Odysseus, but his men inadvertently release them. Indeed aeolian rhythms can disappear and reappear suddenly (Sonkowsky et al. 2005bI).

In Virgil's Aeneid (1.50-86) Aeolus keeps the winds imprisoned in a cave on the island of Aeolia, but at the command of Juno he sends them out to create the storm that drives Aeneas to the Libyan shore. If not Aeolus, then certainly a majestic alias, the solar wind (SW), ionized particles emanating from the sun and blowing by satellites which measure their speed, may have driven some of the components of a spectrum of human blood pressure (BP) in the past if one may judge from the SW speed doing so now, Figs 3a-f. With a lag corresponding to the length of a transyear, $\tau$, some of these components disappear in the systolic BP of a man (FH) when they are lost in the SW speed, as qualified and amplified below. Figs $3 a-e$ as a whole suggest that some other biospheric aeolians can persist in the absence of counterparts of the SW speed. The term "aeolian" would include the phenomena described by Bartels as quasipersistence in quasi-periodic variables, reported by him in plots such as Fig. 2a (Bartels 1936, 1959), but would require the procedural desiderata of chronomics, estimates of the uncertainties involved, Figs 3b, 3d, 3e - see Halberg et al. (2006).

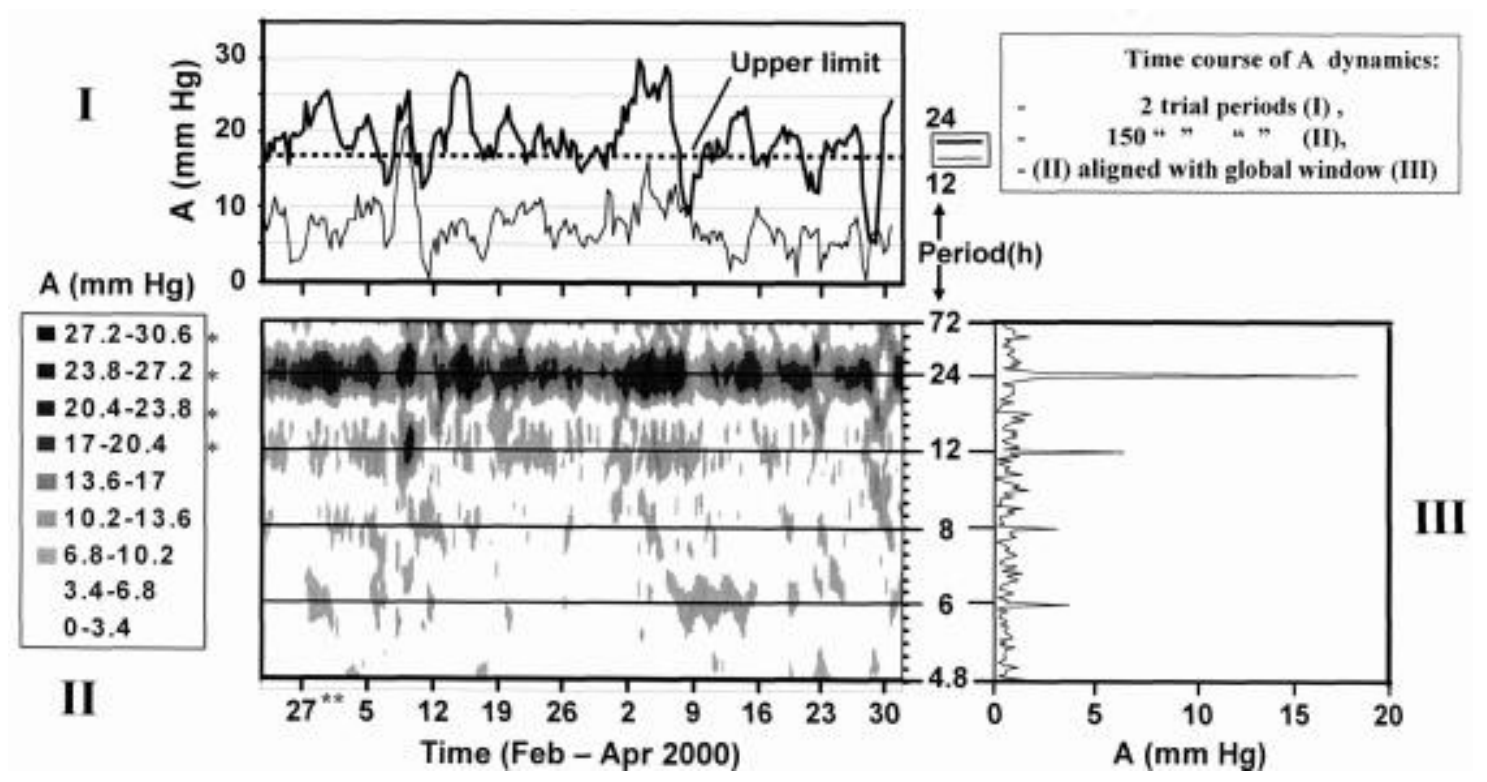

Fig. 2d. Gliding amplitude (A) spectral window (I, II) shows relative prominence of spectral components, mostly intermittent CHAT* with occasional ultradian prominence. Gliding spectral window in the circadian region of human blood pressure. Note consistent prominent 24 -hour component with a large signal-to-noise ratio in the context of other spectral components. While in the total (global) window, section III right, only overall peaks at a few frequencies are revealed, the gliding window permits one to distinguish contemporaneously the dynamics of the time course (underlying the global window) and shows components with a relatively small amplitude and unfavorable aeolian signal-to-noise ratio. A transiently excessive circasemidian amplitude comparable to CHAT was also transiently detected in this amplitudogram. Any risk associated with this condition and/or with broader circadian-to-ultradian or circadian-to-extracircadian variance transpositions remains to be assessed in the light of outcomes.

I, Amplitudogram.

II, Gliding spectral window of the time series (interval $48 \mathrm{~h}$, increment $8 \mathrm{~h}$, harmonic increment 0.1 ), shading of A values begins at $\mathrm{P}$ value $<0.05$.

III, Global spectral window of time series. Circadian Hyper-Amplitude-Tension (upper four shadings in 24-h fit).

** Sundays. 
Further analogies: beyond original cosinors

The difference between looking only for swelling, redness, heat and pain (tumor, rubor, calor and dolor) on the one hand versus making histological and other laboratory examinations of a questionably cancerous tissue and drawing blood for cancer markers, on the other hand, can be compared with the difference between the very many "cycles" reported with neglect of the uncertainties invariably involved in each case on the one hand vs. an attempt to meet the above mentioned desiderata on the other hand (see Halberg et al. 2006). To add the now available uncertainty (interval) estimates such as CIs to each point estimate of a parameter, as suggested in Insert I in Halberg et al. (2006), is but a first provisional step.
Tasks remain such as the need 1. to improve interval estimates for bands (rather than lines) in a spectrum, to account more generally for 2 . nonstationarities and for 3. a correlated (pink) background in a variable characterized by multifrequency intermodulating rhythms; to assess 4. trends, either real ones or part of a cycle with the next lower frequency, and further to assess whenever the data are dense enough, 5. deterministic (and other) chaos that can generate rhythms in its own right (Gonze et al. 2004) and undergoes rhythms that can be quantified by chronomics, for empirical, e.g., diagnostic aims (Otsuka et al. 1997, cf. Burioka et al. 2001), irrespective (as yet) of any chaotic mechanisms that may contribute rhythms (Gonze et al. 2004).
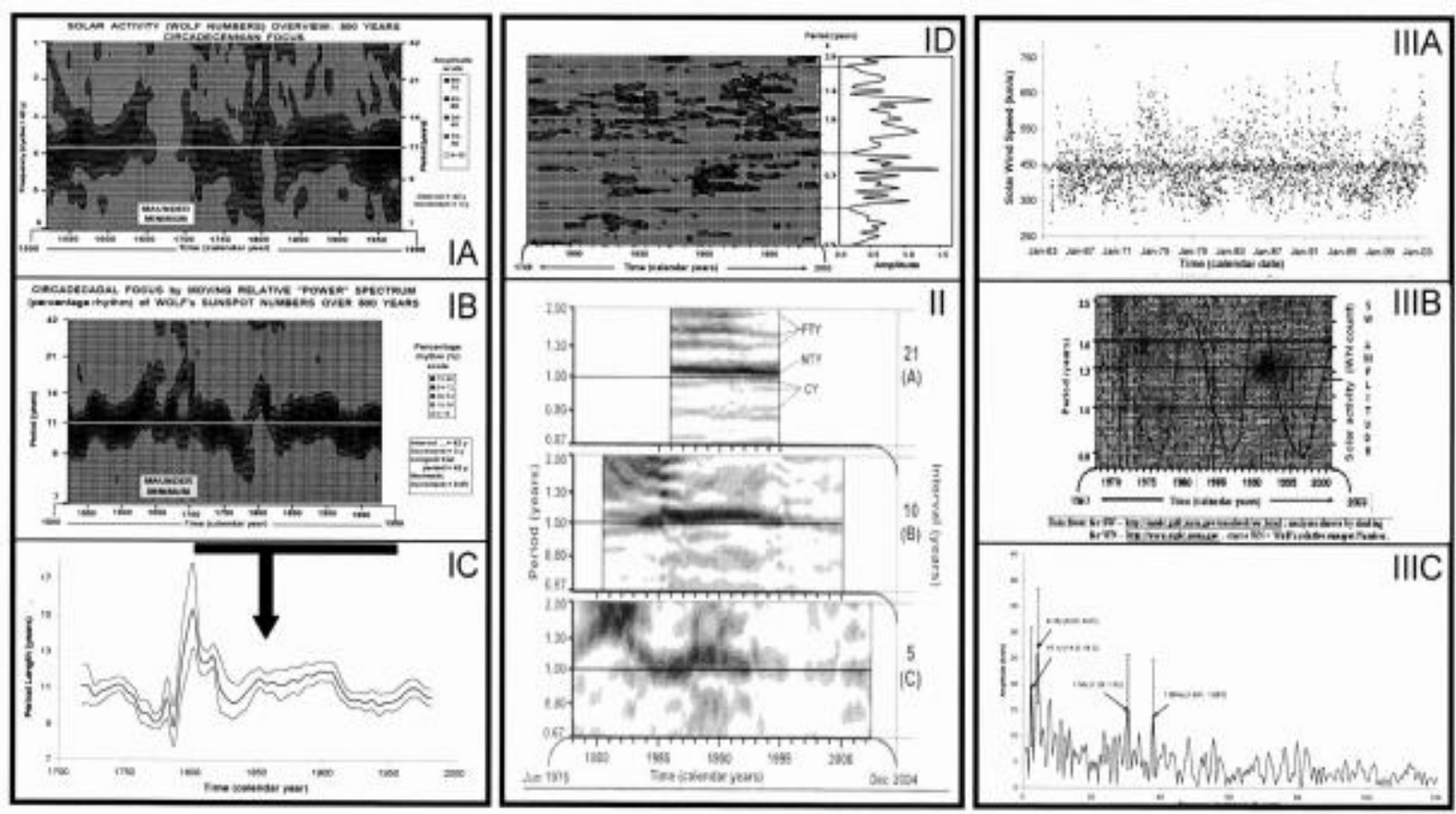

Fig. 2e. Transdisciplinarily applicable methods illustrated for Wolf's relative sunspot numbers (IA-D), terrestrial telescope-assessed solar magnetism (IIA-C) and solar wind speed (IIIA-C)*. Gliding spectral windows of amplitude, IA, and of percentage rhythm, IB. A time series of sunspot numbers from 1500-1995 was kindly provided by Dr. Jaroslav Strestik (Strestik and Mikulecky 1994). The percentage rhythm, but not the amplitude, visualized the persistence of the circadecadal Schwabe cycle during the Maunder minimum. Other illustrative gliding spectral amplitude windows, ID, II, IIIB, or a gliding period with its $95 \%$ confidence interval, IC, of solar activity, including those of terrestrial telescoperecorded solar magnetism, II, are of interest as such and methodologically by showing the trade-off in choosing the interval for analysis between the resolution of dynamic behavior in time vs. frequency. The resolution in frequency increases with the length of the interval analyzed (II bottom to top). Note variability in original data illustrated for the solar wind speed, IIIA measured by satellites, revealing by spectral analysis, IIIC, a very wobbly oscillation, IIIB, that is difficult to discern with the unaided eye when the results of an anticipated 1.30-year cosine curve are fitted to the data, for comparison with an also-fitted precise 1-year trial period, IIIA. A gliding spectral window, IIIB, shows the variability on hand in keeping with variability reported by moving spectra for the solar wind earlier by Mursula and Zieger (2000), and by ourselves (Halberg et al. 2004hI).

* During Maunder's minimum, the about 11-year solar activity cycle persists, as shown by the percentage rhythm (IB), albeit with a much reduced amplitude (IA), the period also varies widely (IC). Also shown by gliding window are wobbly transyears resolved in complementary global window (ID). Deviation from precise calendar year needs resolution better achieved with longer interval progressively displaced throughout time series (IIA-C). Relatively minuscule transyears in solar wind speed, revealed in chronogram (IIIA) and least squares window (IIIC), change as a function of time but not necessarily as a function of solar cycle stage (IIIB). 
Progress in many fields became possible once the eye was aided by a magnifying glass, then by light- and electron-microscopy and eventually by molecular and/or atomic method and/or theory, which latter may account for an about 7-day resonance of certain ions (Ulmer et al. 1995). This comes to mind as one views the transition from periodograms [introduced by Schuster (1906) for geophysics and implemented in biology on a mechanical desk computer (Halberg 1954, 1966, Halberg et al. 2003a)], to the output from currently

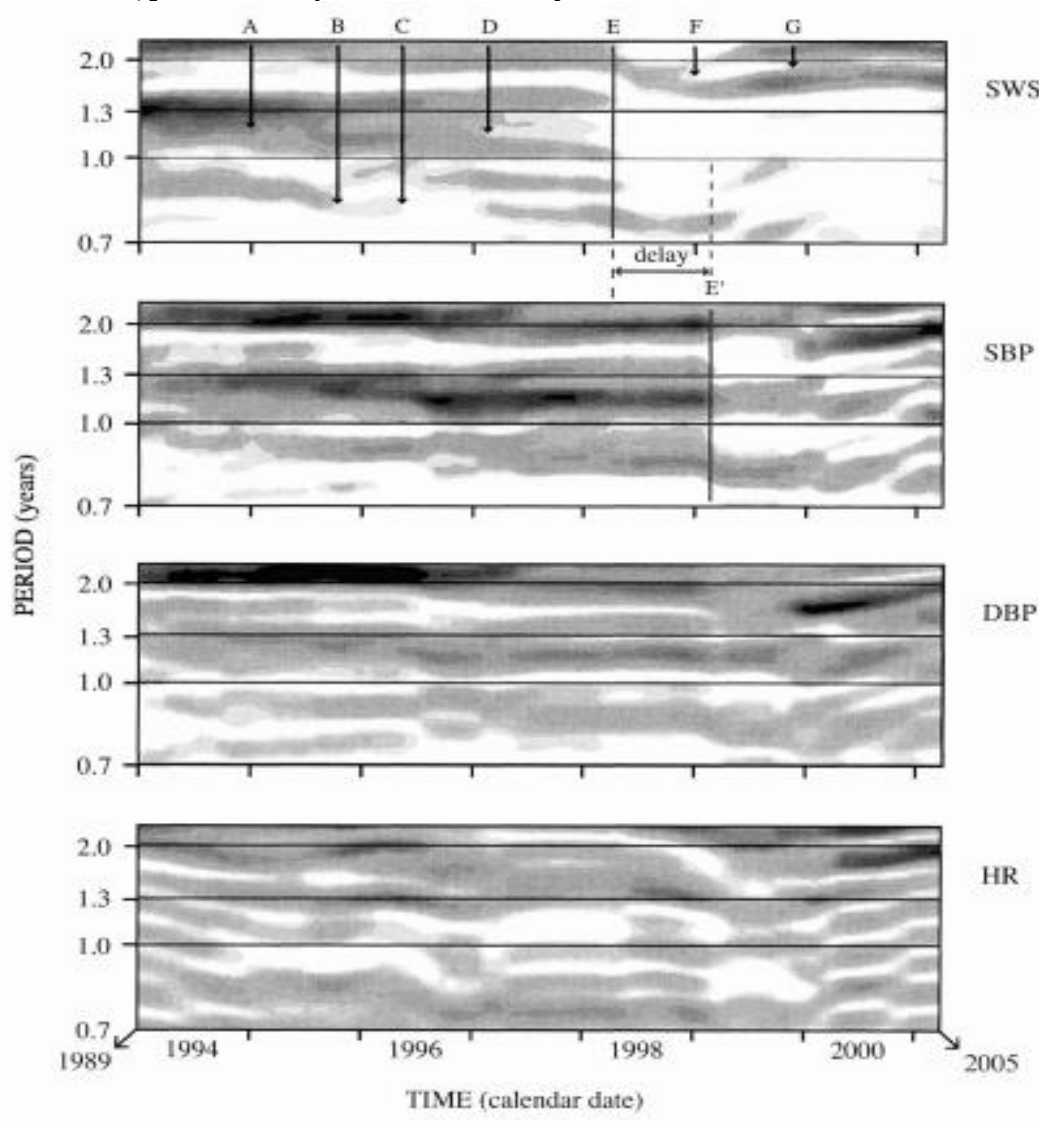

Fig. 3a. Time courses of the frequency structures of the speed of the solar wind (SWS) (top) and of an elderly man's (FH) systolic and diastolic blood pressure and heart rate, SBP, DBP and HR (rows 2-4, respectively), examined by gliding spectral windows. Human systolic (S) blood pressure (BP) selectively resonates with solar wind speed (SWS) (top 2 sections). No obvious resonance, only minor coincidence with diastolic BP (DBP) or heart rate (HR) (bottom 2 sections). Aeolian Rhythms* in gliding spectra of SWS and SBP change in frequency (smoothly [A] or abruptly [B,C,D], bifurcating $[\mathrm{D}, \mathrm{F}]$ and rejoining $[\mathrm{G}]$, they also change in amplitude (B) (up to disappearing [C,E] and reappearing). During a nearly 16year span there are no consistent components with a period averaging precisely 1 year in the 3 physiologic variables, probably an effect of advancing age (see Figs 12 and 13 in Appendix 2 of Halberg et al. 2004hI). While post hoc ergo propter hoc reasoning can never be ruled out, an abrupt change on top in SWS is followed in the second row in SBP by the disappearance of some components, suggesting that as a first demonstration, some of FH's cis- and transyear components were driven by the SW [since they disappeared with a lag of about a transyear following the disappearance (subtraction) of the same components from the SWS spectrum]. The persistence of other spectral features in turn suggests endogenicity, i.e., an evolutionary acquisition of solar transyear oscillations that may reflect solar dynamics for the past billions of years. Blood pressure and heart rate data are from a man 70 years of age at start of around-the-clock monitoring, mostly at 30-min intervals, with interruptions for nearly 16 years.

*FH, man, 70 years (y) of age at start of automatic half-hourly around the clock measurements for $\sim 16 \mathrm{y}(\mathrm{N}=2418$ daily averages, total $\sim 55000$ ). Gliding spectra computed with interval $=8 \mathrm{y}$, resolution low in time but high in frequency, increment $=1$ month, trial periods from 2.5 to $0.4 \mathrm{y}$, with harmonic increment $=0.05$. Darker shading corresponds to larger amplitude. When several of these broad bands disappear in the SWS, at E, parts of the bands in SBP also disappear, with a lag (delay) at E', while other parts persist. These components are presumably built into organisms over billions of years, as persistence without corresponding components in SWS shows, but can be driven in part by the solar wind, as their disappearence after loss of corresponding components in SWS suggests. "Aeolian", derived from Aeolus, Greek God of winds, who packed the winds up and then let them loose and had them change. 
Scheme 1: Imaging biological structural diversities in space-time for alignment with complementary environmental structures*

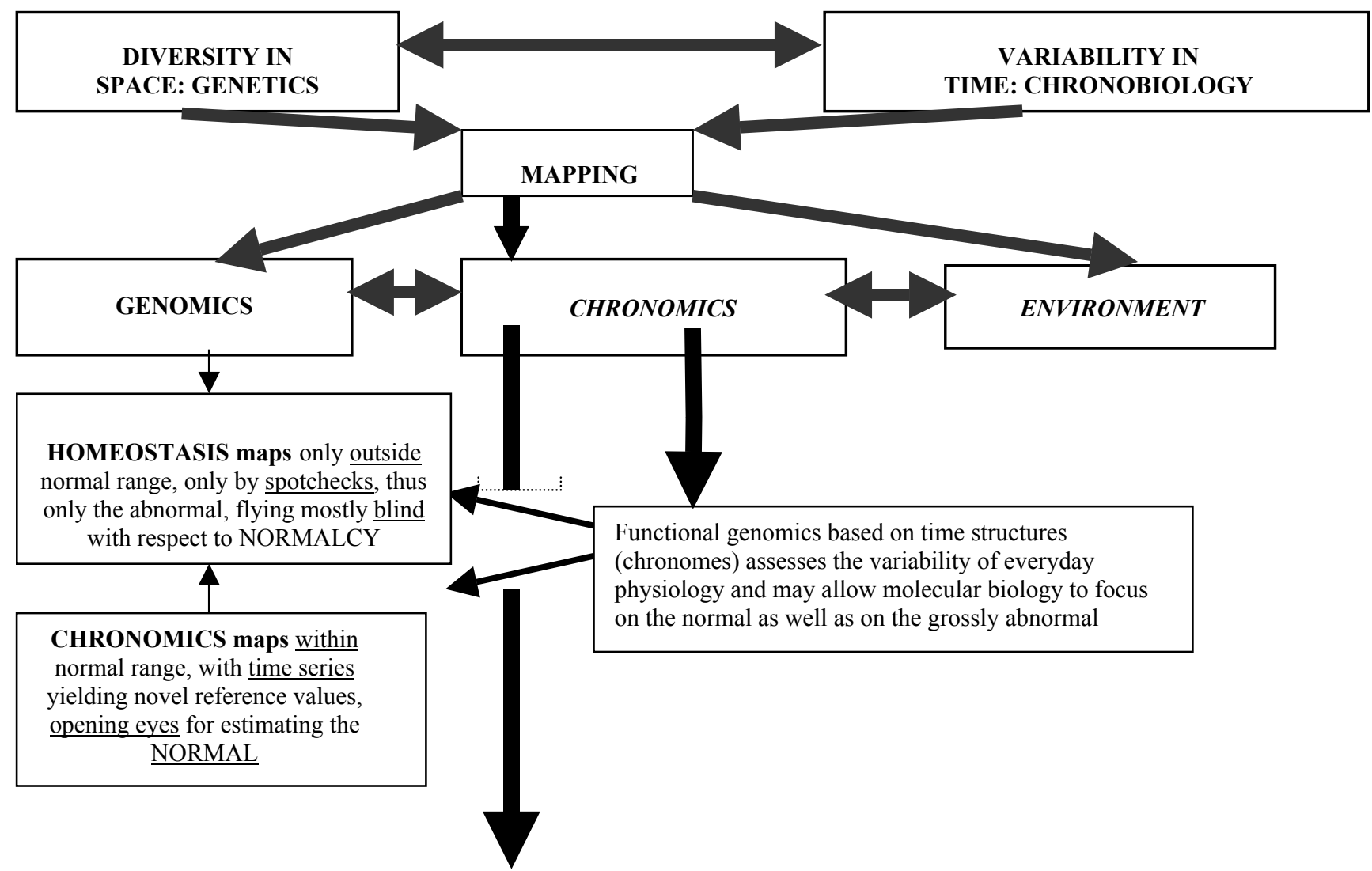

The major merit of chronomics in its own right is the quantification of normalcy and the detection of earliest risk elevation, shadowing meritorious current, only circadian approaches to jet lag, shift-work and even the addition by timed treatment of years to a cancer patient's (partly high quality) life, achievements second only to prevention: Pre-habilitation rather than only REhabilitation, the basis of a timely and timed treatment of risk elevation for health promotion

\footnotetext{
*An outcome of puzzles encountered in the 1950s (Halberg and Visscher 1950; more in Halberg F et al, J Circadian Rhythms, http://www.jcircadianrhythms.com/content/pdf/1740-3391/1/2.pdf)

**Based on usually time-, gender-, age-, geography-, ethnicity- and social class-unspecified normal ranges that constitute the curtain of ignorance drawn over everyday physiology by homeostatic baselines, lifted by imaging time structures of rhythms with frequencies covering over 10 orders of magnitude in and around us
}

Turning back to the analogy, equivalents of a magnifying glass were the single and populationmean cosinors. These led to linear least-squares spectra combined with non-linear rhythmometry for the preferably concomitant analysis of multiple periodic and other components, including trends that, de rigueur, should be concomitantly fitted with the periodic components (Halberg 1969). To plan for the possibility of examining whether any trends are but part of spectral components with a period longer than the available data series, maps of known periodic components (Halberg et al. 2001a, 2003b, Cornélissen et al. 2000a, 2004aI) help to avoid blunders, such as mistaking part of a cycle for a trend and taking it as an indication for therapy, Fig. 5 (Halberg et al. 2001b).

To resolve changes with time in the characteristics of a spectral component, such as (a circadian or) an infradian component, the week, chronobiological serial sections were used by 1965 (Halberg et al. 1965); they allow time-microscopic focus on the dynamic behavior of the timestructure (chronome)-adjusted mean, the MESOR $(\mathrm{M})$, of the amplitude (A) and the acrophase $(\phi)$, each characteristic with a CI, and such sections can 


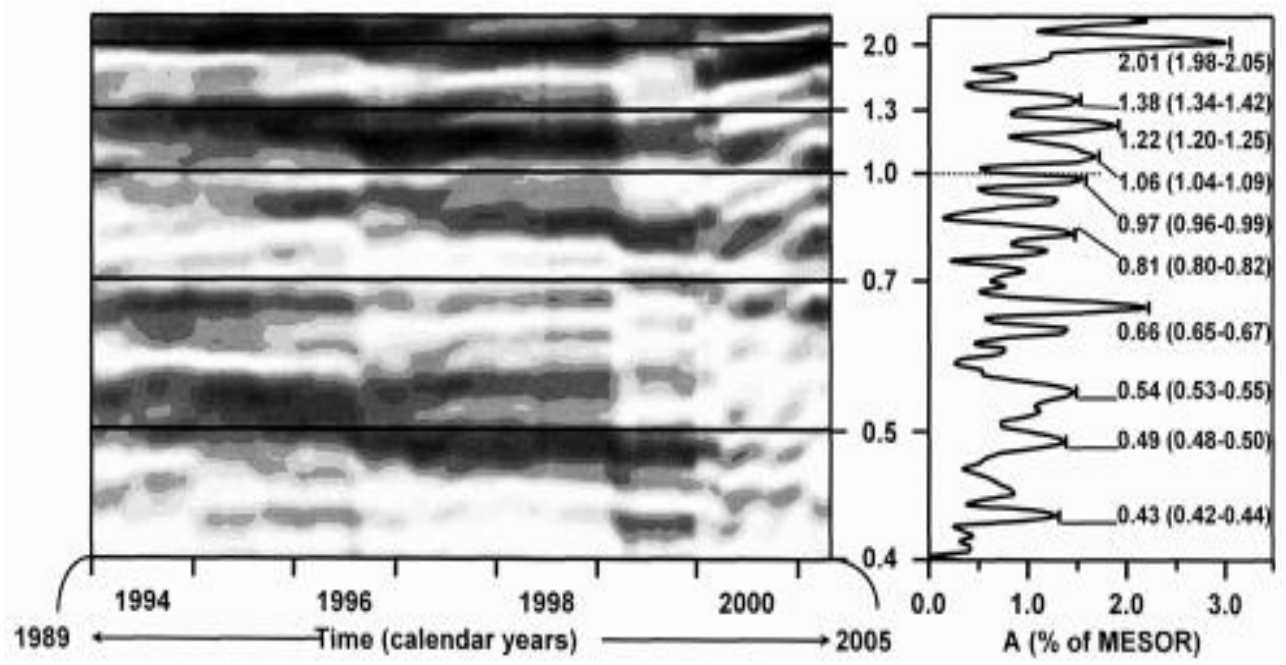

Fig. 3b. Gliding (left) and global (right) spectral windows of systolic blood pressure of an elderly* show a consistent (left) circadiennian (2-year) component as major peak (right) and several other partly transient aeolian trans- and cis-years and -halfyears. Global spectral window summarizes and extends the frequency range of the smaller window in the second row of Fig. 3a and complements it with a numerical indication of the candidate periods, $\tau$, found, revealing components with tentative ordering $95 \%$ confidence intervals of $\tau$ s given in parentheses. This perspective over a broader spectral region reveals the variability in amplitude not only around the year but also around the half-year and beyond. Since only anticipated components can be taken at face value, and since the data had gaps, some of the $\tau$ s are possibly spurious.

* FH, man, 70 years (y) of age at start of automatic half-hourly around the clock measurements for $\sim 16 \mathrm{y}(\mathrm{N}=2418$ daily averages, totally $\sim 55000$ ). Gliding spectrum computed with interval $=8 \mathrm{y}$, increment $=1$ month, trial periods from 2.5 to $0.4 \mathrm{y}$, with harmonic increment $=0.05$. Darker shading corresponds to larger amplitude (A). Small vertical bars close to the spectral peaks in global spectrum $=95 \%$ confidence intervals of periods, also shown in digits in parentheses.

be complemented, again non-linearly, by resolving changes with time, in $\tau$ and in its CI (Halberg et al. 2000a), Fig. 2e bottom left (Cornélissen et al. 2000a). All of the studies herein rest on the contributions of many others. Some (not all) of them did not consider cycles as their primary focus (Vallot et al. 1922, Düll and Düll 1934, 1935, Stoupel 1976, 1999, Stoupel et al. 1996); others reported associations after eliminating cycles (Villoresi et al. 1994a and b, 1995).

It is to the credit of Richardson et al. (1994) and the school of Mursula (Mursula and Zieger 1999 and 2000, Mursula et al. 2003, Mursula and Vilppola 2004) to have approached transyears from the perspective of the solar wind and geomagnetics, and to the credit of Valdés-Galicia et al. (2004, 2005), Valdés-Galicia (2005) and Mendoza et al. (in press) from the viewpoint of galactic cosmic rays (cf. also the methodological approach by Attolini et al. [1987]). They have set the stage for the study of reciprocal cycles in biology and of putative neartransyears in physics (Halberg et al. 2004dI, Cornélissen et al. 2005fI). Moreover, Mendoza and Díaz-Sandoval (2000) extended the studies on myocardial infarction (MI) and other conditions diagnosed on the occasion of ambulance calls in Moscow (Halberg et al. 1991, Breus et al. 1995, 2002) and of MIs in Minnesota (Halberg et al. 2000a, Cornélissen et al. 2002) to Mexico City.

In discussing the expected pulsations of the heliosphere relevant to cosmic ray pulsations,
Dorman and Ptuskin (1981) report that these may vary from a year to tens of years. In this wide range, we hope that transdisciplinary near- and fartransyears, such as those in the unicellular Acetabularia, may allow us to trace solar activity for the past 500 million years, the span for which this giant unicell has presumably been on earth (Berger and Kaever 1992) (and hoping that it did not drastically change its chronome in the interim).

\section{Gliding spectral windows}

An enlarged focus on a range of $\tau \mathrm{s}$ is provided by gliding spectral windows that display the dynamics in time of the A, Figs $3 a$ and $3 b$, or of the percentage rhythm, Fig. 2e, or of probability (not shown), preferably in alignment with corresponding global summaries of the same windows. As a complement for the timemicroscopic chronobiologic serial section, they illustrate the changing chronome of physiological, physical and/or other variables in a given frequency range. For this purpose, least squares spectra are computed over a specified interval (much shorter than the observation span) that is progressively displaced by a given increment throughout the entire record. Results can be either $3 \mathrm{D}$ charts or surface charts, displaying, by shading or color, the estimated amplitudes (A), percentage rhythms (PR) or ordering P-values at each trial period for each interval displaced along the pertinent time scale. 

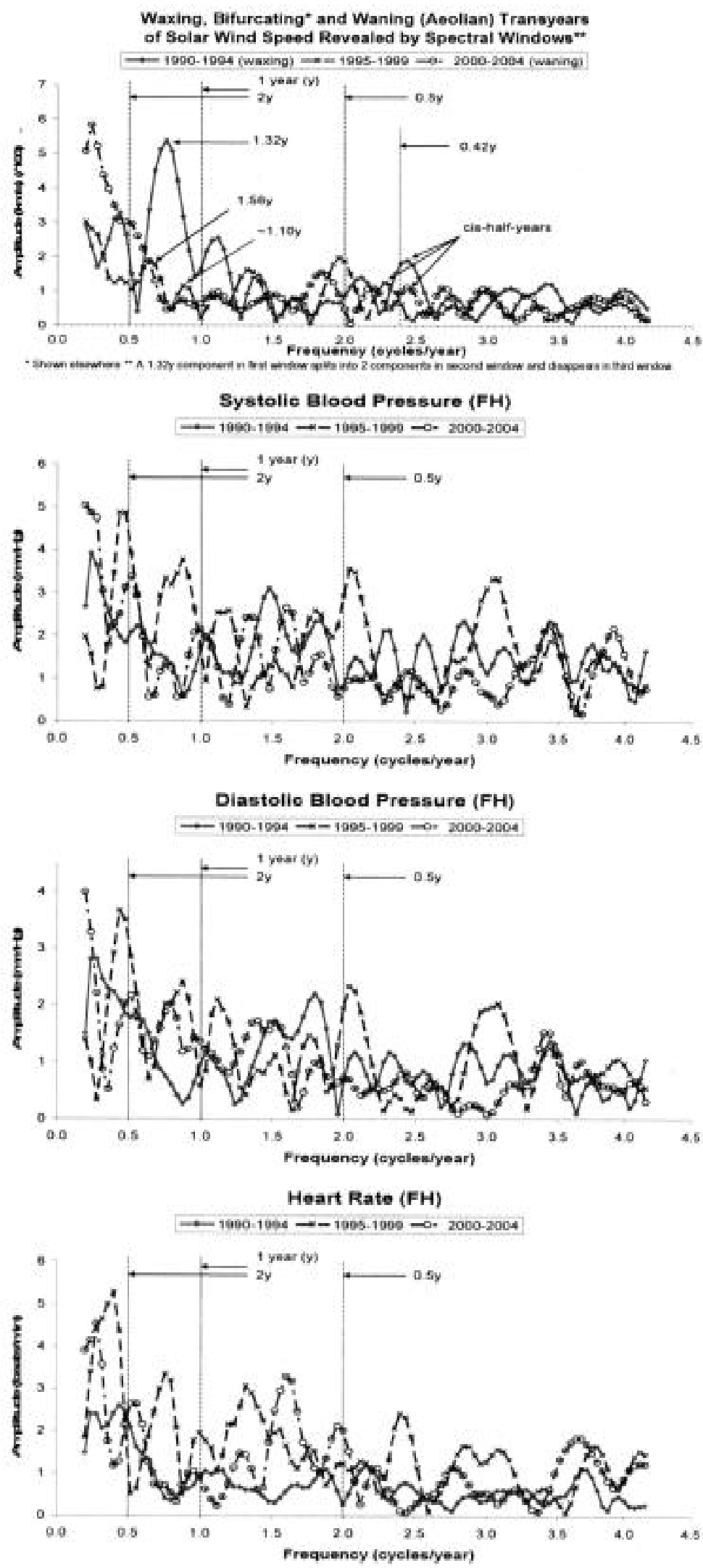

Fig. 3c. Spectral windows over consecutive 5-year spans complement the 8-year intervals of Figs 3a and b and confirm the eventual disappearance of a transyear from the solar wind speed. The biological data with the small print may suffice only to show the great variability that prompted the use of 8-year intervals in Figs 3a and b. Blood pressure and heart rate data are from a man 70 years of age at start of a nearly 16-year record of around-the-clock monitoring, mostly at 30 -min intervals, with interruptions ( $\mathrm{N}=2,418$ daily averages from a total of about 55,000 measurements). This perspective over a broader spectral region reveals the variability in amplitude not only around the year but also around the half-year and beyond a 2-year trial period. 


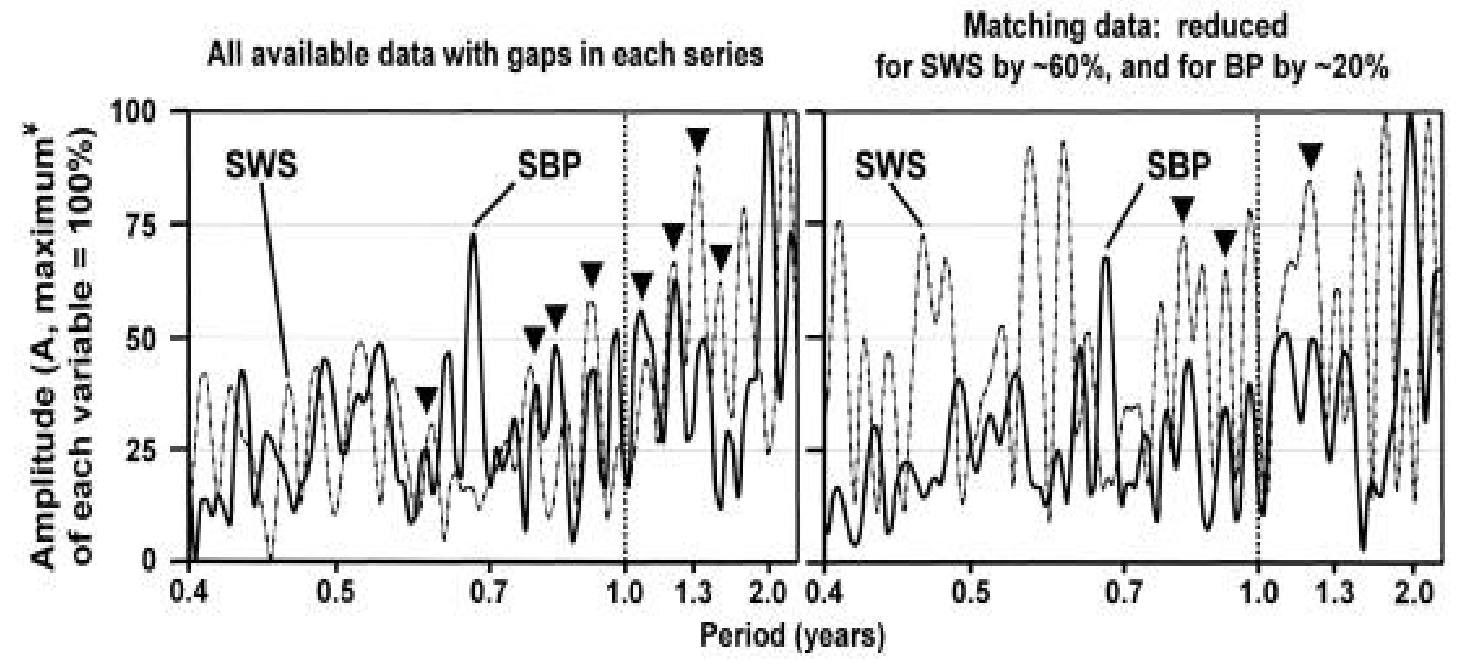

Fig. 3d. An unseen solar wind's speed, as such or as proxy, may drive the human circulation in the face of gapassociated artifacts produced by decimation (right). Cis \& trans - halfyearly \& yearly components of solar wind speed $(\mathrm{SWS})^{*} \&$ of an elderly's systolic blood pressure (SBP)**. Note both non-overlap \& overlap ( $\bullet$ ) of period's Cls***. Highly variable ("aeolian") components in the solar wind speed share some, but not all components in human systolic blood pressure and heart rate; some of these components are lost upon decimation while others remain as peaks in their own right, or as peaks corresponding to those in the solar wind speed. Note further (spurious!) amplification by decimation and thus by larger gaps of some components in the solar wind speed that spuriously increase greatly as compared to their much smaller amplitude when more extensive data are analyzed.

* SWS from http:/nssdc.gsfc.nasa.gov/omniweb/ow.html, gap-associated artifacts are retrospectively unavoidable.

** SBP from FH, man, 70 years (y) of age at start of automatic half-hourly around the clock measurements for $\sim 16 \mathrm{y}$ $(\mathrm{N}, 2418$ daily averages, total $\sim 55000)$.

*** Periods $(\tau)$ of spectral peaks, validated by non-zero amplitudes, are assumed to coincide (shown by arrows) if their $95 \%$ confidence intervals (CI) overlap, lack of arrows denotes non-overlapping. No peak corresponds to $\tau=1 \mathrm{y}$, no CI overlap in the cis-half-yearly spectral region. The transyear peak in each variable (in the matching data, graph on the right) was anticipated. Note the gap-associated spurious increases in A of SWS with $\tau$ s shorter than $0.7 \mathrm{y}$.

${ }^{*}$ in the range examined.

Gliding spectra, or usually gliding spectral windows, in themselves give only a macroscopic and subjective view of the data transferred into the period domain and hence are best accompanied by global spectral windows, as in Fig. 3b. Their viewing, as such, is not time-microscopic, insofar as a window does not distinguish anticipated from other components and thus the CIs of the $\tau$ of too many periods cannot all be taken at face value, a
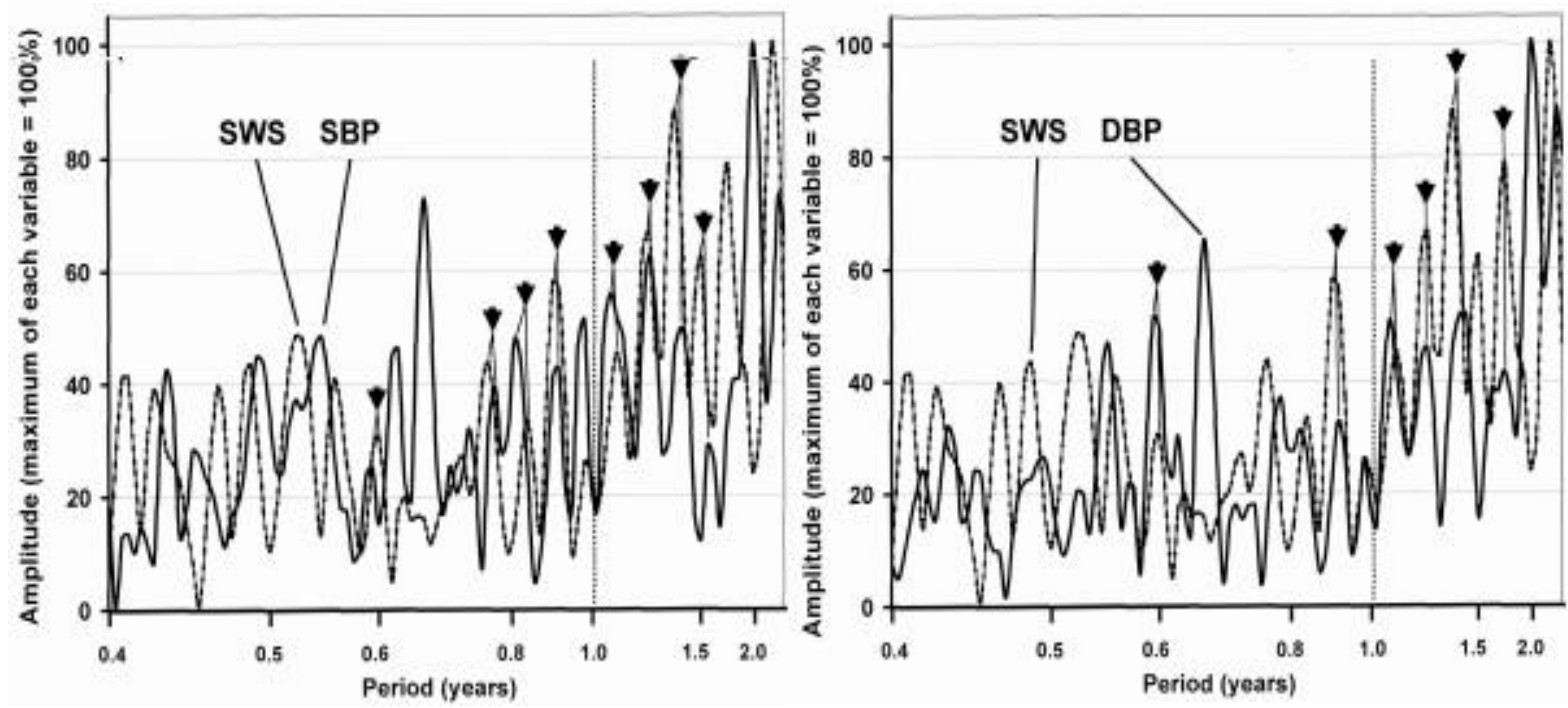

Fig. 3e. "Aeolian", highly variable components in the solar wind speed share some, but not all components in human systolic (left) and diastolic (right) blood pressure. 


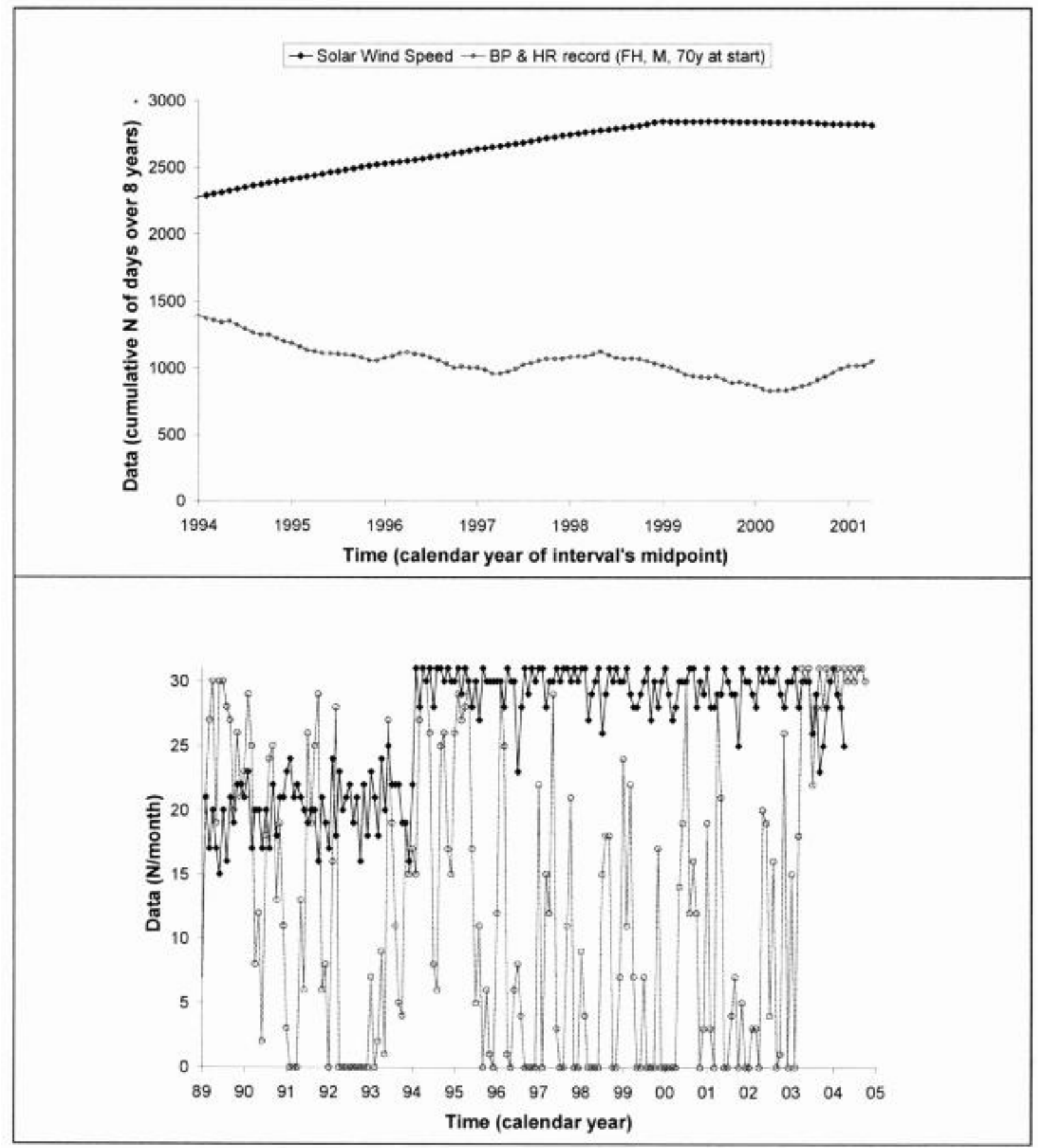

Fig. 3f. Patterns in amount of physical (Solar Wind Speed, SWS) and physiological (Blood Pressure, BP, and Heart Rate, HR) data per month do not obviously account for changes in time structure seen in (8-year interval) gliding spectra of these variables. Another precaution in looking for potential artifacts that might lead to the disappearance of the transyear component in SWS. As seen from the cumulative record, there was a change in data density on the SWS with values/month being much more complete later in the record than initially, but there seems to be no coincidence between the disappearance of the transyear component in SWS in Fig. 3a (top row) or events in the second row in SBP and in the amount of data available per month in this fugure.

* Shown as numbers of days with data (bottom), cumulated over sliding 8-year interval (top).

qualification of Fig. 3b. When there is a component with a large signal-to-noise ratio, the interpretation of results in a gliding spectrum is straightforward, seen as a dark band changing only little in amplitude or frequency as a function of time, Fig. 2e, section II, top row. Likewise, a non-stationary component with a large signal-to-noise ratio that progressively changes its frequency (drifts) will also be seen as a single dark band, as recurring changes within a relatively narrow frequency range 
(frequency modulation) and/or as recurring changes in the extent of darkness (amplitude modulation). In these cases, the gliding spectrum is most informative, providing information amenable to further statistical testing or modeling. Similar considerations apply to a global spectral window or spectrum.

When the signal-to-noise ratio of a given component becomes smaller, however, it eventually becomes difficult to distinguish between the signature of a wobbly but real signal and that of mere noise (random variation). For this reason, it is important that any interpretation from the gliding spectra be complemented by additional analyses, such as other gliding spectra prepared with different intervals, Fig. 2e II, see the second panel (second and third rows from top), global spectral windows, fractionated spectra, preferably averaged by population-mean cosinor. The same linear and nonlinear fractionated and global analyses are best carried out also on noise (not shown herein). Analyses of comparable frequency domains of transdisciplinary (e.g., physiological vs. physical or vice versa) data, as the case may be, are also desirable to determine whether a given finding can be replicated and has the anticipated high extent of its generality associated with solar activity. It seems unfortunate that too many times this association is based on data covering very few cycles of the often intermittent aeolian periodicity investigated (Chizhevsky 1938, Zigel' 1979), with the notable exception of a meta-analyzed incidence of cholera in Moscow (Halberg et al. 2001c).

\section{Choice of interval (I)}

Given data recorded over a span $\mathrm{T}$ and interest in a given spectral region such as that bracketting transyears, choosing an interval (I) for pergressive analyses in a gliding spectrum to be displaced in increments shorter than the interval analyzed (pergressively) throughout the data series needs to consider competing desiderata. On the one hand, I should be long enough to assure a sufficient resolution in frequency (for instance to allow discrimination between the circannual component and a 1.33-year transyear, it should be at least 4 years). On the other hand, I should not be too long, so as to allow for enough independent assessments of the component under investigation [for instance if $\mathrm{T}$ (the total series) covers 16 years and $\mathrm{I}$ is set to 4 years, there will be only 4 replications]. In the case of Figs $3 a$ and $3 b, T$ is 16 years and $I$ is 8 years. This choice allows a relatively good distinction between 1.0- and 1.3-year components but not between 1.0- and 1.1-year components. There are barely 2 independent assessments of the spectral signature in this spectral range. It should be noted that this amount of replicability is not enough when the signals are wobbly and a change in time structure is anticipated and needs to be assessed. Global spectral windows thus became indispensable but have their limitations, Fig. $3 \mathrm{~d}$.

\section{Sampling interval}

Least squares spectra have the advantage that they are applicable to non-equidistant data. Such spectra are reliable as long as the data are fairly uniformly distributed throughout the time series. Problems occur, however, when data are missing according to a given pattern (such as always by night) or when there are too many and/or too long gaps in the data series. When non-equidistant data are analyzed by a gliding spectrum and the number of data per interval changes drastically due to gaps, it should be kept in mind that amplitudes tend to increase with decreasing numbers of data. As a result, a given component may spuriously appear to become more prominent when fewer data are available for analysis. This is particularly troublesome in the case of preparing gliding spectra of percentage rhythm (PR) rather than amplitude (because the same total $100 \%$ variability is distributed over fewer points, the average PR is increased accordingly). In the case of Fig. $3 \mathrm{~d}$, the problem related to gaps is illustrated for the case of the solar wind speed (SWS) data. Gliding spectra are shown for all available data and for data decimated to match the biological data: the appearance of spurious spectral peaks of relatively large amplitude are seen in the presence of gaps created by decimations.

\section{Statistical significance}

Whether preparing gliding spectra of P-values or using $\mathrm{P}$-values as a guide to select shadings for amplitude or percentage rhythm, one should keep in mind that the P-values cannot be taken at face value and are at most of ordering value. The major reason for this limitation stems from the deviation from testing only anticipated components as stipulated in the cosinor method (Halberg 1969, Halberg et al. 2001a). P-values are obtained at each trial period for each interval, thereby rendering any adjustment for multiple testing useless to implement for lack of efficiency. Other violations from underlying assumptions may also apply (lack of independence of residuals, non-normality of residuals, and heteroscedasticity). Hence, when dark bands give the impression that the components shown are prominent and statistically significant, this may or may not be the case.

\section{Assumption of normality}

Whether signals under investigation are stationary or non-stationary, least squares spectra assume that data (or, if there is a prominent signal, residuals obtained after its subtraction) are normally distributed, at least locally, that is within each interval of a gliding spectrum. This assumption is violated by the presence of a trend in the data. It is 
also violated in the presence of colored (correlated, so-called pink) noise. In the data of Fig. $3 \mathrm{~d}$, a trend is present with respect to Fig. $3 \mathrm{e}$ in the case of $\mathrm{HR}$ $(\mathrm{r}=-0.771)$ and a second-order polynomial is significant for both DBP $\left(\mathrm{P}<10^{-38}\right)$ and SBP $\left(\mathrm{P}<10^{11}\right)$. Accordingly, amplitudes in the lowfrequency part of the spectrum are unduly inflated.
This includes the transyear region of the spectrum. Such trends would be less problematic for shorter intervals, but with an interval of 8 years, trends are to be taken into consideration and hence are reported so that eventually they are removed before further analysis.

\section{CHAT? \\ EPP?}

DHRV?

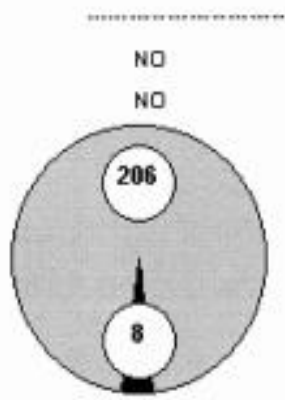

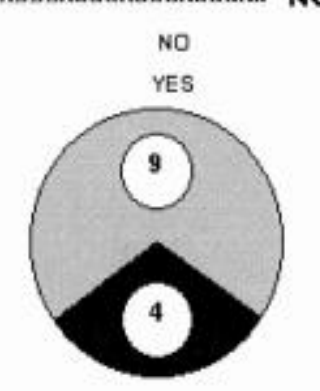

10
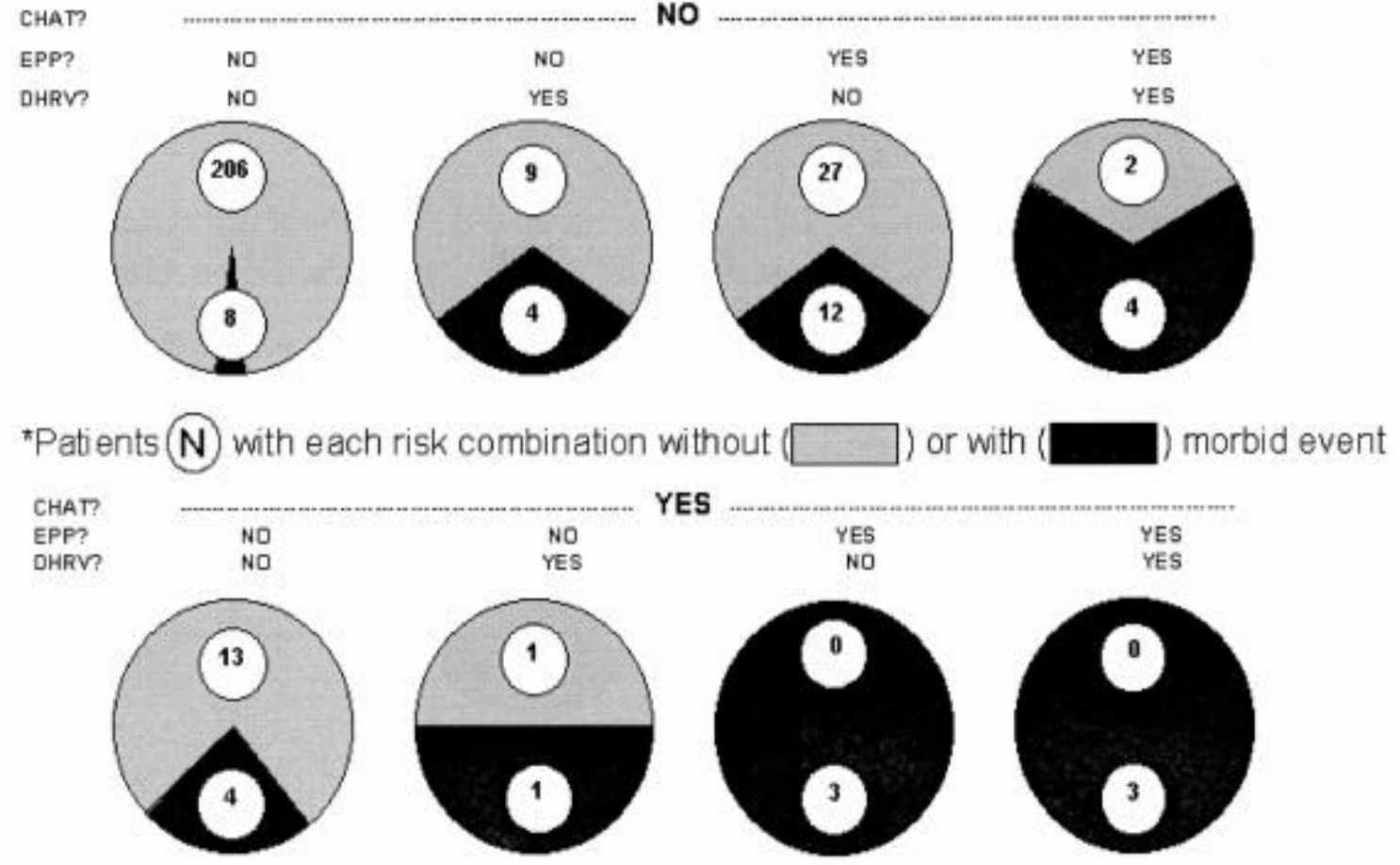

${ }^{*}$ Results from 6-year prospective study on 297 (adding all Ns) patients classified by 3 risks ( 8 circles), supported by findings on total of 2,807 subjects for total of over 160,769 sets of blood pressure and heart rate measuremets. Data from K. Otsuka.

Fig. 4. Decreased heart rate variability (DHRV), circadian hyper-amplitude-tension (CHAT) and elevated pulse pressure (EPP) are separate cardiovascular disease risks*. CHAT is one of several conditions related to the variability in blood pressure (BP) and/or heart rate (HR) that is associated with an increase in vascular disease risk. The circadian (or preferably circaseptan profile) with too large a pulse pressure (the difference between systolic [S] BP and diastolic [D] BP, i.e., between the heart's contraction or relaxation, or the extent of change in pressure during a cardiac cycle) and a decreased HR variability (gauged by the standard deviation of HR) in relation to a threshold, preferably eventually all in gender- and age-matched peers are two other risk conditions (as is an abnormal circadian timing of BP but not of HR, not shown). Vascular disease risk is elevated in the presence of any one of these risk factors, and is elevated further when more than a single risk factor is present, suggesting that these abnormalities in variability of BP and HR are mostly independent and additive. Abnormalities in the variability of blood pressure and heart rate, impossible to find in a conventional office visit (the latter aiming at the fiction of a "true" blood pressure), can raise cardiovascular disease risk (gauged by the occurrence of a morbid event like a stroke in the next six years) from $4 \%$ to $100 \%$. By comparison to subjects with acceptable blood pressure and heart rate variability, the relative cardiovascular disease risk associated with a decreased heart rate variability (DHRV), an elevated pulse pressure (EPP) and/or circadian hyper-amplitude-tension (CHAT) is greatly and statistically significantly increased. These risks, silent to the person involved and to the care provider, notably the risk of CHAT, can usually be reversed by chronobiologic self-help, also with a non-pharmacologic approach in the absence of MESORhypertension.

\section{Standard}

By its nature, a gliding spectrum can only look at a limited frequency range of the global spectrum. In some cases, this limited spectral region may include a prominent and ubiquitous component such as the usually (but not invariably) prominent circadian rhythm and/or the sometimes prominent circannual. In such cases, more often than not, the strong circadian or circannual signal can readily be used as a standard to which other components of interest (such as circaseptans or transyears, respectively) may be compared (Halberg et al. $2004 \mathrm{hI}$ ). It can then be readily determined whether these other components are present, what their 
relative prominence is, and how their prominence changes versus that of the circadian or circannual rhythm used as standard. This comparison is particularly valuable for comparisons of a photic spectral component with a presumably non-photic (magnetic) cycle by an amplitude ratio. In some other cases, the problem is much more complicated, notably when there may not be a spectrally proximal reference standard.

This is the case, for instance, for transyears in Fig. 3, since a consistent circannual component is clearly not present. In other cases as well, a circannual signal may be absent, and more generally, it is not necessarily prominent and may fade with advancing age (figures 12 and 13 of Appendix 2 in Halberg et al. 2004hI). When failing or absent, there may not be a standard available for comparison. Transyears then need to be compared among each other. The comparison becomes problematic when they are not very prominent and very wobbly. In Fig. 3, the absence of a circannual component synchronized with the calendar year constitutes an important observation in itself and applies to others among the very young and the very old. Nonetheless the lack of a circannual variation renders the assessment of any transyears the more difficult.

\section{Scaling}

In the absence of a standard, choosing a scale becomes arbitrary. In an attempt to proceed in a consistent manner, an 8-shade scale has been chosen, the lightest shade corresponding to an amplitude of zero and the darkest shade corresponding to the maximal amplitude for all trial periods and intervals. In the presence of a component with a strong signal-to-noise ratio, this kind of scale seems to be adequate. It becomes problematic, however, when only weak signals are present or when it becomes difficult to distinguish between a weak and wobbly signal or mere noise. Assuming that a gliding spectrum is prepared of a noise series, "peaks" and "valleys" will occur below the level of statistical significance. Using the 8 -shading scale, the gliding spectrum will show dark bands corresponding to the non-significant spectral "peaks" in the same way as if they were statistically significant, thereby rendering the interpretation of the results difficult.

The problem becomes more acute when the interval is long versus the length of the series, as the dark bands will tend to show some continuity or consistency that may not be present, as revealed from analyses based on a shorter interval. The amplitudes in Fig. 3b are small (mostly less than $3 \%$ of the MESOR) and judging from the many peaklets in the global spectral window, it is unlikely that all correspond to actual signals. Many could represent no more than variations in the extent of noise. The fact that corresponding periods can be determined nonlinearly is to be viewed with utmost caution as the nonlinear program does not perform well in the presence of gaps. The abrupt discontinuance of some components in SBP when the $\mathrm{SW}$ ceases to exhibit them then remains a pièce de résistance and the presence of the same components in other series of others is also supportive (Watanabe et al. 2005bI).

\section{HUMAN RESONANCE, PAST AND PRESENT, WITH THE SOLAR WIND?}

Involuntarily, an idea of antiquity comes to mind: Our knowledge of natural phenomena is nothing else but an echo received by our organs of the real processes of the universe (Involontairement, une antique idée nous vient à l'esprit: notre connaissance des phénomènes de la nature ne serait pas autre chose qu'un écho, reçu par nos organes, des processus réels de l'univers). Alexander Leonidovich Chizhevsky (1897-1964) (1938, cf. Zigel' 1979).

\section{Self-help in health care by senior author $(F H)$}

A time series of an elderly man's (FH) systolic blood pressure (SBP) serves to illustrate both selfhelp in health care and, as a dividend from vascular self-monitoring, provides information of basic interest. The time series of FH was obtained under various conditions of health and medication and had earlier shown the value of monitoring for health surveillance with a view of diagnosing and treating conditions of disease risk elevation as well as actual illness (Cornélissen et al. 2004cI). Intermittent monitoring, Fig. 3f, repeatedly revealed elevations in $\mathrm{M}$ and/or in A of BP. Once alerted, e.g., the elevated BP MESOR could be lowered $(\mathrm{P}=0.017)$ and the excessive swing (CHAT) eliminated ( $\mathrm{P}=0.029)$ (figure on $\mathrm{p} .41$ of Halberg et al. 1995) merely by changing the timing of medication (of diltiazem $\mathrm{HCl} 240 \mathrm{mg}$ /day from 08:00 to 00:00) based on his prior BP summary. The drastic clinical difference has a precursor in the laboratory in the history of assay development: over half a century earlier, when it was learned that the administration of a drug according to body time can make a difference of orders of magnitude between $2.8 \mathrm{mg}$ and $1 \mu \mathrm{g}$ - in the dose needed to detect its effect, Fig. 6.

The elevation of A of BP above gender- and age-matched limits, i.e., circadian hyper-amplitudetension or CHAT, carries a risk of stroke greater than that of MESOR-hypertension (Fig. 9 on p. 30 of Halberg et al. 1995). This elevated risk of CHAT, even in the absence of an elevated BP MESOR, is now documented in extensive statistics, in the light of outcomes (Table 1 in Cornélissen et al. 2005bI) concerning longevity in a follow-up of 


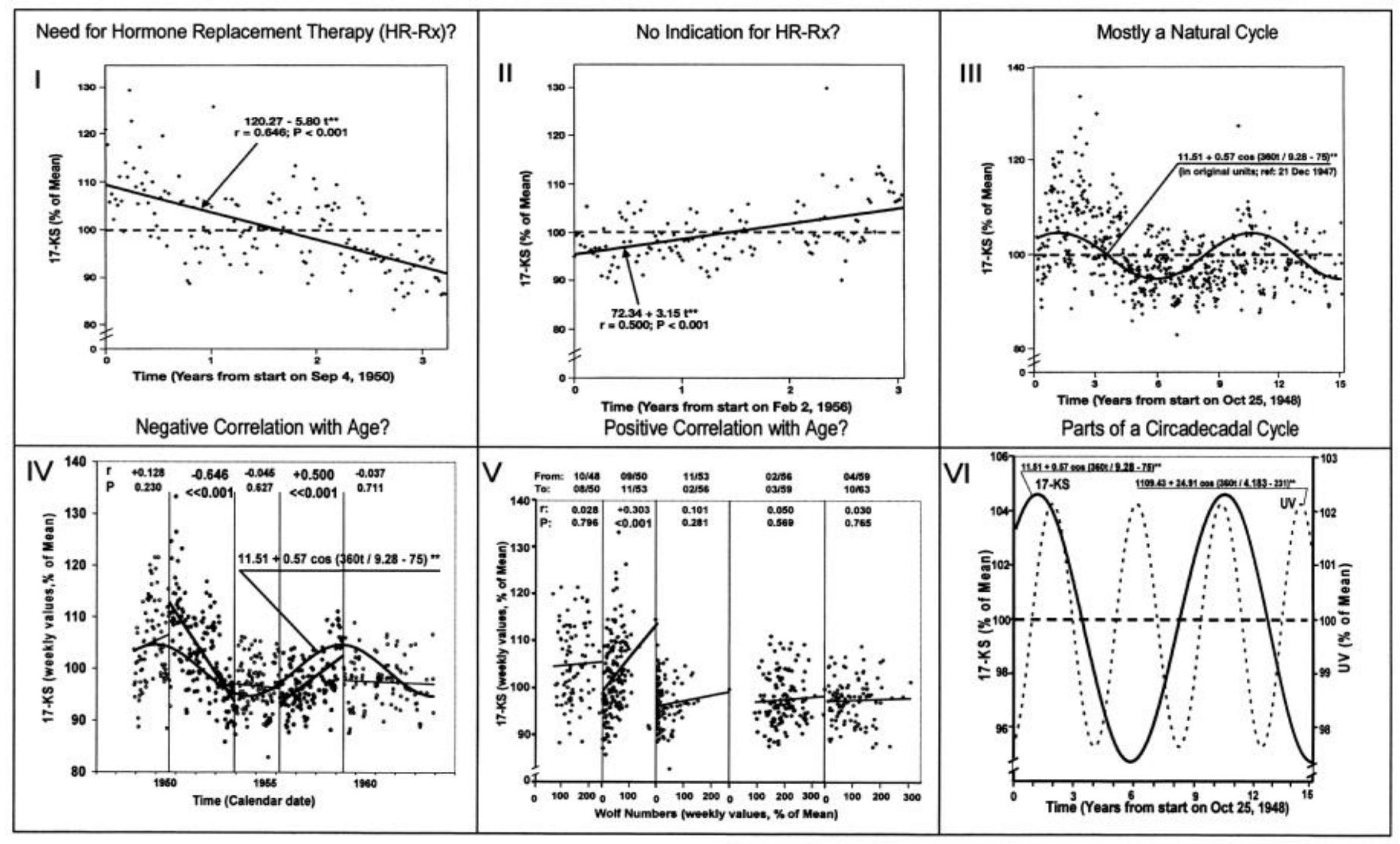

Fig. 5. Contradictory correlations of hormonal metabolites with age (I, II, IV - 5 of them) or with solar activity (V - 5 of them) stem in part from a common years-long cycle (III, IV, VI). Variabilities along the scale of decades, a confusing source of variation if ignored, can become a new, quantified reference value (Halberg et al. 2001b). Note further that the same clinically healthy man's urine can have drastically different periods in its volume vs. its content of hormonal metabolites. 
28 years (Halberg et al. 2002), concerning hard events such as strokes, myocardial infarctions, nephropathy or retinopathy, in a follow-up of 6 years (Halberg et al. 1995, Otsuka et al. 1996), among others, Fig. 4 (Halberg et al. 1995, 2002, Otsuka et al. 1996, Cornélissen et al. 2004cI). After other adjustments of medication (again, by changes in its timing along the scale of body time rather than clock-hour or by omission of an in-retrospect unnecessary medication), the correction of both MESOR-hypertension and CHAT was made possible in the light of a chronomically interpreted surveillance.

Transyears and cis-halfyear

We next examine any signature in human SBP by a purely physical (intermittent) oscillation (Richardson et al. 1994, Mursula and Zieger 2000, Mursula et al. 2003) of the speed (S) of the SW (SWS), i.a., with a period, $\tau$, of about 15 months
(1.3 years). Such a component in SWS splits and then disappears, Figs $3 \mathrm{a}$ and $3 \mathrm{c}$ top rows. In the same rows, there is no consistent oscillation with a $\tau$ of precisely 12 months. Such transyears (longer than 1 year) are also found in SCD in Minnesota that have accumulated since this diagnosis was separated from that of myocardial infarction (MI) by the tenth revision of the International Classification of Diseases (ICD10), which established it as code I46.1. These SCD in Minnesota also have no calendar-year component in their spectra and only a transyear pattern during the recent years examined, along with a cishalfyear that also shows geographic or other magnetic specificity, Fig. 7. By contrast, a calendar-year component is more prominent than the transyear in 29 years of data on deaths from MI in Minnesota (Halberg et al. 2000a, Cornélissen et al. 2002).

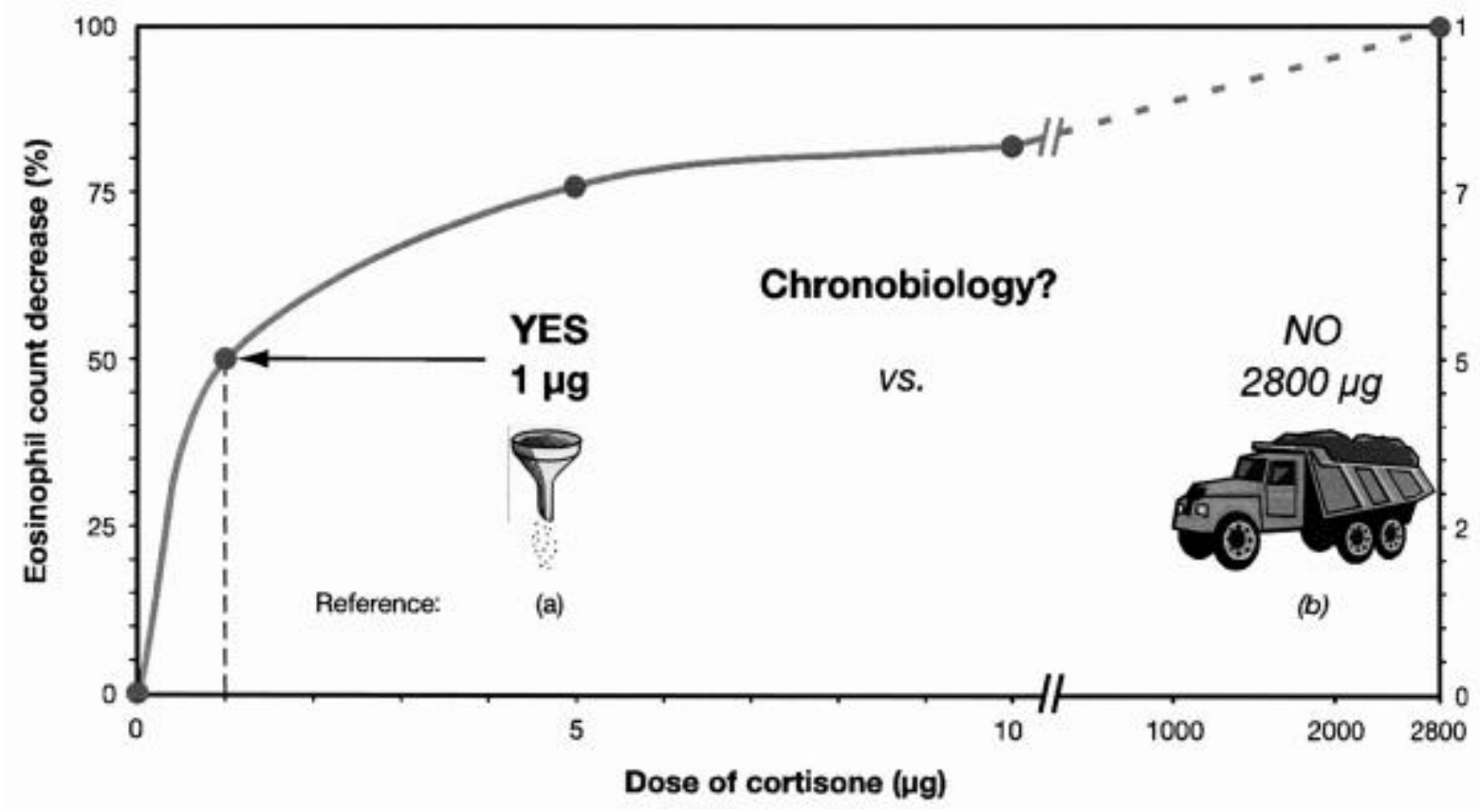

Fig. 6. Using chronobiology, a 2800-fold decrease in dosage proved successful*. A bioassay used $2.8 \mathrm{mg}$ of cortisone as the standard and counts of blood cells for 24 hours (Halberg 1952). Taking rhythms into account results in a great gain in sensitivity from this chronomic approach: cell depressing activity was detected with $1 \mu \mathrm{g}$ of the same substance (Halberg 1953). When the same hormone was tested only in the ascending phase of the circadian rhythm in count of these blood cells, the increase in sensitivity of the assay is depicted by comparing the minuscule dose on the left, taking into account the rhythm with the dose depicted as a truckload on the right, when the rhythm was "eliminated" by depressing the cell count to zero for 24 hours.

* Harvard, 1948-49, without chronobiology - a (Halberg 1952) vs. Minnesota 1950s - b (Halberg 1953) with chronobiology.

An about 2-year component

There are other components, such as a prominent about 2-year component in SBP and SWS that corresponds to Obridko and Rivin's (1996) quasibiennial variation (cf. also Kishcha et al. 1999, Ivanov and Obridko 2001, 2002, Ivanov et al. 2001, 2002). Thus, we confront another example of nearly matching physical and biological cycles in and around us. The $\tau$ of the circadiennial component of FH of 2.01-year length, with a CI from 1.98 to 2.05 , by far the largest component in Fig. 3b, depends, of course, as does the $\tau$ of all aeolians, upon the length and the temporal and spatial placement of the biological time series and will almost certainly change as these specifications change. Figs $3 \mathrm{a}$ and $\mathrm{b}$ also show components shorter than a year, i.e., cisyears, and a broad transhalf-yearly component at the outset that in SBP 
splits, with one arm becoming a cis-halfyear. Thereafter, there is an abrupt change, like that in the transyear of this variable; the change in prominence occurs with the same lag after the abrupt change in the SWS seen in the top row of Fig. 3a. The finding that part of a transyear and of a cis-halfyear persist in SBP when they are no longer detected in the SWS supports a degree of endogenicity of transyears and cis-halfyears, while other components, lost with a lag after the cessation of an 1 1.3-year transyear in SWS, are in keeping with a prior driving of part of the SBP spectrum by the SWS, Fig. 3 as a whole. Furthermore, peaks in global spectral windows of SBP and SWS were tested for overlapping vs. nonoverlapping CIs of their periods, $\tau \mathrm{s}$ (when the CIs of their amplitudes did not overlap zero). Some of these CIs of $\tau \mathrm{s}$ in the SWS and SBP overlapped, in keeping with the driving of SBP by the SWS; others did not overlap, in keeping with endogenicity, i.e., with the persistence of a component in SBP when it was no longer detected in SWS.

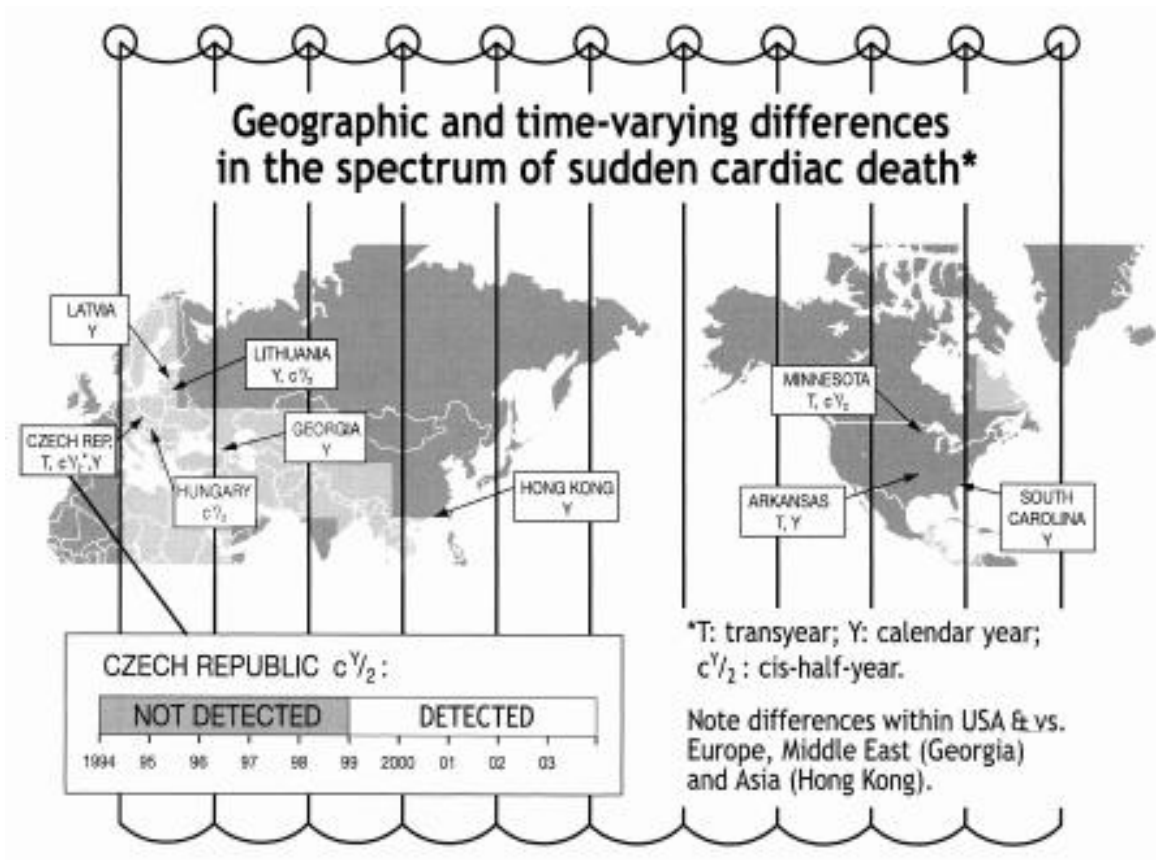

Fig. 7. A curtain of uncertainty, because of limited available data, hides any time- and geographic (geomagnetic or dip-magnetic) site-specificity of various spectral aspects of sudden cardiac death. Thus, we find a transyear in Minnesota with a cis-half-year $(\mathrm{cY} / 2)$ and both a calendar year and a transyear in Arkansas and the Czech Republic: at the latter site a cis-half-year, corresponding in length to an also-transient period of hard solar flares (Rieger et al. 1984), is detected after but not before 1999 (Halberg et al. 2005fI). In 1998, Peter V. Minorsky re-evaluated latitudinal differences in coconut palms' foliar spiral direction (FSD); he hypothesized that latitude-dependent biases in FSD, a non-Mendelian trait, will be associated with a temporally varying component of the earth's magnetic field. Earth currents, which are measurable in trees, bias the difference of auxin (or auxin transport proteins) in young embryos, such that left-handed palm trees (LHP) are produced preferentially in the Northern Hemisphere and right-handed ones (RHP) in the Southern Hemisphere. He built his observations on a previously collected data base by Davis and Davis, revealing that the ratio of LHP - RHP / total was better correlated with magnetic (dip) latitude than with geographic or geomagnetic (centered dipole) latitude. Most recently, Minorsky and Bronstein (2005) referred to this classical case of morphological antisymmetry in which dextral and sinistral forms are not inherited and are equally common within a species, proposing that Pc1-induced earth currents may bias the diffusion of morphogens in coconut palm embryos, thereby giving rise in asymmetries of FSD. Whether other geographic differences in sudden cardiac death may also relate to any magnetic latitude deserves scrutiny. It is noteworthy in any event that cardiac arrhythmias can also transiently reveal a transyear or a cishalfyear, each in a different solar Schwabe cycle stage, as seen from the limited data in Table 4.

While chance can never be ruled out and is particularly difficult to assess in the case of aeolians, the spectral peak at a 1.3-year trial period in biology, albeit not in physics is anticipated and is statistically significant below the 5\% level, with the qualifications discussed under Method. The relevance of these findings to mechanisms of disease stems from the possibility of beats among transyearly components and/or calendar-yearly component that could lead to exacerbations of disease or death. Thus far unexplained is the finding only of a transyear and no calendar-yearly component in SCD in Minnesota, Fig. 7. We shield against extremes of felt temperature and seen light, but not against cycles in the unseen, yet possibly experienced effect (Vallot et al. 1922, see also Faure 1927), resolved by the time macromicroscopy and telescopy of Fig. 3 (suggesting a 
biological association with SWS). Heating and air conditioning may account for our inability to detect a consistent about-calendar-yearly component in all displays of Fig. 3.

The persistence of at least part of a transyear in SBP in the absence of a corresponding component in SWS suggests a putative evolutionary signature of SWS in SBP that compares favorably with any built-in but undetected signature of the seasons in the SBP of FH. An endogenous aspect of transyears was documented earlier by non-overlapping CIs of transyear $\tau \mathrm{s}$ in SWS and SBP on a MESORhypertensive man under treatment (Halberg et al. 2003b, Cornélissen et al. 2004gI). We interpret Fig.
3 , with all its qualifications, by concluding that aeolians with a period statistically significantly longer than a calendar year (transyears) are built into organisms, yet may resonate with the SWS and that transyears deserve attention for both their basic and putative applied importance.

Transyears are found by cosinor, without exception in by now 46 physiologic time series, most of them covering decades mostly with more than single daily measurements from 14 individuals; their CIs cover neither the length of precisely 1.00 nor that of precisely 2.00 years (Cornélissen et al. 2004gI and unpublished).

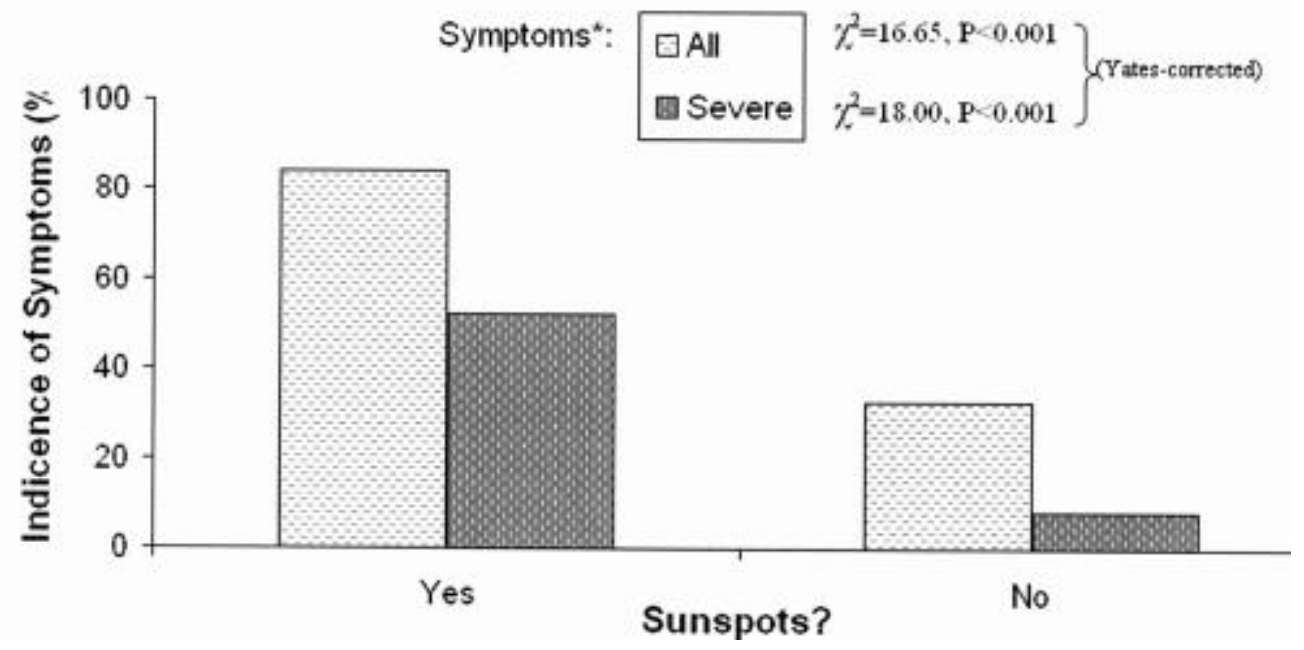

Fig. 8. Associations of clinical symptoms* with sunspots. Meta-analysis of what thoughtful and observant clinicians reported as an association of symptoms with solar activity over 80 years ago. Even mild symptoms, such as excitability, insomnia, tiredness, aches, muscle twitches, etc., have long been associated with sunspots (Vallot et al. 1922). We stand on the shoulders of many others who noted a lead in phase by a day of symptoms vs. sunspots.

* Symptoms of diseases of the heart, vessels, liver, kidney and nervous system, ranging from mild to severe, such as excitability, insomnia, tiredness, aches, muscle twitches, polyuria, digestive troubles, jitteriness, shivering, spasms, neuralgia, neural crises, asthma, dyspnea, fever, pain, vertigo, syncope, high blood pressure, tachycardia, arrhytmia, and true angina pectoris. From: Vallot et al. (1922).

Self-study by a cardiologist (YW)

The findings on YW (Table 1) are in keeping with those on FH; both differ from those of RBS (Sothern et al. 2005I) (Table 2): again only a transyear and no calendar-year-component was found in another human adult's SBP (Watanabe et al. 2005bI). Starting at 34 years of age, a clinically healthy cardiologist (YW) began monitoring his $\mathrm{S}$, mean arterial (MA) and DBP and HR automatically around the clock, for some years at 15-minute and thereafter at 30-minute intervals, with a Colin ABPM-630 monitor for 15 years and thereafter with an A\&D TM-2421. A global spectral window shows both near-transyears shorter than 1.2 years and fartransyears, longer than 1.2 years, of 1.043 , 1.12 and 1.83-year length, respectively, Table 1, and shows components of 2.09, 5.91 and 9.00-year length. Based on 18 years of data, a gliding spectral window of SBP, carried out with intervals of 8 years, demonstrates for SBP, most of the time solely transyears (Watanabe et al. 2005bI). The lack of a 1-year component in both a gliding and a global spectral window of YW is again noteworthy for an adult exposed to the seasons of Tokyo, Japan, and twice a year, for a week at a time for the past 6 years, to Minnesota winters and summers (he regularly visited Minnesota in January and August).

While, in the first several years of the record, two symmetrical components bracket the year in the gliding spectrum and could be a modulation by a component with a lower frequency, a wobbly and gradually lengthening component again corresponds to an about 1.3-year length reported earlier by physicists for SWS, also shown to be intermittent in the light of a much longer record of Wolf's relative sunspot numbers (Fig. 2d, Halberg et al. 2004hI). Moreover, the data on Wolf's 
numbers are equidistant (and those of YW are mostly equidistant with gaps not exceeding 2 weeks), whereas in FH gaps were larger, as seen in Fig. 3f. YW's record is thus relatively free of artifacts associated with unequidistant data from larger gaps. Any effects of trends that contribute a pink spectrum and of a change in instrumentation, however, remain to be kept in mind for YW and any effect of medications as well as gaps for $\mathrm{FH}$. Further requiring consideration is the question whether the transyear may resonate with components in the SWS and/or cosmic rays (Valdes-Galicia et al. 1996) or with geomagnetics driven by the SWS (Richardson et al. 1994, Mursula and Zieger 2000, Rangarajan and Barreto 2000, Mursula et al. 2003), a question also remaining open for the resonance of human heart rate (HR) with circaseptans in the cosmos (Cornélissen et al. 1996).

Table 1: Double amplitudes of components investigated in an 18-year record of blood pressure and heart rate

\begin{tabular}{|c|c|c|c|c|c|c|c|c|}
\hline Variable & M & $\begin{array}{l}\text { Period }(95 \% \\
\text { CI) (years) }\end{array}$ & $2 \mathrm{~A}(95 \% \mathrm{CI})$ & $\begin{array}{l}2 \mathrm{~A} \\
(\% \mathrm{M})\end{array}$ & 1 y $2 \mathrm{~A}$ & SE $(95 \% \mathrm{CI})$ & $\begin{array}{l}1 \mathrm{y}-2 \mathrm{~A} \\
(\% \mathrm{M})\end{array}$ & $\begin{array}{l}\text { A } 1.3 y / \\
\text { A } 1 y(\%)\end{array}$ \\
\hline SBP & 127.2 & $\begin{array}{l}1.386 \\
(1.335,1.436)\end{array}$ & $1.78 \quad(0.62,2.92)$ & 1.40 & 0.89 & 0.37 & 0.70 & 199.1 \\
\hline MAP & 97.4 & $\begin{array}{l}1.380 \\
(1.342,1.418)\end{array}$ & $2.00 \quad(1.02,2.96)$ & 2.06 & 1.19 & $0.31(0.58,1.84)$ & 1.22 & 167.8 \\
\hline DBP & 77.3 & $\begin{array}{l}1.241 \\
(1.173,1.309)\end{array}$ & $0.70(-0.04,1.44)$ & 0.90 & 1.07 & $0.24(0.60,1.54)$ & 1.38 & 65.4 \\
\hline HR & 80.5 & $\begin{array}{l}1.367 \\
(1.324,1.411)\end{array}$ & $1.74(0.76,2.74)$ & 2.16 & 1.90 & $0.32(1.26,2.54)$ & 2.36 & 91.5 \\
\hline
\end{tabular}

M: MESOR (midline-estimating statistic of rhythm), a rhythm-adjusted mean; 2A: double amplitude, extent of predictable variation within one cycle; y: year; Ty: transyear; CI: confidence interval; SE: standard error; S: systolic; D: diastolic; MA: mean arterial; BP: blood pressure; HR: heart rate. As are very small in health, but by the reference standard of the 1-y A, the Ty-A is numerically larger for SBP and MAP. The Ty-A is also larger than the 1-y A in the pattern of sudden cardiac death in some geographic locations (cf. Fig. 7). From Watanabe et al. 2005bI.

\section{Nowcasts and forecasts of space weather: mechanisms}

The forecast of changes in space weather (Dorman et al. 1993, 1995) is pertinent for the care of patients with MIs and may relate to SCD, notably at specific sites such as Arkansas, the Czech Republic and Minnesota. The associations shown in Fig. 3 point to BP as a possible receptor of SWS effects, yet the pineal and hypothalamus have also been documented to be involved in mediating effects of environmental magnetism (Halberg et al. 2005gI, Jozsa et al. 2005dI). Furthermore, any effect of SWS on biologically closed electric currents (BCEC) must not be excluded (Nordenström and Nordenström 2004, Rosch and Nordenström 2004). To cite the Chinese sage Laotzu describing Qi, according to Paul Rosch and
Björn Nordenström, his words apply to the SW insofar as its associations on earth are concerned:

Look, it cannot be seen - it is beyond form.

Listen, it cannot be heard - it is beyond sound.

Grasp, it cannot be held - it is intangible.

But the evidence in Figs 3 and 8 suggests that an association with the SWS may become assessable and evidence in Fig. 7 that it may provide clues to hard events. A scrutiny of the temporal aspects of an electrical circulatory system, reminiscent of and a possible basis for ancient Chinese concepts of meridians that conduct Qi (chi) energy will have to be aligned with a possible role of circadian rhythms in melatonin (Burch et al. 1999, Weydahl et al. 2001) in the pineal and the hypothalamus and perhaps in the gut (Halberg et al. 2005dI, Jozsa et al. 2005aI, Zeman 
et al. 2005aI). Many problems, if not all, notably those revolving around magnetics, may be better approached by taking into account the time-, frequency-, phase-, variable- and site-specificities of components in a wide spectrum of photic and non-photic (aeolian) environmental cycles with their coded signatures in biology including human affairs, health and economics (Komlos et al. 2004I). The new periodicities and old periodicities in new variables abound, beyond Table 3; all await the subtraction and addition approach carried out by the sun with Fig. 3, that for the transyear being a follow-up on the evidence showing that the weekly component of human heart rate is amplified and dampened by the presence and absence of a corresponding component around us (Cornélissen et al. 1996). The role and mechanisms of putative effects of physical variables await testing in appropriate facilities on earth to approach major problems of humankind in a budding chronobioethics, but in the interim the subtractionaddition approach can serve to identify the activities to be tested.

Table 2: More prominent didecadal than about-yearly components in the systolic (S) and diastolic (D) blood pressure (BP) of a clinically healthy man*

Cosinor

\begin{tabular}{|c|c|c|c|c|c|}
\hline $\begin{array}{l}\text { Periods } \\
(\tau, \text { years })^{* *}\end{array}$ & Variable & $\begin{array}{l}\text { Double amplitude } \\
\quad(\mathrm{mm} \mathrm{Hg})\end{array}$ & $\mathrm{P}$ & & $\begin{array}{l}\mathrm{P} \text { from } \\
\text { ANOVA }\end{array}$ \\
\hline \multirow[t]{2}{*}{20.000} & SBP & 4.7 & $<0.001$ & Original data & $<0.001$ \\
\hline & DBP & 4.2 & $<0.001$ & & $<0.001$ \\
\hline \multirow[t]{2}{*}{1.000} & SBP & 2.3 & $<0.001$ & (Residuals from linear trend & $<0.001$ \\
\hline & DBP & 1.8 & $<0.001$ & and from $\tau=20.0 \mathrm{y}$ ) & $<0.001$ \\
\hline \multirow[t]{2}{*}{1.157} & SBP & 0.85 & $<0.001$ & As above and residuals & NS \\
\hline & DBP & 0.41 & 0.058 & further from $\tau=1.0 \mathrm{y}$ & NS \\
\hline \multirow[t]{2}{*}{1.320} & SBP & 0.88 & $<0.001$ & $"$ & $<0.001$ \\
\hline & DBP & 0.81 & 0.002 & $"$ & 0.003 \\
\hline \multirow[t]{2}{*}{1.688} & SBP & 1.06 & $<0.001$ & $"$ & $<0.001$ \\
\hline & DBP & 1.04 & $<0.001$ & $"$ & $<0.001$ \\
\hline
\end{tabular}

\footnotetext{
* RBS, 35 years of 2-7 daily self-measurements starting May 11, 1967, at 20.5 years of age. The transyears constitute minor components, since they are averaged over a wide, relatively young age; in the same subject the transyear/calendar-year amplitude ratio has been shown to change from below to above unity, as the subject reached his $50 \mathrm{~s}$.

** $\tau$ found by linear-nonlinear rhythmometry Cf. also Fig. $9 \mathrm{~b}$
}

\section{New cis-circasemiannual biological cycles in human disease}

A 154-day [0.42- year (y)] cycle in the occurrence of hard solar flares had been recorded via the Solar Maximum Mission Satellite by Gamma Ray Spectrometry (Rieger et al. 1984, cf. also Dennis 1985, Lou 2000, Ballester et al. 2002, 2004, Temmer et al. 2005). In the geomagnetic index $\mathrm{K}_{\mathrm{p}}$, this cis-halfyear is present in a section of the data. It is found, as another case of near-matching cycles in human SCD in some geographic locations but not in others and not at all times, Fig. 7 (Fiser et al. 2005I, Halberg et al. 2005dI). In SCD in the Czech Republic, it is both time- as well as site-specific, i.e., undetected during several years, yet detected thereafter, Fig. 7, bottom left). Cis-circasemiannual components are also found in Minnesota, Lithuania and Hungary, but not in some other locations during the same span, Fig. 7. What seems interesting further, both cis-halfyears and transyears are found in cardiac arrhythmia in the Republic of Georgia, each in a different stage of the Schwabe cycle period, Table 4.

\section{Caveats}

The danger of blunders lurks large in chronomics and is the larger the smaller the number of replications, which in turn depends largely on the 
length of the $\tau$ involved. Difficulties stem from the aeolian nature of the cycle itself and the often unfavorable signal-to-noise ratio, from dealing often with unequidistant and scarce data with few or no replications, from the temptations of generalizing beyond the site-, frequency-, time- and variable-specificities involved and of extrapolating to mechanisms among matching cycles from temporal associations that need not be causal. To enable a chronometaanalysis (notably of publicly supported research), it follows that information on items relating to these specificities should become a standard requirement, as a sine qua non, requested by journal editors. To illustrate remaining uncertainties, for instance, when all data on SCD available thus far (from only a few state health departments that have responded to requests) are pooled, irrespective of site, a calendar-yearly component is prominent. It is then comforting but not conclusive to find that the newly found biological 0.42-cis-halfyear as well as the transyear have some physical counterparts in hard solar flares or the SWS, respectively.

What is certain, sufficient evidence is in hand, shown behind a curtain of uncertainty drawn over the findings in Fig. 7, to suggest that data provision for analysis, if not the analysis itself, should become a mandate of state health departments, implemented by the World Health Organization by requests to national governments.

Near-matching circaseptennians in and around us Circaseptennians are also transdisciplinary: they were found in gonadal indices of marine invertebrates, the replication in this case being across species, in the purple sea urchin (Strongylocentrotus purpuratus) and the black chiton (Katarina tunicata), perhaps as a measure of oceanic pollution (Francine Halberg et al. 1974, 1987, Halberg et al. 1987), with similar results found in data from another investigation (Pearse et al. 1985). Circaseptennians are also reported in a series of variables analyzed by Prof. Miroslav Mikulecky (1994a) and associates on the incidence of toxicariasis (Mikulecky and Ondrejka 1994), on the prevalence in Slovakia of echinococcosis in pigs and sheep (Dubinsky et al. 1993), on leptospirosis infections in Slovakia (Mikulecky et al. 1997), on viral tick-borne encephalitis, presumably associated with global warming, and in atmospheric pollution (Cilek et al. 1990). A report on a 7-year pattern in clinical hepatitis $\mathrm{A}$ is documented only over 9 years (Polakoff 1990) and a 7-year periodicity in measles, is mentioned by Tulchinsky et al. (1990). Adding to the transdisciplinary aspect, Verhulst and Onghena (1996) described a circaseptennian in the number of births by birth year of the founders of quantum physics, data meta-analyzed, confirmed and with their $\tau$ estimated by us with the CI indeed covering
7 years (Cornélissen et al. 1998). Furthermore, Mikulecky (1994b) and Kondrashov et al. (2005) described, the latter based on a 1300-year record, a rhythm in the height of water in the Nile, which the latter associate with a North Atlantic oscillation, resulting in atmospheric pressure differences between Iceland and the Azores (Strestik et al. 1994, Kehse 2005). It is the more interesting that we recently detected a circaseptennian in monthly averages of daily values for solar magnetism assessed by a telescope in Stanford, while the monthly standard deviations showed the circadecadal Schwabe cycle (Cornélissen et al. 2005fI), another hint of the desirability of looking both at means and at dynamics rather than only at one or the other aspect of time series.

Indeed, a plot of the daily values of solar magnetism as a function of time between 1968 and 2004, combining data from Crimea and Stanford, shows four bursts about 10 years apart. Around 1970, 1982, 1989 and 2002, solar magnetism is seen to vary greatly, with values in the range from about -200 to about +200 microTeslas $(\mu \mathrm{T})$. By contrast, at other times, around 1977, 1987 and 1997, the variability in solar magnetism is much less, the range being reduced to between about \pm 20 $\mu \mathrm{T}$. The naked eye does not discern much change in the overall mean value which seems to oscillate around zero. These first macroscopic impressions (and the fact that spectral analyses revealed an about 7-year rather than an about 10-year component apparent to the naked eye) prompted the computation of monthly means and standard deviations (SDs), so that any long-term changes as a function of time in the mean value of solar magnetism could be seen, no longer being obscured by the very large changes from one day to another.

Plots of the monthly SDs as a function of time confirmed the presence of an about 10-year cycle, the SD varying from only a few $\mu \mathrm{T}$ to about 100 $\mu \mathrm{T}$. Nonlinearly, this component was resolved as having a period of 10.305 years $(95 \% \mathrm{CI}: 10.003$, $10.608)$ with a large amplitude of $19.8 \mu \mathrm{T}(95 \% \mathrm{CI}$ : 16.0, 23.6). By contrast, monthly means varied only within about $\pm 40 \mu \mathrm{T}$, with only occasional lower values reaching $-100 \mu \mathrm{T}$ or higher values reaching about $100 \mu \mathrm{T}$, seen mostly but not invariably in the data from the Crimea. Overall, corroborating original visual impressions, the mean value is indeed close to zero $(-0.7 \mu \mathrm{T})$. Linearnonlinear least squares analyses do not detect any about 10 -year cycle. Instead, an about 7-year cycle is found, as is an about 5.164-year variation, corresponding to the second harmonic of the major 10.3-year cycle characterizing the monthly SDs. Nonlinearly, the periods are resolved as averaging 7.08 (95\% CI: 6.65, 7.51) and 5.16 (95\% CI: 4.90, $5.43)$ years, with corresponding As of 10.0 (95\% CI: $4.75,15.24)$ and 8.1 (95\% CI: $2.73,13.42) \mu \mathrm{T}$, much smaller than the A of the about 10 -year cycle 
Table 3: Chronomics: $10.5-$ and $\sim 21-y e a r$ cycles in and around us

\begin{tabular}{|c|c|c|c|c|c|c|c|c|c|}
\hline \multirow{2}{*}{\multicolumn{2}{|c|}{ Discipline and variable }} & & \multicolumn{3}{|c|}{ Period (years) } & \multicolumn{2}{|c|}{ Series duration } & \multirow{2}{*}{\multicolumn{2}{|c|}{$\begin{array}{l}\text { Number } \\
\text { of data } \\
\text { sampling }\end{array}$}} \\
\hline & & & \multirow[t]{2}{*}{$\begin{array}{l}\text { Lower } \\
\text { limit* }\end{array}$} & \multirow[t]{2}{*}{$\begin{array}{l}\text { Best } \\
\text { Fit }\end{array}$} & \multirow[t]{2}{*}{$\begin{array}{l}\text { Upper } \\
\text { limit* }\end{array}$} & \multirow[t]{2}{*}{ Dates } & \multirow[t]{2}{*}{ Years } & & \\
\hline \multicolumn{5}{|l|}{ Environment } & & & & & \\
\hline 1 & \multicolumn{2}{|c|}{$\mathrm{aa}=$ Antipodal Geomagnetic Index } & 10.12 & 10.63 & 11.13 & 1890-1999 & 110 & $1 /$ year & \\
\hline 2 & \multicolumn{2}{|c|}{$\mathrm{Kp}=$ Planetary Geomagnetic disturbance } & 10.32 & 10.58 & 10.85 & 1932-1999 & 68 & $1 /$ month & \\
\hline 3 & \multicolumn{2}{|c|}{$\mathrm{WN}=$ Wolf's relative sunspot number } & 10.37 & 10.54 & 10.70 & 1890-1999 & 110 & $1 /$ year & \\
\hline 4 & - Dst $=$ Equato & ial geomagnetic disturbance & 8.75 & 10.85 & 12.96 & 1973-1999 & 27 & " & \\
\hline & & & 10.48 & 10.51 & 10.55 & 1700-1999 & 300 & " & \\
\hline 5 & Bipolarity "Hz & le Cycle" ** & 20.86 & 21.10 & 21.26 & 1890-1999 & 110 & " & \\
\hline & & & 21.42 & 21.43 & 21.43 & 1700-1999 & 300 & " & \\
\hline Biology & & & & & & & & & \\
\hline 6 & Prokaryotes: $A$ & ir Bacterial Sectoring & 9.12 & 9.45 & 9.81 & 1970-1982 & 13 & 3,744 & Italy \\
\hline 7 & Eukaryotes: U & icellular Algal $\mathrm{O}_{2}$ Production & 7.79 & 9.24 & 11.87 & 1980-1991 & 11 & 324 & Germany \\
\hline Physiology**: & & & & & & & & & \\
\hline 8 & Mood (RBS) & & 10.11 & 11.50 & 13.41 & 1966-1998 & 33 & $\sim 5 /$ day & USA \\
\hline 9 & Time (1-Minu & e) Estimation (RBS) & 9.38 & 10.29 & 11.37 & 1966-1998 & 33 & " & " \\
\hline 10 & Urinary $17-\mathrm{ke}$ & osteroid excretion $(\mathrm{CH})$ & 8.70 & 9.30 & 9.90 & $1948-1963$ & 15 & $1 /$ day & Denmark \\
\hline 11 & Peak Expirato & y Flow (RBS) & 10.36 & 11.74 & 13.11 & 1966-1998 & 33 & $\sim 5 /$ day & USA \\
\hline 12 & Respiratory R & te (RBS) & 10.13 & 12.50 & 17.32 & 1966-1998 & 33 & " & " \\
\hline 13 & Systolic Blooc & Pressure - SBP (RBS) & 9.05 & 10.21 & 11.36 & $1966-1998$ & 33 & " & " \\
\hline 14 & Standard Devi & ation of SBP (YW) & 8.85 & 10.43 & 12.76 & 1987-1998 & 11 & $\sim 48$ / day & Japan \\
\hline 15 & Diastolic Bloo & Pressure - DBP (RBS) & 10.09 & 10.98 & 11.87 & 1966-1998 & 33 & $\sim 5 /$ day & USA \\
\hline 16 & Standard Devi & ition of DBP (YW) & 6.18 & 7.82 & 10.02 & $1987-1998$ & 11 & $\sim 48 /$ day & y Japan \\
\hline 17 & Heart Rate - $\mathrm{H}$ & $\mathrm{R}(\mathrm{YW})$ & 9.54 & 12.93 & 17.91 & 1987-1998 & 11 & " & 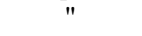 \\
\hline 18 & Standard Devi & ation of HR (YW) & 8.27 & 11.52 & 16.22 & $1987-1998$ & 11 & " & \\
\hline Pathology & & & & & & & & & \\
\hline 19 & Myocardial In & arction & 10.00 & 10.80 & 11.70 & 1960-1996 & 37 & 129,205 & 5 USA \\
\hline 20 & Leptospirosis & $* * * *$ & 9.40 & 10.80 & 12.40 & 1949-1995 & 47 & 2,907 & Slovakia \\
\hline 21 & Diabetes & $* * * *$ & 7.70 & 10.40 & 13.30 & 1985-1995 & 11 & 1,369 & " \\
\hline Anthropon & at birth & & & & & & & & \\
\hline & Body Weight & Boys & & & & & & & \\
\hline 22 & & Minnesota & 9.53 & 23.19 & 27.67 & 1963-1998 & 36 & $2,136,74$ & 45 USA \\
\hline 23 & & Alma-Ata Russians & 14.99 & 17.17 & 20.07 & 1946-1998 & 53 & $9,056 \mathrm{~K}$ & Kazakhstan \\
\hline 24 & & " Kazakhs & 18.39 & 21.24 & 24.05 & 1946-1998 & 53 & 3,459 & " \\
\hline 25 & & $\begin{array}{l}\text { Moscow } \\
\text { Girls }\end{array}$ & & 10.49 & & $1874-1985$ & 112 & 5,987 & Russia \\
\hline 26 & & Minnesota & 20.58 & 23.46 & 26.83 & 1963-1998 & 36 & $1,039,46$ & 64 USA \\
\hline 27 & & Alma-Ata Russians & 15.21 & 17.75 & 21.06 & $1946-1998$ & 53 & 9,105 & Kazakhstan \\
\hline 28 & & Kazakhs & 15.44 & 21.45 & 27.45 & $1946-1998$ & 53 & 3,448 & \\
\hline 29 & & Moscow & 9.70 & 10.29 & 11.01 & $1874-1985$ & 112 & 5,840 & Russia \\
\hline & & Both genders & & & & & & & \\
\hline 30 & & Denmark & 14.71 & 17.94 & 22.68 & 1973-1994 & 22 & $1,166,20$ & 06 Denmark \\
\hline & Body Length & Boys & & & & & & & \\
\hline 31 & & Alma-Ata Russians & 15.82 & 18.58 & 22.38 & $1946-1998$ & 53 & $9,026 \quad \mathrm{l}$ & Kazakhstan \\
\hline 32 & & Moscow & 18.76 & 20.28 & 21.86 & 1874-1985 & 112 & 5,976 & Russia \\
\hline & & Girls & & & & & & & \\
\hline 33 & & Alma-Ata Russians & 16.13 & 19.20 & 23.39 & 1946-1998 & 53 & $9,105 \quad \mathrm{l}$ & Kazakhstan \\
\hline 34 & & Kazakhs & 15.72 & 19.60 & 25.40 & 1946-1998 & 53 & 3,485 & " \\
\hline 35 & & Moscow & 19.05 & 20.76 & 22.78 & $1874-1985$ & 112 & 5,976 & Russia \\
\hline & & Both genders & & & & & & & \\
\hline 36 & & Denmark & 20.81 & 23.55 & 26.55 & 1973-1994 & 22 & 1,166206 & 66 Denmark \\
\hline & Head Circum & erence & & & & & & & \\
\hline 37 & & oys Moscow & 17.71 & 19.23 & 20.75 & $1874-1985$ & 112 & 5,976 & Russia \\
\hline 38 & & firls " & 18.42 & 20.73 & 23.95 & 1874-1985 & 112 & 5,820 & " \\
\hline Demography & & & & & & & & & \\
\hline 39 & Birth rate & & 8.63 & 9.43 & 10.23 & $1940-1996$ & 57 & 57 & USA \\
\hline & & & 17.61 & 21.33 & 25.05 & $1940-1996$ & & & \\
\hline Motivation & & & & & & & & & \\
\hline 40 & Religious activi & y of Jehovah's Witnesses & 17.52 & 20.44 & 24.45 & 1950-1999 & $\begin{array}{ll}50 & 3 \\
& 5,\end{array}$ & $\begin{array}{l}328,572^{\#} \mathrm{~W} \\
, 653,987^{\# \#}\end{array}$ & Worldwide \\
\hline Criminality & & & & & & & & & \\
\hline 41 & Homicide & & 8.99 & 10.58 & 12.16 & $1900-1998$ & 99 & 99 & USA \\
\hline & & & 19.23 & 20.35 & 21.62 & & & & \\
\hline Wars & & & & & & & & & \\
\hline 42 & International ba & thes & 21.87 & 21.96 & 22.06 & 599BC-1957 & $7 \quad 2556$ & $2556 \mathrm{~W}$ & Norldwide \\
\hline
\end{tabular}

* $95 \%$ confidence limit; not shown if cycle is not statistically significant; ** Computed by changing the sign of WN at each WN minimum; ***RBS - Dr. Robert B. Sothern, CH - Dr. Christian Hamburger, YW - Dr. Yoshihiko Watanabe; **** Data contributed by Dr. Miroslav Mikulecky; ${ }^{*}$ in 1950; ${ }^{* \#}$ in 1999, pool of 103 (and other unspecified number of) sites 
Table 4. Do we need more than heating and air conditioning? Do we have to compensate for magnetics? Periodicities in Human Electrocardiograms Show a Circa-Cis-Semiannual (Cis-Halfyear) Cycle Matching the Rhythm of Hard Solar Flares, but No Transyear, in One 10-year Schwabe Cycle Stage and Vice Versa in Another Stage: In Most of Various Cardiac Arrhythmias, a Transyear (TY) is Prominent during a Span of Maximal Solar Activity (1989-1990) and a Cis-Halfyear during the Descending Phase of Solar Cycle \#22 (1983-1984)*

\begin{tabular}{|c|c|c|c|c|c|c|c|c|c|c|c|c|c|c|c|}
\hline \multirow[t]{2}{*}{ Arrhythmia } & \multirow{2}{*}{$\begin{array}{l}- \\
\mathrm{P}\end{array}$} & \multicolumn{2}{|c|}{ Period $=1 \mathrm{y}$} & \multirow{2}{*}{$\begin{array}{l}- \\
\text { Period }\end{array}$} & \multicolumn{5}{|c|}{$\mathrm{TY}($ trial period $=1 \mathrm{y})$} & \multicolumn{6}{|c|}{ CisHalfYear $($ Trial period $=0.42 \mathrm{y})$} \\
\hline & & A & $\phi$ & & $(95 \%$ & $\mathrm{CI})$ & A & $(95 \%$ & CI) & Period & $(95 \%$ & CI) & A & $(95 \%$ & $\mathrm{CI})$ \\
\hline & \multicolumn{15}{|c|}{$1983-1984$} \\
\hline $\mathrm{S}$ & 0.034 & 0.058 & -234 & 0.932 & 0.647 & 1.216 & 0.06 & 0.00 & 0.13 & 0.431 & 0.400 & 0.462 & 0.11 & 0.04 & 0.18 \\
\hline Ps & 0.079 & 0.042 & -228 & 0.974 & 0.605 & 1.343 & 0.04 & -0.02 & 0.10 & 0.439 & 0.413 & 0.464 & 0.12 & 0.06 & 0.17 \\
\hline V1 & 0.002 & 0.087 & -207 & 1.024 & 0.760 & 1.288 & 0.09 & 0.01 & 0.16 & 0.432 & 0.401 & 0.463 & 0.12 & 0.05 & 0.20 \\
\hline $\mathrm{Vm}$ & 0.034 & 0.056 & -214 & 1.000 & 0.647 & 1.353 & 0.06 & -0.01 & 0.12 & 0.438 & 0.408 & 0.467 & 0.11 & 0.05 & 0.18 \\
\hline $\mathrm{Pv}$ & 0.255 & 0.008 & -70 & 1.000 & 0.484 & 1.516 & 0.00 & 0.00 & 0.02 & - & - & - & - & - & - \\
\hline $\mathrm{Pp}$ & 0.151 & 0.009 & -230 & 1.000 & 0.546 & 1.454 & 0.00 & 0.00 & 0.02 & - & - & - & - & - & - \\
\hline
\end{tabular}

1989-1990

$\begin{array}{lcccccccccccccccccc}\text { S } & \mathbf{0 . 3 8 6} & \mathbf{0 . 0 2 4} & \mathbf{- 1 1} & - & - & - & - & - & - & 0.528 & 0.456 & 0.599 & 0.06 & 0.00 & 0.11 \\ \text { Ps } & =0.001 & \mathbf{0 . 0 6 9} & \mathbf{- 6 4} & 1.347 & 1.042 & 1.652 & 0.09 & 0.03 & 0.14 & - & - & - & - & - & - \\ \text { V1 } & 0.001 & \mathbf{0 . 1 0 3} & \mathbf{- 6 6} & 1.439 & 1.044 & 1.834 & 0.13 & 0.04 & 0.22 & - & - & - & - & - & - \\ \text { Vm } & \mathbf{0 . 1 6 2} & \mathbf{0 . 0 3 6} & \mathbf{- 6 7} & 1.690 & 0.979 & 2.400 & 0.10 & 0.04 & 0.15 & - & - & - & - & - & - \\ \text { Pv } & \mathbf{0 . 8 2 6} & \mathbf{0 . 0 0 3} & \mathbf{- 5} & - & - & - & - & - & - & 0.361 & 0.331 & 0.390 & 0.02 & 0.00 & 0.04 \\ \text { Pp } & 0.095 & \mathbf{0 . 0 1 6} & \mathbf{- 4} & 1.289 & 0.879 & 1.700 & 0.02 & 0.00 & 0.05 & - & - & - & - & - & -\end{array}$

*Data from Tbilisi (Georgia) from Dr Levan Tvildiani. P: P-value from zero-amplitude (no-rhythm) test; A: Amplitude (in number of cases per day); $\phi$ : Acrophase, in (negative) degrees, with $360^{\circ} \equiv$ period length; $0^{\circ}=1$ Jan 1983. S: supraventricular extrasystoles; Ps: supraventricular paroxysmal tachycardia; V1: ventricular single extrasystoles; Vm: ventricular multiple extrasystoles; Pv: paroxysmal ventricular tachycardia; Pp: paroxysm of atrial fibrillation. A cycle with a period shorter than a half-year, also found in Wolf's relative sunspot numbers (see Cornélissen et al. 2005I) spectra on page S7 and described for hard solar flares by Rieger A. et al. 1984. If we find out how precisely these cosmic, perhaps solar, signatures act, we may shield from, or rather compensate for their unseen and not obviously identified effects as need be.

characterizing the monthly SDs.

These results confirm the visual impression that the major feature in the data relates to the among-day differences in the extent of change in solar magnetism, here gauged by monthly SDs. From a purely methodological viewpoint, analyses performed on monthly means and SDs rather than on the original daily values are further justified by the fact that most statistical tests such as the regression of periodic functions carried out here rely on the assumption that the variance remains constant as a function of time (homeoscedasticity). This assumption is clearly violated in the case of the daily values of solar magnetism. Analyses restricted to the original values in this case would have completely missed the prominent about 10year cycle in the variability of solar magnetism.

\section{Near-transyears}

A prior analysis of the Stanford data on solar magnetism from May 1975 to April 2002 (27 years) detected a component that was nonlinearly resolved as having a period of 1.048 (95\% CI: $1.030,1.065)$ years, non-overlapping the calendar year (Cornélissen et al 2005fI). When the analyses were repeated for the longer record including the
Crimea data and covering the span from 1968 to 2004 (about 37 years), the nonlinear estimates of the near-transyear were different: the period was found to average only 1.025 (95\% CI: $1.012,1.038)$ years. The about $4 \mu \mathrm{T} \mathrm{A}$ of this component was about the same in both analyses and its $95 \%$ CI did not overlap zero, Fig. $2 b$.

Noteworthy is the observation that the period of 1.025 years found for the longer record does not fall within the $95 \%$ CI of the period estimate from the shorter record, and vice versa, the period estimate characterizing the shorter record of 1.048 years falls outside the $95 \%$ CI of the period estimate from the longer record. A change in the opposite direction from a component with a CI that covers the precise 1-year length to one that does not do so, is also seen for SBP in Fig. 2b. This may be because we are dealing with 'aeolians' that can be wobbly around and in us. If this is the case as it probably is, the $95 \%$ CIs obtained by nonlinear least squares are likely much too liberal, being too narrow. The question may then be raised whether we are truly dealing with near-transyears or whether a more conservative $95 \%$ CI may not include the calendar year. Only analyses of longer and longer records of solar magnetism or of 
variables influenced by it may provide an answer to this question, yet here we need to specify for all aeolians that the longest available record is the decisive estimate and that it is subject to change with the further length of the series. The record of solar wind speed is longer than that of magnetism and both records are handicapped by gaps. To the extent to which it can be assumed that signals characterizing SWS or solar magnetism also characterize in part variables such as aa or $\mathrm{K}_{\mathrm{p}}$, geomagnetism being influenced by solar magnetics, results on time series on aa that is still longer and equidistant seem to add valuable information. Peaks on either side of the 1-year period then raise

\section{Systolic Blood Pressure}

RBS - SBP (20 years) Ret: 1 Jan 1967

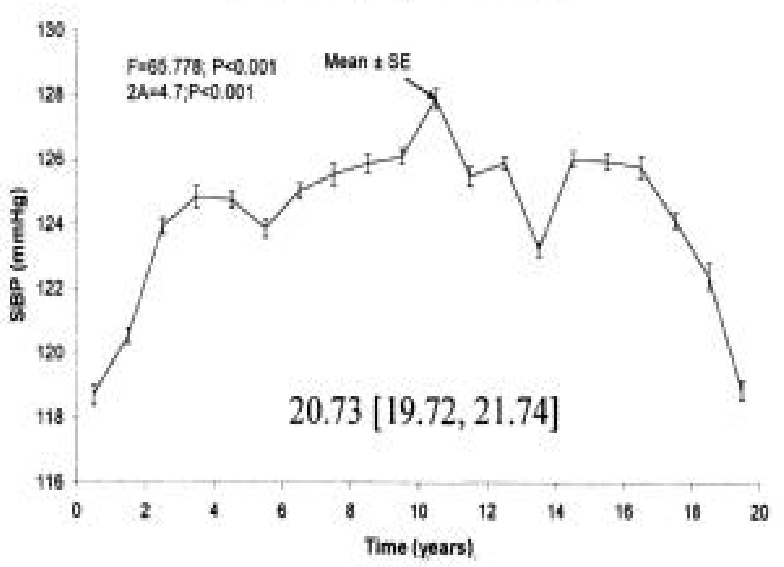

RBS - SBP (1.0 year) Ref: 1 Jan 1967 (Residuals from Linear Trend + NL 20.0y)

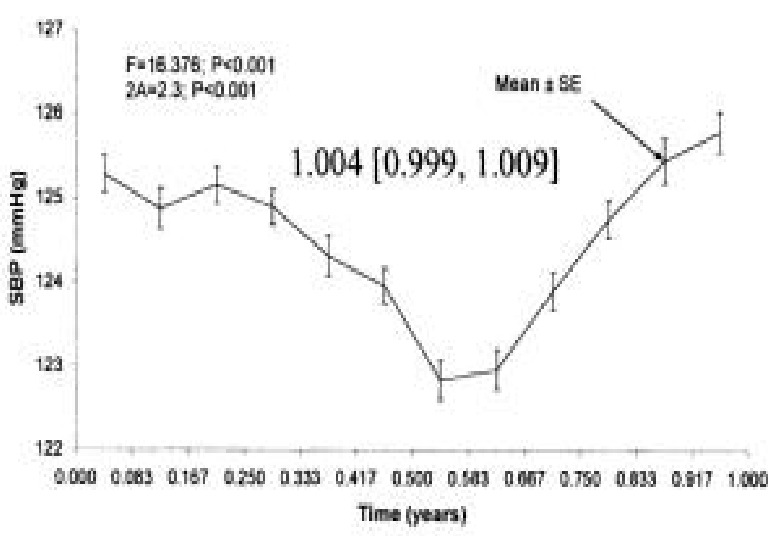

the question of a possible modulation of a calendaryearly component (Cornélissen et al. 2005fI). Gaps notwithstanding, a still longer record of the auroras remains to be analyzed. But here, biology can provide a transdisciplinary perspective. Acetabularia has presumably existed on earth for 500 million years (Berger and Kaever 1992); it does show a near-transyear in the spectrum of its oxygen production over 14 years, as does human 17-ketosteroid excretion over 15 years by a clinically healthy man. Both may reflect the signature of the SWS coded in algae and a man's nucleic acid by the SW as it blew millions and probably billions of years ago (von Steiger 2004).

\section{Diastolic Blood Pressure}

RBS - DBP (20 years) Ref: 1 Jan 1987

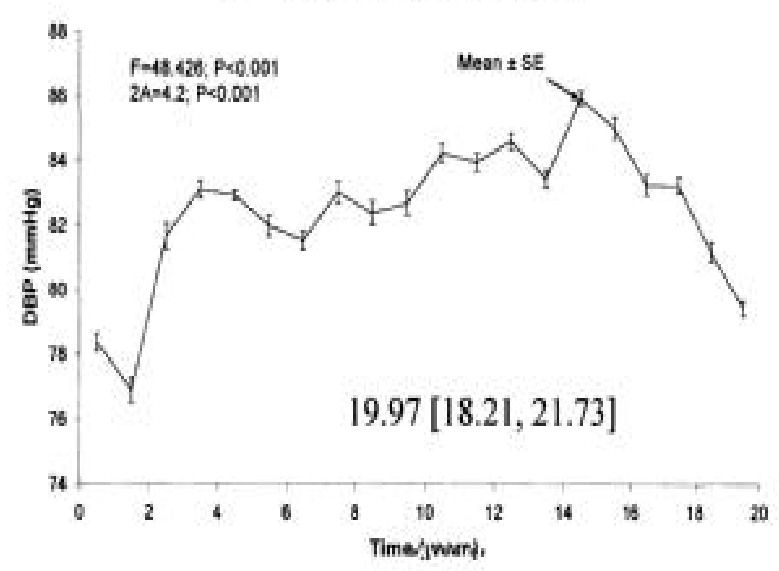

RBS - DBP (1.0 year) Ref: 1 Jan 1967 (Residuals from Linear Trend + NL 20.0y)

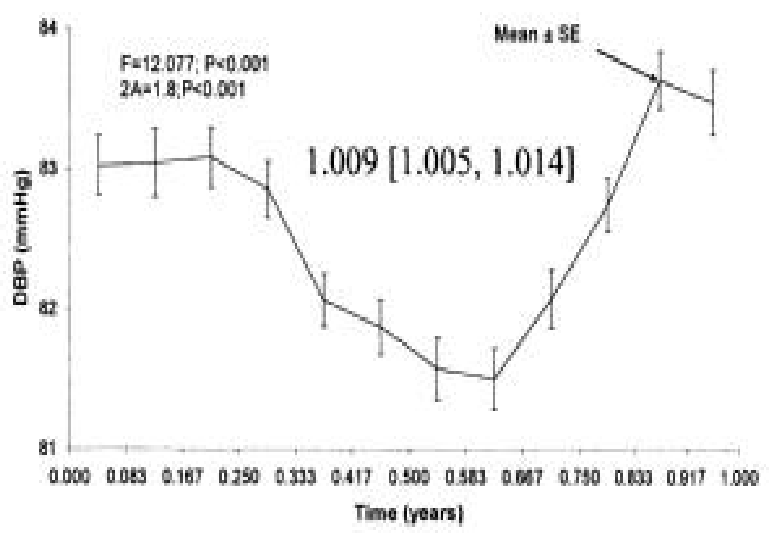

Fig. 9a. Non-Photic as well as Photic Influences on Human Blood Pressure* (RBS, M, 20.5 y at start of record). A circadidecadal cycle (top) in the blood pressure of a clinically healthy man's (RBS) 35-year-long record (of, on the average, 5 daily measurements) exceeds by far the extent of circannual (seasonal) change (bottom).

* 5-year record of self-measurements (about 5/day) stacked over 20 years (top) or 1 year (bottom); periods correspond to spectral peaks, validated nonlinearly by non-overlap of zero by the $95 \%$ confidence interval (CI) of the amplitude. Listed nonlinear estimates of periods with corresponding 95\% CIs (in years) were obtained by considering model consisting of given component with anticipated period (used for stacking) fitted separately with addition of linear trend. Not shown are transyears, also resolved nonlinearly, notably a component with period about 1.3 years characterizing solar wind speed (SBP: 1.319 [1.296, 1.342], DBP: [1.296, 1.346]. 


\section{CIRCADIDECADALS IN POPULATIONS WITH SITE-SPECIFIC PHASES}

In 112 years (1874-1985) of neonatal body length and head circumference in Moscow collected by the late Boris Nikityuk (Halberg et al. 2001d), linear-nonlinear least-squares rhythmometry yields an estimate of a circadidecadal spectral component with a CI of its $\tau$ which covers a $\tau$ of 20 years. Shorter but larger data sets on body length, summarized for 1,166,206 Danish babies born from 1973 to 1994, reveal a circadidecadal amplitude over 3 times larger than the yearly amplitude (Halberg et al. 2003b), based on data taken off a publication (Wohlfahrt et al. 1998). Circadidecadal $\tau \mathrm{s}$ are also found in body weight elsewhere (Halberg et al. 2003b), including 2,136,745 newborns in Minnesota; they are part of a map of decadal and didecadal cycles reported earlier, Table 3. We emphasize that the site-specificity, with respect to different frequencies involved in SCD in different geographic locations, is extended to phase-differences of neonatal circadidecadals supported by data on $3,252,957$ babies.

\section{Circadidecadals in an individual}

Figs $9 \mathrm{a}$ and $\mathrm{b}$ and Table 2 extend an about 20-year rhythm from populations to an individual's physiology, showing that in a man (RBS) during the documented age span, the circadidecadal amplitude is larger than that of the calendar-yearly spectral component; the circadidecadal range covers twice the range of the calendar-yearly change (Sothern et al. 2005I). Transyears with $\tau$ longer than a calendar year have a relatively small amplitude in this subject's record, who started selfmeasurements at 20.5 years of age, in whom transyears were previously found to increase in prominence when he passed 50 years of age. Circadecadal components were described earlier in the same subject with a $\tau$ of $10.21 \mathrm{y}$ for SBP and 10.98y for DBP, Table 3 (Halberg et al. 1998), estimated based on a span from 1966 to 1998. Whereas the span here analyzed is longer, the data on the circadidecadal cycle are limited to less than two cycles, and of course require extension.

\section{DISCUSSION}

One series of morphological neonatal data on both weight and length and on head, chest and abdominal circumference covers about 5.5 circadidecadal cycles. Others are also available with single or no replications, but are based on large populations supporting the findings on a number of other population variables that exhibit cycles of similar length - birth rates, religious activity, homicide and international battles (Halberg et al. 2004hI; for related aspects cf. Ertel 1993a,b, 1994, 1996, 1997, Mikulecky 1993, 1994a, 1997), Table 3. In themselves, such findings are at best hints and must not imply causal relations as such. When, in turn, there is a geographic (geomagnetic?) latitude-dependence, an association deserves testing (Starbuck et al. 2002), the limitations of currently available data sets notwithstanding.

A remove-and-replace or subtraction-andaddition approach, applied earlier to circadian rhythms (Halberg et al. 1951, cf. Halberg 1953, $1955 b)$ and to the biological week (Cornélissen et al. 1996) is critical; it is now extended, in part, to transyears in Figs 3a-f. The presence of statistically significant counterparts in biology, as neartransyears, near the spectral lines reported originally, among others, by Shapiro (1967), Fraser-Smith (1972) and Delouis and Mayaud (1975) in geomagnetics and now of an 0.42-year in SCD corresponding to the $\tau$ in the physical data of Rieger et al. (1984) add credence to the transdisciplinary scientific significance of such waxing and waning "aeolian" (both physical and biological) spectral components.

In the pre-computer, pre-satellite era, Julius Bartels had championed the statistical nature of terrestrial magnetic activity by referring to quasipersistence in quasi-periodic variables: "since the phenomenon seems to produce a geophysical effect only with (a) certain probability and since all geophysical theories either grow out of statistical results or must be subjected to statistical tests" (Bartels 1959). We would have replaced the "or" in the foregoing citation with "and" and further qualify it by the empirical findings of free-running (Halberg et al. 2003a), as one of us did in person in a discussion with Bartels in 1953 (Halberg 1953, cf. Halberg 2000) and accordingly refer again to Halberg et al. 2006. The caveat here repeated is against the tempting stacking of the data, as Bartels $(1932,1959)$ and many others, including ourselves, have done thereafter with notable exceptions such as the use of chronobiologic serial sections (Halberg et al. 1965) and of moving spectra to study dynamics (Mursula and Zieger 2000, Halberg et al. 2004hI). The stacking prevented the discovery of components differing from a known period such as precisely 1 year or 1 day (Bartels 1932).

\section{Chronomics, the indispensable control}

Fifty-six years ago, it seemed relatively easy to recognize the dangers of ignoring circadian rhythms by work along the scale of 24 hours for several weeks, Figs 10 and 11 (Halberg and Ahlgren 1980, cf. Halberg et al. 2003a). One identified the relative roles of synchronizers and assumed that one could then use the lighting and feeding regimens for manipulating the temporal location along the 24-hour scale of a given thus 
probably locked-in rhythm. It worked most of the time, but in the interim we learned that presumably light-synchronized circadians can be phase-shifted by a magnetic storm (cf. Chibisov et al. 2004bI, Halberg et al. 2005dI, Jozsa et al. 2005dI).

At this time and in the future, it will take much patience by those working prospectively on infradians that may not be synchronized but aeolianized (read: partly free-running). It takes waiting for years to recognize that an apparent early decline in sexual function is but a manifestation of a natural circadecadal cycle, that may not need hormone replacement therapy, Fig. 5. How much of the literature on aging is confounded by undetected infradians that have to be mapped and explored at least by systematic spotchecks, Fig.
5 bottom right shows that two variables in the same urine, namely volume vs. hormonal breakdown products, can behave differently, hormonal metabolites having a $\tau$ in the circadecadal range but not the volume. In the circannual spectral region, they also differ, in that a rhythm in urine volume is 1 -year synchronized, but not the endocrine rhythm (Halberg et al. 2004hI). One must wait for decades before replicating circadecadal or circadidecadal rhythms and is happy when two circadidecadal cycles can be approximated (Table 2, Figs 9a, b). Few may have the opportunity of replicating a quindecadal cycle (Halberg et al. 2000a) by autorhythmometry on themselves!

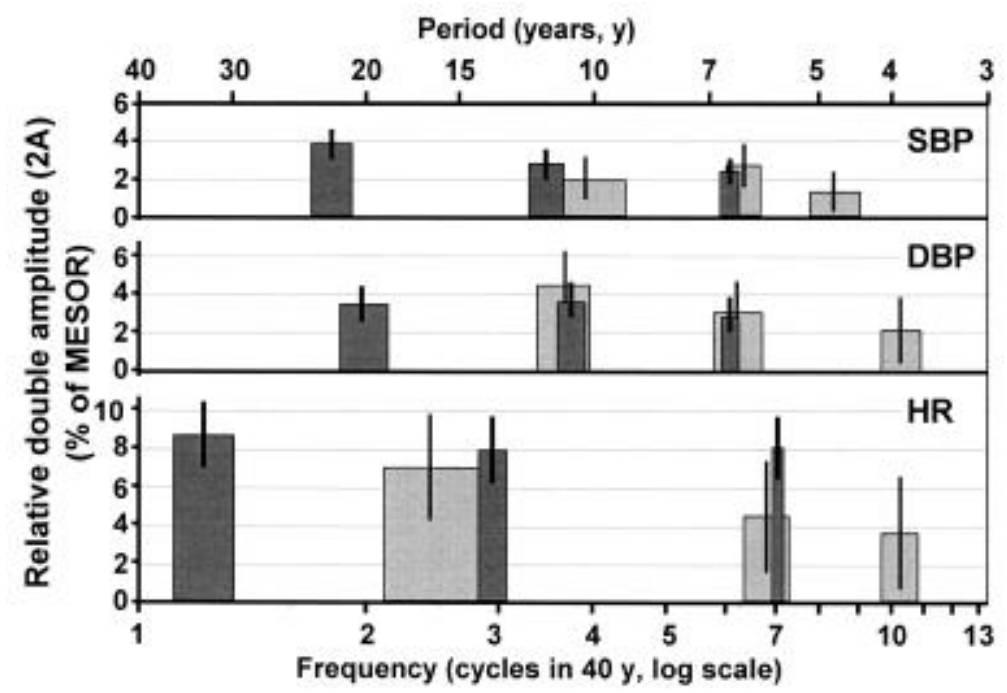

Fig. 9b. Some solar signatures in cardiovascular spectra; corroboration after 38 years of some results obtained after 31 years of self-monitoring. Corroboration of some non-photic cycles described in 31-year record in extended 38-year record. Data collected by RBS, a MESOR-normotensive man, 20.5 years old at the start of ongoing record of $\sim 5$ daily selfmeasurements. Light bars: 31 -y series detrended by stepwise regression using a 6 th-order polynomial at the outset and removing first and last 6 months prior to analysis of residuals. Dark bars: record extended to 38 y (not detrended). Widths of bars correspond to $95 \%$ confidence intervals (CIs) of the periods, vertical lines at the tops of bars to $95 \%$ CIs of 2 As. 38year MESORs: systolic blood press ure $(\mathrm{SBP})=125 \mathrm{~mm} \mathrm{Hg}$; diastolic blood pressure $(\mathrm{DBP})=83 \mathrm{~mm} \mathrm{Hg}$; heart rate $(\mathrm{HR})=$ 74 beats/min

\section{INTERIM VIEW OF WHAT WE HAVE LEARNED}

In the foregoing part of this article, we have documented, among others, a circadidecadal (about 20 -year cycle, in a healthy man's blood pressure, in an individualized fashion, based on a 38-year series. We show further an about 0.42-year component in sudden cardiac death at several but not all geographic sites. This cis-halfyear is transient yet recurrent and otherwise aeolian in its behavior, as it also happens to be in the solar wind, where it was described by physicists before us. We learned about spectral components longer than the calendar year by a few weeks (near-transyears) that were neglected in physics and are new to biology. Spectral components longer than a year by several months, far-transyears, also recognized as transient yet recurrent in physics are, perhaps, less transient in human blood pressure. They may be genetically coded like circadians.

Results from a subtraction approach (by the solar wind) suggest that part of the spectrum of a human circulation may be driven by the solar wind and that some other far-transyearly components are built-in and continue to be present in the absence of a reciprocal environmental counterpart. 
In a follow-up, we shall present the methodological implications of cycles for transdisciplinary science and immediate applications in self-help with automated hardware and software in a health care that will eventually change from spotchecks to chronomic surveillance for a life time.

\section{ACKNOWLEDGEMENT}

Web access to physical data is appreciated, made possible with the help notably of K.W. Ogilvie (NASA GSFC), A.J. Lazarus (MIT) and M.R. Aellig (MIT).

This work was supported by the U.S. National Institutes of Health (GM/13981).

\section{REFERENCES}

Attolini M.R., Cecchini S., Galli M.: A search of cosmic-ray variations generated by pulsations of the heliosphere. Astrophys. Space Sci. 134: 103-114, 1987.

Ballester J.L., Oliver R., Carbonell M.: Return of the near 160 day periodicity in the photospheric magnetic flux during solar cycle 23. Astrophys. J. 615:L173- L176, 2004.

Ballester J.L., Oliver R., Carbonell M.: The near 160 day periodicity in the photospheric magnetic flux. Astrophys. J. 566:505-511, 2002.

Bartels J.: L'activité du magnétisme terrestre et ses relations avec les phénomènes solaires. In de Valbreuze R. (ed.): Comptes rendus des travaux de la onzième section et de la treizième section, Congrès international d'électricité, Paris 1932. Gauthier-Villars, Paris 1932, pp. 77-88.

Bartels J.: Statistik periodischer und quasiperiodischer Vorgänge. Med. Welt 5: 1307-1310, 1936.

Bartels J.: Statistical studies of quasi-periodic variables: with illustrative examples from geophysics. Carnegie Institution of Washington 1959. (Reprints of three papers from Terrestrial Magnetism and Atmospheric Electricity: Terrestrial magnetic activity and its relations to solar phenomena. Terr. Mag. Atmosph. Electr. 37: 1-52, 1932; Statistical methods for research on diurnal variations, Terr. Mag. Atmosph. Electr. 37: 291-302, 1932; Random fluctuations, persistence, and quasi-persistence in geophysical and cosmical periodicities. Terr. Mag. Atmosph. Electr. 40: 1-60, 1935.)

Berger S., Kaever M.J.: Dasycladales: An Illustrated Monograph of a Fascinating Algal Order. Thieme-Verlag, Stuttgart 1992.

Besicovitch A.S.: Almost Periodic Functions. Dover Publications, Cambridge 1954.
Bingham C., Arbogast B., Cornélissen Guillaume G.: Inferential statistical methods for estimating and comparing cosinor parameters. Chronobiologia 9:397-439, 1982.

Breus T.K., Chibisov S.M., Baevsky R.M., Schebzuhov K.V.: The Chronostructure of heart Biorhythms under Effects of External Environment Factors. Polygraph Service, People's Friendship University of Russia, Moscow 2002.

Breus T., Cornélissen G., Halberg F., Levitin A.E.: Temporal associations of life with solar and geophysical activity. Ann. Geophys. 13: 1211-1222, 1995.

Brown F.A. Jr: Response to pervasive geophysical factors and the biological clock problem. Cold Spring Harb. Symp. Quant. Biol. 25:57-71, 1960.

Burch J.B., Reif J.B., Yost M.G.: Geomagnetic disturbances are associated with reduced nocturnal secretion of a melatonin metabolite in humans. Neurosci. Lett. 266: 209-212, 1999.

Burioka N., Cornélissen G., Halberg F., Kaplan D.T.: Relationship between correlation dimension and indices of linear analysis in both respiratory movement and electroencephalogram. Clin. Neurophysiol. 112: 1147-1153, 2001

Chibisov S.M. (ed).: Proceedings, III International Conference on "Civilization diseases in the spirit of V.I. Vernadsky". People's Friendship University of Russia, Moscow, October 1012, 2005. $425 \mathrm{pp}$.

Chibisov S.M., Cornélissen G., Halberg F.: Magnetic storm effect on the circulation of rabbits. Biomed. Pharmacother. 58 (Suppl 1): S15-S19, 2004I.

Chibisov S.M., Cornélissen G., Halberg F.: Sphygmochrons: blood pressure (BP) and heart rate (HR) monitoring profiles for comparisons with non-Muscovite peers. Abstract III. International Conference, Civilization Diseases in the Spirit of V.I. Vernadsky, People's Friendship University of Russia, Moscow, Oct. 10-12, 2005I, pp. 416419.

Chizhevsky A.L.: Les épidémies et les perturbations électromagnétiques du milieu extérieur. Éditions Hippocrate, Paris 1938.

Cilek M., Mikulecky M., Ondrejka P.: Sulphur dioxide concentration, perinatal mortality and immaturity decreased in Bratislava 19741988. International Symposium on Biorhythms in Clincal Medicine, Bratislava, Czechoslovakia, September 5-6, 1990. p. 6.

Cornélissen G., Halberg F.: Impeachment of casual blood pressure measurements and the fixed limits for their interpretation and chronobiologic recommendations. In 
Portaluppi F., Smolensky M.H. (eds.): Timedependent Structure and Control of Arterial Blood Pressure. Ann. N.Y. Acad. Sci. 783: 24-46, 1996.

Cornélissen G., Halberg F.: Chronomedicine. In Armitage P., Colton T. (eds.): Encyclopedia of Biostatistics, 2nd ed., John Wiley \& Sons Ltd, Chichester, UK 2005aI, pp. 796-812.

Cornélissen G., Halberg F., Wendt H.W. et al.: Resonance of about-weekly human heart rate rhythm with solar activity change. Biologia (Bratislava) 51:749-756, 1996.

Cornélissen G., Sothern R.B., Halberg Francine, Halberg Franz: 7-year (circaseptennian) patterns in psychology and biology? Comment on Verhulst and Onghena. Psychol. Rep. 82:483-487, 1998.

Cornélissen G., Halberg F., Gheonjian L. et al.: Schwabe's $\sim 10.5$ - and Hale's 21-year cycles in human pathology and physiology. In Schröder W. (ed.): Long- and Short-Term Variability in Sun's History and Global Change, Science Edition, Bremen 2000a, pp. 79-88.

Cornélissen G., Chen Ch.H., Siegelova J., Halberg F.: Vascular disease risk syndromes affecting both MESOR-normotensives and MESOR-hypertensives: a meta-analysis of 2039 cases. Scr. Med. (Brno) 74:81-86, 2001.

Cornélissen G., Halberg F., Breus T. et al.: Nonphotic solar associations of heart rate variability and myocardial infarction. J. Atmos. Solar-Terr. Phys. 64:707-720, 2002.

Cornélissen G., Axelrod D.E., Halberg F.: Aboutweekly variations in nocturia. Biomed. Pharmacother. 58 (Suppl 1):S140-S144, 2004aI.

Cornélissen G., Delmore P., Halberg F.: Health Watch 3: Dedicated, on his $80^{\text {th }}$ birthday, to Earl E. Bakken, the developer of the implantable cardiac pacemaker for long-term use (and founder of Medtronic Inc., the company manufacturing many devices for rehabilitation) to be better-known in the future for pre-habilitation. Halberg Chronobiology Center, University of Minnesota/Department of Communications, Medtronic, Inc., Minneapolis 2004bI 31 pp. www.phoenix.tcieee.org/Phoenix_Bibliography.htm

Cornélissen G., Halberg F., Bakken E.E. et al.: 100 or 30 years after Janeway or Bartter, Healthwatch helps avoid "flying blind". Biomed. Pharmacother. 58 (Suppl 1):S69S86, 2004cI.

Cornélissen G., Halberg F., Hamburger C. et al.: Chronomics: multiple distinct yearly cycles in urinary steroid metabolite excretion. Abstract, $2^{\text {nd }}$ International Symposium, Problems of Rhythms in Natural Sciences, Moscow,
March 1-3, 2004. Russian People's Friendship University, Moscow 2004dI, pp. 17-18.

Cornélissen G., Halberg F., Perfetto F. et al.: Chronomics (time structure) of melatonin. Abstract O-2, X. Int. Cong. Auxology, 4-7 July 2004, Edizioni Centro Studi Auxologici, Florence, 2004eI, p. 18.

Cornélissen G., Johnson P., Stead W.W. et al.: Chronome of a 20-year series of mortality from tuberculosis in Arkansas. Abstract (Read by Title) 7;, In Matsubayasi K. (ed.): Proceedings, $5^{\text {th }}$ International Workshop on Chronoastrobiology and Chronotherapy, Division of Human-Nature Dynamics, Center for Southeast Asian Studies, Nov 6, 2004fI, pp. 58-60.

Cornélissen G., Masalov A., Halberg F. et al.: Multiple resonances among time structures, chronomes, around and in us. Is an about 1.3-year periodicity in solar wind built into the human cardiovascular chronome? Hum. Physiol. 30: 86-92, 2004gI.

Cornélissen G., Palermo J., Carandente F. et al.: Chronomics: chronome of suicides in Minnesota (1968-2002). Abstract, Noninvasive Methods in Cardiology, 2.11.2004, Congress MEFA, Brno, Czech Republic, Nov. 2.-4., 2004hI, p. 8.

Cornélissen G., Otsuka K., Halberg F. Neartransyear in solar magnetism. Biomed. Pharmacother. 59 [Suppl 1]: S5-S9, $2005 f I$.

Delouis H., Mayaud P.N.: Spectral analysis of the geomagnetic activity index aa over a 103-year interval. J. Geophys. Res 80:4681-4688, 1975.

Dennis B.D.: Solar hard X-ray bursts. Solar Physics 100:465-490, 1985.

Dorman L.I., Ptuskin V.S.: The expected pulsations of the heliosphere relevant to cosmic ray variations. Astrophys. Space Sci. 79:397-404, 1981.

Dorman L.I., Iucci N., Villoresi G.: The use of cosmic rays for continuous monitoring and prediction of some dangerous phenomena for the Earth's civilization. Astrophys. Space Sci. 208:55-68, 1993.

Dorman L.I., Villoresi G., Belov A.V. et al.: Cosmic-ray forecasting features for big Forbush decreases. Nuclear Phys. B (Proc. Suppl.) 39A: 136-144, 1995.

Dubinsky P., Mikulecky M., Ondrejka P., Stefancikova A.: Prevalence of echinococcosis in pigs and sheep in the Slovak Republic. Vet. Parasitol. 51:149-154, 1993.

Düll T., Düll B.: Über die Abhängigkeit des Gesundheitszustandes von plötzlichen Eruptionen auf der Sonne und die Existenz einer 27tägigen Periode in den Sterbefällen. Virchows Arch. 293:272-319, 1934. 
Düll T., Düll B.: Zusammenhänge zwischen Störungen des Erdmagnetismus und Häufungen von Todesfällen. Deutsch. Med. Wschr. 61: 95, 1935.

Ertel S.: Die Gauquelin-Planeteneffekte. Grenzgeb. Wiss. 42: 99-114, 1993a.

Ertel S.: Mit Sonnenflecken korreliert? Prüfmethode I: Für seltene historische Ereignisse. Testfall: Grippepandemien. Z. Parapsychol. Grenzgeb. Psychol. 35: 178211, 1993b.

Ertel S.: Influenza pandemics and sunspots - easing the controversy. Naturwissenschaften 82: 308-310, 1994.

Ertel S.: Space weather and revolutions: Chizhevsky's heliobiological claim scrutinized. Stud. Psychol. (Bratisl) 39: 3-22, 1996.

Ertel S.: Bursts of creativity and aberrant sunspot cycles: hypothetical covariations. In: Nyborg H. (ed.): The Scientific Study of Human Nature: Tribute to Hans J. Eysenck at 80, Elsevier Science; New York 1997, pp. 491508.

Farkas M.: Periodic Motions. Applied Mathematical Sciences, v. 104. SpringerVerlag, New York 1994.

Faure M.: Les radiations astrals: leur role possible dans la pathologie humaine. La Presse médicale (7 Décembre):1499-1501, 1927.

Fiser B., Siegelova J., Dusek J. et al.: Seven-day blood pressure monitoring and casual blood pressure measurement. Abstract, Noninvasive Methods in Cardiology, Brno, Czech Republic, Sept. 14, 2005aI, p. 11.

Fiser B., Siegelova J., Dusek J. et al.: Assessment of high blood pressure risk for stroke. J. Hypertens. 34 (Suppl 2): S151, 2005bI.

Fraser-Smith A.C.: Spectrum of the geomagnetic activity index Ap. J. Geophys. Res. 77: 42094220, 1972.

Gonze D., Halloy J., Goldbeter A.: Stochastic models for circadian oscillations: emergence of a biological rhythm. Int. J. Quantum Chem. 98:228-238, 2004.

Halberg F.: Some correlations between chemical structure and maximal eosinopenia in adrenalectomized and hypophysectomized mice. J. Pharmacol. Exp. Ther. 106:135-149, 1952.

Halberg F.: Some physiological and clinical aspects of 24-hour periodicity. J. Lancet 73: 20-32, 1953.

Halberg F.: Beobachtungen über 24 StundenPeriodik in standardisierter Versuchsanordnung vor und nach Epinephrektomie und bilateraler optischer Enukleation, 20 ${ }^{\text {th }}$ meeting of the German Physiological Society, Homburg/Saar,
September, 1953. Ber. ges. Physiol. 162:354355, 1954.

Halberg F.: Resolving power of electronic computers in chronopathology: an analogy to microscopy. Scientia (Milano) 101:412-419, 1966.

Halberg F.: Physiologic considerations underlying rhythmometry, with special reference to emotional illness. Symposium on Biological Cycles and Psychiatry. In Ajuriaguerra de J. (ed): Symposium Bel-Air III. Cycles biologiques et psychiatrie. Georg, Geneva/Masson et Cie, Paris 1968, pp. 73126.

Halberg F.: Chronobiology. Annu. Rev. Physiol. 31:675-725, 1969.

Halberg F.: Historical encounters between geophysics and biomedicine leading to the Cornélissen-series and chronoastrobiology. In Schröder W. (ed.): Long- and Short-Term Variability in Sun's History and Global Change, Science Edition, Bremen 2000, pp. 271-301.

Halberg F., Ahlgren A.: Prologue: puzzles regarding biologic rhythms and their implications for self-help in health care. In Scheving L.E., Halberg F. (eds.): Chronobiology: Principles and Applications to Shifts in Schedules, Sijthoff and Noordhoff, Alphen aan den Rijn, The Netherlands 1980, pp. v-xxiii.

Halberg F., Visscher M.B.: Regular diurnal physiological variation in eosinophil levels in five stocks of mice. Proc. Soc. Exp. Biol. (N.Y.) 75: 846-847, 1950.

Halberg F., Visscher M.B., Flink E.B. et al.: Diurnal rhythmic changes in blood eosinophil levels in health and in certain diseases. J. Lancet 71:312-319, 1951.

Halberg F., Engel R., Halberg E., Gully R.J.: Diurnal variations in amount of electroencephalographic paroxysmal discharge and diurnal eosinophil rhythm of epileptics on days with clinical seizures. Fed. Proc. 11: 62, 1952.

Halberg F., Bittner J.J., Gully R.J. et al.: 24-hour periodicity and audiogenic convulsions in I mice of various ages. Proc. Soc. Exp. Biol. (N.Y.) 88:169-173, 1955a.

Halberg F., Spink W.W., Albrecht P.G., Gully R.J.: Resistance of mice to brucella somatic antigen, 24-hour periodicity and the adrenals. J. Clin. Endocrinol. 15: 887, 1955 b.

Halberg F., Engeli M., Hamburger C., Hillman D.: Spectral resolution of low-frequency, smallamplitude rhythms in excreted 17-ketosteroid; probable androgen induced circaseptan desychronization. Acta Endocrinol. (Copenh) 50 (Suppl. 103):5-54, 1965. 
Halberg F., Cornélissen G., Sothern R.B. et al.: International geographic studies of oncological interest on chronobiological variables. In Kaiser H. (ed.): Neoplasms Comparative Pathology of Growth in Animals, Plants and Man. Williams and Wilkins, Baltimore 1981, pp. 553-596.

Halberg F., Breus T.K., Cornélissen G. et al.: International Womb-to-Tomb Chronome Initiative Group: Chronobiology in space. Keynote, 37th Ann. Mtg. Japan Soc. for Aerospace and Environmental Medicine, Nagoya, Japan, Nov. 8-9, 1991. University of Minnesota/Medtronic Chronobiology Seminar Series \#1, Dec. 1991. Medtronic Inc., Minneapolis 1991.

Halberg F., Cornélissen G., International Womb-toTomb Chronome Initiative Group: Resolution from a meeting of the International Society for Research on Civilization Diseases and the Environment (New SIRMCE Confederation), Brussels, Belgium, March 17-18, 1995: Fairy tale or reality? Medtronic Chronobiology Seminar \#8. Medtronic Inc., Minneapolis, MN, April 1995. URL http://www.msi.umn.edu/ halberg/

Halberg F., Cornélissen G., Sonkowsky R.P. et al.: Chrononursing (chronutrics), psychiatry and language. New Trends Exper. Clin. Psych. 14: 15-26, 1998.

Halberg F., Cornélissen G., Otsuka K. et al.: Crossspectrally coherent $\sim 10.5-$ and 21-year biological and physical cycles, magnetic storms and myocardial infarctions. Neuro Endocrinol. Lett. 21: 233-258, 2000a.

Halberg F., Smith H.N., Cornélissen G. et al.: Hurdles to asepsis, universal literacy, and chronobiology - all to be overcome. Neuro Endocrinol. Lett. 21 145-160, 2000b.

Halberg F., Cornélissen G., Otsuka K. et al.: Chronomics. Biomed. Pharmacother. 55 (Suppl. 1): 153-190, 2001a.

Halberg F., Cornélissen G., Watanabe Y. et al.: Near 10-year and longer periods modulate circadians: intersecting anti-aging and chronoastrobiological research. J. Gerontol. A Biol. Sci. Med. Sci. 56: M304-M324, 2001b.

Halberg F., Cornélissen G., Otsuka K. et al.: Essays on chronomics spawned by transdisciplinary chronobiology: Witness in time: Earl Elmer Bakken. Neuro Endocrinol. Lett. 22:359-384, $2001 \mathrm{c}$.

Halberg F., Cornélissen G., Otsuka K. et al.: Chronoastrobiology: neonatal numerical counterparts to Schwabe's 10.5 and Hale's 21 year sunspot cycles. In memoriam Boris A. Nikityuk. Int. J. Prenat. Perinat. Psychol. Med. 13:257-280, 2001d.

Halberg F., Cornélissen G., Schwartzkopff O. et al.: Messung und chronobiologische
Auswertung der Variabilitäten von Blutdruck und Herzfrequenz zur Prophylaxe schwerwiegender Krankheiten. Sitzungsberichte der Leibniz-Sozietät, 54:127-156, 2002.

Halberg F., Cornélissen G., Katinas G. et al.: Transdisciplinary unifying implications of circadian findings in the 1950 s. J. Circadian Rhythms 1: 2, doi:10.1186/1740-3391-1-2, 2003a.

Halberg F., Cornélissen G., Schack B. et al.: Blood pressure self-surveillance for health also reflects 1.3-year Richardson solar wind variation: spin-off from chronomics. Biomed. Pharmacother. 57 (Suppl. 1): S58-S76, $2003 \mathrm{~b}$.

Halberg F., Cornélissen G., Bingham C. et al.: Chronomics: Imaging in time by phase synchronization reveals wide spectralbiospheric resonances beyond short rhythms. ("Wenn man über kurze Rhythmen hinausgeht") In memoriam - lost future: Dr. Ing. habil. Dr. rer. nat. Barbara Schack: 1952-2003. Neuro Endocrinol. Lett. 24:355380, 2003c.

Halberg F., Cornélissen G., Stoynev A. et al.: Season's Appreciations 2002 and 2003. Imaging in time: The transyear (longer-thanthe-calendar year) and the half-year. Neuro Endocrinol. Lett. 24:421-440, 2003 d.

Cf. also Season's Appreciations 2001. Neuroendocrinol. Lett. 23: 170-187, 2002; Season's Appreciations 2000: Chronomics complement, among many other fields, genomics and proteomics. Neuroendocrinol. Lett. 22: 5373, 2001; Circasemicentennial season's appreciations. Neuroendocrinol. Lett. 21: 59-68, 2000; Season's appreciations 1998. Neuroendocrinol. Lett. 20: 31-43, 1999; AND Season's appreciations 1997. In: Proc. 3rd International Symposium of Chronobiology and Chronomedicine, Kunming, China, October 7-12, 1998. Chinese Society for Chronobiology and Chronomedicine, Chengdu, China 1998, pp. 4-15.

Halberg F., Cornélissen G., Bakken E.E. et al.: Transyears: new endpoints for gerontology and geriatrics or confusing sources of variability? J. Gerontol. A Biol. Sci. Med. Sci. 59:1344-1347, 2004aI.

Halberg F., Cornélissen G., Faraone P. et al.: Chronomics: a cartographic memory in chronomes (time structures) of exophased human to prokaryotic endocycling. Abstract, Biological Effects of Solar Activity, Pushchino, Russia, Apr. 6-9, 2004bI, unpaginated.

Halberg F., Cornélissen G., Faraone P. et al.: A transdisciplinary near-transyear in Acetabularia validates its counterpart in the solar wind and geomagnetics. Abstract (Read by Title) 3, In Matsubayasi K. (ed.): Proceedings, $5^{\text {th }}$ International Workshop on Chronoastrobiology and Chronotherapy, Division of Human-Nature Dynamics, Center 
for Southeast Asian Studies, Nov. 6, 2004 cI, p. $43-51$.

Halberg F., Cornélissen G., Katinas G. et al.: In memoriam: Ion Baciu. Mutually supporting neartransyears in solar and terrestrial magnetics, microbial and cell biology, physiology and pathology. In: Cornélissen, G. Kenner, R. Fiser, B. Siegelova J. (eds.): Proceedings, Symposium Chronobiology in Medicine. Dedicated to the $85^{\text {th }}$ Anniversary of Professor Franz Halberg, Masaryk University, Brno 2004dI, pp. 78-86.

Halberg F., Cornélissen G., Otsuka K. et al.: For BIOCOS and the ICC: BIOCOS: centrally analyzed home ABPM for health care and cardiovascular science. Abstract PS2, $3^{\text {rd }}$ Int Congress on Cardiovascular Disease, Taipei, Taiwan, Nov. 26-28, 2004. Int. J. Cardiol. 97 (Suppl. 2): S1-S2, 2004eI.

Halberg F., Cornélissen G., Otsuka K. et al.: Home ambulatory blood pressure and heart rate monitoring in practice and for science: transyears and magnetoperiodism vs. photoperiodism. Abstract S8-02, $3^{\text {rd }}$ Int Congress on Cardiovascular Disease, Taipei, Taiwan, 26-28 Nov 2004. Int. J. Cardiol. 97 (Suppl 2): S12, $2004 \mathrm{fI}$.

Halberg F., Cornélissen G., Panksepp J. et al.: Near-transyears in geophysics and autism. Abstract, Noninvasive Methods in Cardiology, Congress MEFA, Nov. 2.-4., 2004, Brno, Czech Republic, 2004gI, p. 7.

Halberg F., Cornélissen G., Regal P. et al.: Chronoastrobiology: proposal, nine conferences, heliogeomagnetics, transyears, near-weeks, near-decades, phylogenetic and ontogenetic memories. Biomed. Pharmacother. 8 (Suppl 1):S150-S187, 2004hI.

Halberg F., Chibisov S.M., Radysh I.V. et al.: Time structures (chronomes) in us and around us. People's Friendship University of Russia, Moscow 2005bI.

Halberg F., Cornélissen G., Faraone P. et al.: Prokaryotic and eukaryotic unicellular chronomics. Biomed. Pharmacother. 59 (Suppl 1): S192-S202, 2005cI.

Halberg F., Cornélissen G., Jozsa R. et al.: Circadian-circaseptan changes in plasma and pineal melatonin of rats during magnetically quiet and stormy conditions. Abstract, III. International Conference, Civilization Diseases in the Spirit of V.I. Vernadsky, People's Friendship University of Russia, Moscow, Oct. 10.-12., 2005dI, pp. 30-32.

Halberg F., Cornélissen G., Katinas G. et al.: Theodor Hellbrügge: 85 years of age - Ad multos transannos, sanos, fortunatos et beatos. J. Circadian Rhythms 3: 2, doi:10.1185/17403391-3-2, 2005eI.
Halberg F., Cornélissen G., Otsuka K. et al.: Incidence of sudden cardiac death, myocardial infarction and far- and near-transyears. Biomed. Pharmacother. 59 (Suppl. 1): S239S261, $2005 f I$.

Halberg F., Cornélissen G., Panksepp J. et al.: Chronomics of autism and suicide. Biomed. Pharmacother. 59 (Suppl. 1):S100-S108, $2005 \mathrm{gI}$.

Halberg F., Cornélissen G., Schwartzkopff O.: Ambulatory blood pressure monitoring. In Pella D., Singh R.B., Chiang C.E., Kong C.W., Rastogi S.S. (eds): How to Reverse the Risk of Heart Attack, Hypertension and Diabetes. International College of Nutrition \& International College of Cardiology, 2nd ed., MYODEA, Moradabad 2005hI, pp. 41-52.

Halberg F., Cornélissen G., Katinas G. et al.: Chronobiology's progress. Part II, Chronomics for an immediately applicable biomedicine. J. Appl. Biomed. 4: in press. 2006.

Halberg Francine, Halberg F., Giese A.: Circannual biochemical and gonadal index rhythms of marine invertebrates. In Scheving L.E., Halberg F., Pauly J.E. (eds.): Chronobiology, Proc. Int. Soc. for the Study of Biological Rhythms, Little Rock, Ark., Georg Thieme Publishers, Stuttgart, Igaku Shoin Ltd., Tokyo 1974, pp. 703-708.

Halberg Francine, Halberg F., Sothern R.B. et al.: Consistent synchronization and circaseptennian (about 7-yearly) modulation of circannual gonadal index rhythm of three marine invertebrates. Prog. Clin. Biol. Res. 227A:225-238, 1987.

Huntington E.: Civilization and Climate. Yale University Press, New Haven, CT 1915.

Huntington E.: Season of Birth: Its Relation to Human Abilities. John Wiley \& Sons, New York 1938.

Ivanov E.V., Obridko V.N.: Cyclic variations of CME velocity. Solar Phys. 198:179-196, 2001.

Ivanov E.V., Obridko V.N.: Zonal structure and meridional drift of large-scale solar magnetic fields. Solar Phys. 206:1-19, 2002.

Ivanov E.V., Obridko V.N., Ananyev I.V.: Sector structure, rotation, and cyclic evolution of large-scale solar magnetic fields. Solar Phys. 199:405-419, 2001

Ivanov E.V., Obridko V.N., Shelting B.D.: Quasibiennial oscillations of the solar magnetic fields. In Wilson A. (ed.): Solar Variability: from Core to Outer Frontiers. The $10^{\text {th }}$ European Solar Physics Meeting, Sept. 9-14, 2002, Prague, Czech Republic. ESA SP-506, Vol. 2. ESA Publications Division, Noordwijk 2002, pp. 847-850.

Jozsa R., Halberg F., Cornélissen G. et al.: Chronomics, neuroendocrine feedsidewards 
and the recording and consulting of nowcasts - forecasts of geomagnetics. Biomed. Pharmacother. 59 (Suppl. 1):S24-S30, 2005aI.

Jozsa R., Olah A., Cornélissen G. et al.: Circadian and extracircadian exploration during daytime hours of circulating corticosterone and other endocrine chronomes. Biomed. Pharmacother. 59 (Suppl. 1):S109-S116, 2005bI.

Jozsa R., Olah A., Csernus V. et al.: Extracircadians and circadians of corticosterone, prolactin and endothelin-1 in the rat assessed on antiphasic lighting regimens. Abstract, 6th Int. Cong. Worldwide, Aug. 26-27, 2005, Hungarian Medical Academy, Budapest, 2005cI.

Jozsa R., Olah A., Csokas N. et al.: Circadiancircaseptan profile of circulating corticosterone in fed and starved rats. Abstract, III. International Conference, Civilization Diseases in the Spirit of V.I. Vernadsky, People's Friendship University of Russia, Oct. 10-12, Moscow, 2005dI, pp. 113-115.

Jozsa R., Olah A., Csokas N. et al.: Chronomics of pituitary adenylte cyclase-activating polypeptide (PACAP) in head and heart of chick embryos. Abstract, III. International Conference, Civilization Diseases in the Spirit of V.I. Vernadsky, People's Friendship University of Russia, Oct. 10-12, Moscow, 2005eI, pp. 115-118.

Katinas G.S., Cornelissen G., Otsuka K. et al.: Why continued surveillance? Intermittent blood pressure and heart rate abnormality under treatment. Biomed. Pharmacother. 59 (Suppl 1): S141-S151, 2005bI.

Katinas G., Nintcheu-Fata S., Cornélissen G. et al.: Moving least-squares spectra scrutinize chronomics in and around us. Scr. Med. (Brno) 78: 115-120, 2005dI.

Kehse U.: Woher die sieben fetten und sieben mageren Jahre kamen. http:// www.wissenschaft.de /wissen/news/ 254226.html.15.vi.2005.

Kishcha P.V., Dmitrieva I.V., Obridko V.N.: Longterm variations of the solar-geomagnetic correlation, total solar irradiance, and northern hemispheric temperature (1868-1997). J. Atmos. Solar-Terr. Phys. 61:799-808, 1999.

Komlos J., Cornélissen G., Woitek U. et al.: Time structures, chronomes, of soldiers' stature mimicking Hale cycle in neonatal body length. Biomed. Pharmacother. 58 (Suppl 1): S135-S139, 2004I.

Kondrashov D., Feliks Y., Ghil M.: Oscillatory modes of extended Nile River records (A.D. 622-1922). Geophys. Res. Lett. 32: L10702, doi:10.1029/2004GL022156, 2005.
Levitan B.M., Zhikov V.V. (Longdon L.W., translation): Almost Periodic Functions and Differential Equations. Cambridge University Press, Cambridge, UK 1982.

Lou Y.Q.: Rossby-type wave-induced periodicities in flare activities and sunspot areas or groups during solar maxima. Astrophys. J. 540: 1102-1108, 2000.

Luce G.G.: Biological rhythms in psychiatry and medicine. U.S. Public Health Service Publication \#2088. National Institute of Mental Health, Chevy Chase, Maryland 1970.

Marquardt D.W.: An algorithm for least-squares estimation of nonlinear parameters. J. Soc. Indust. Appl. Math. 11:431-441, 1963.

Mendoza B., Díaz-Sandoval R.: Relationship between solar activity and myocardial infarctions in Mexico City. Geofis. Int. 39: 53-56, 2000.

Mendoza B., Velasco V.M., Valdés-Galicia J.F.: Mid-term periodicities in the solar magnetic flux. Solar Phys., in press.

Mikulecky M. (ed.): The Moon and Living Matter. Kosice, Slovakia, Sept. 23-25, 1993. Slovak Medical Society, Bratislava 1993, 97 pp.

Mikulecky M. (ed.): Sun, Moon and Living Matter. Bratislava, Slovakia, June 28-July 1, 1994. Slovak Medical Society, Bratislava 1994a, $159 \mathrm{pp}$.

Mikulecky M.: My heart, the earth, the moon and the sun. In: Mikulecky M. (ed.): Sun, Moon and Living Matter. Bratislava, Slovakia, June 28-July 1, 1994. Slovak Medical Society, Bratislava 1994b, pp. 150-157.

Mikulecky M. (ed.): Chronobiology \& Its Roots in the Cosmos. High Tatras, Slovakia, Sept. 2-6, 1997. Slovak Medical Society, Bratislava 1997, $287 \mathrm{pp}$.

Mikulecky M., Bakoss P., Kmety E.: Leptospiral infections in Slovakia 1949-1995: trends and periodicities. In: Mikulecky M. (ed.): Chronobiology \& Its Roots in the Cosmos. High Tatras, Slovakia, Sep. 2-6, 1997. Slovak Medical Society, Bratislava 1997, pp. 207212.

Mikulecky M. Jr., Ondrejka P.: Toxocariasis in Slovakia, its research in the world and the sun? In: Mikulecky M. (ed.): Sun, Moon and Living Matter. Bratislava, Slovakia, June 28July 1, 1994. Slovak Medical Society, Bratislava 1994, pp. 136-138.

Mursula K., Zieger B.: Simultaneous occurrence in mid-term periodicities in solar wind, geomagnetic activity and cosmic rays. Proc. $26^{\text {th }}$ ICRC, 7:123-126, 1999.

Mursula K., Zieger B.: The 1.3-year variation in solar wind speed and geomagnetic activity. Adv. Space Res. 25:1939-1942, 2000.

Mursula K., Vilppola J.H.: Fluctuations of the solar dynamo observed in thesolar wind and 
interplanetarymagnetic field at $1 \mathrm{AU}$ and in the outer heliosphere. Solar Phys. 221:337349, 2004.

Mursula K., Zieger B., Vilppola J.H.: Mid-term quasi-periodicities in geomagnetic activity during the last 15 solar cycles: connection to solar dynamo strength. To the memory of Karolen I. Paularena (1957-2001). Solar Phys. 212:201-207, 2003.

Nintcheu-Fata S., Katinas G., Halberg F. et al.: Chronomics of tree rings for chronoastrobiology and beyond. Biomed. Pharmacother. 57 (Suppl 1):S24-S30, 2003.

Nordenström B.E.W., Nordenström J.: The paradigm of biologically closed electric circuits and its clinical applications. In Rosch P.J., Markov M.S. (eds): Bioelectromagnetic Medicine, Marcel Dekker; New York 2004, pp. 697-707.

Obridko V.N., Rivin Yu.R.: The role of solar magnetic field in the neutrino flux modulation. Astron. Astrophys. 308:951-956, 1996.

Otsuka K., Cornélissen G., Halberg F.: Predictive value of blood pressure dipping and swinging with regard to vascular disease risk. Clin. Drug Invest. 11: 20-31, 1996.

Otsuka K., Cornélissen G., Halberg F.: Circadian rhythmic fractal scaling of heart rate variability in health and coronary artery disease. Clin. Cardiol. 20:631-638, 1997.

Pauly J.E., Scheving L.E. (eds.): Progress in Clinical and Biological Research, volumes 227A and B: Advances in Chronobiology, Parts A and B, Proc. XVII Int. Conf. Int. Soc. Chronobiol., Little Rock, Ark., USA, Nov. 37, 1985. Alan R. Liss, New York 1987.

Pearse J.S., Pearse V.B., Giese A. et al.: Circannual rhythm with similar timing characterizes gonadal index of a marine invertebrate (ochre star) studied 30 years apart. Chronobiologia 12:264, 1985.

Polakoff S.: Reports of clinical hepatitis A from Public Health and hospital microbiology laboratories to the PHLS Communicable Disease Surveillance Centre during the period 1980-1988. J. Infect. 21:111-117, 1990.

Refinetti R.: Circadian Physiology. $2^{\text {nd }}$ ed. CRC Press, Boca Raton 2006.

Reinberg A., Smolensky M.H.: Biological rhythms and medicine. Cellular, metabolic, physiopathologic, and pharmacologic aspects. Springer, New York 1983.

Reindl K., Falliers C., Halberg F., Chai H., Hillman D., Nelson W.: Circadian acrophases in peak expiratory flow rate and urinary electrolyte excretion of asthmatic children: phase-shifting of rhythms by prednisone given in different circadian system phases. Rass. Neurol. veg. 23: 5-26, 1969
Richardson J.D., Paularena K.I., Belcher J.W., Lazarus A.J.: Solar wind oscillations with a 1.3-year period. Geophys. Res. Lett. 21: 1559-1560, 1994.

Rieger A., Share G.H., Forrest D.J. et al.: A 154day periodicity in the occurrence of hard solar flares? Nature 312:623-625, 1984.

Rosch P.J., Nordenström B.E.W.: Is there an electrical circulatory system that communicates internally and externally? In Rosch P.J., Markov M.S. (eds.): Bioelectromagnetic Medicine, Marcel Dekker, New York 2004, pp. 229-249.

Schuster A.: On the periodicities of sun-spots. Phil. Trans. Roy. Soc. London Series A 206:69100, 1906.

Shapiro R.: Interpretation of the subsidiary peaks at periods near 27 days in power spectra of geomagnetic disturbance indices. J. Geophys. Res. 72:4945-4949, 1967.

Sonkowsky R.P., Cornélissen G., Chibisov S.M. et al.: Myriadennian, including perhaps millionennian or the shorter megennian - a choice to be made: invitation for comment. Abstract, III. International Conference, Civilization Diseases in the Spirit of V.I. Vernadsky, People's Friendship University of Russia, Moscow, Oct. 10-12, 2005aI, pp. 123-125.

Sonkowsky R.P., Cornélissen G., Schwartzkopff O. et al.: "Aeolians": intermittent in the environment, more persisting in human physiology. Abstract, III. International Conference, Civilization Diseases in the Spirit of V.I. Vernadsky, People's Friendship University of Russia, Moscow, Oct. 10-12, 2005bI, pp. 126-127.

Sonkowsky R.P., Cornélissen G., Siegelova J. et al.: Myriadennian cyclicities in the tradition of Archimedes and the International System of Units (SI): invitation for comment. Abstract, Noninvasive Methods in Cardiology, Brno, Czech Republic, Sept. 14, 2005cI, p. 21.

Sonkowsky R.P., Halberg F.: Latin verse-ictus and multimodal entrainment. Electron. Antiq. 8.2: 7-23, 2005dI.

Sothern R.B., Cornélissen G., Katinas G. et al.: Circannual variation in human diastolic blood pressure during consecutive solar cycles. Scr. Med. (Brno) 78: 107-114, 2005I.

Starbuck S., Cornélissen G., Halberg F.: Is motivation influenced by geomagnetic activity? Biomed. Pharmacother. 56 (Suppl. 2):S289s-S297, 2002.

Stoupel E.: Forecasting in Cardiology. John Wiley \& Sons, New York 1976.

Stoupel E.: Effect of geomagnetic activity on cardiovascular parameters. J. Clin. Basic Cardiol. 2:34-40, 1999. 
Stoupel E., Petrauskiene J., Kalediene R. et al.: Distribution of deaths from ischemic heart disease and stroke. Environmental and aging influences in men and women. J. Basic Clin. Physiol. Pharmacol. 7:303-319, 1996.

Strestik J., Mikulecky M.: An attempt to predict the Wolf sunspot numbers for the next decades using those observed so far. In Mikulecky M. (ed.): Sun, Moon and Living Matter. Bratislava, Slovakia, June 28-July 1, 1994. Slovak Medical Society, Bratislava 1994, pp. 163-169.

Temmer M., Veronig A., Hanslmeier A.: On the 24- and 155-day periodicity observed in solar Halpha flares. In Hanslmeier A., Veronig A., Messerotti M. (eds.): Solar Magnetic Phenomena. Proceedings of the $3^{\text {rd }}$ Summer School and Workshop, Solar Observatory, Kanzelhöhe, Kärnten, Austria, Aug. 25-Sept. 5, 2003. Astronomy and Astrophysics Space Science Library, v. 320. Springer, Dordrecht 2005, pp. 211-214.

Touitou Y., Haus E. (eds.): Biological Rhythms in Clinical and Laboratory Medicine. SpringerVerlag, Berlin 1992.

Tulchinsky T.H., Abed Y., Ginsberg G. et al.: Measles in Israel, the West Bank, and Gaza: continuing incidence and the case for a new eradication strategy. Rev. Infect. Dis. 12: 951-958, 1990.

Ulmer W., Cornélissen G., Halberg F.: Physical chemistry and the biologic week in the perspective of chrono-oncology. In Vivo 9: 363-374, 1995.

Valdés-Galicia J.F.: Low energy galactic cosmic rays in the heliosphere. Adv. Space Res. 35: 755-767, 2005.

Valdés-Galicia J.F., Pérez-Enríquez R., Otaola J.A.: The cosmic-ray 1.68-year variation: a clue to understand the nature of the solar cycle? Solar Phys. 167:409-417, 1996.

Valdés-Galicia J.F., Lara A., Maravilla D.: Heliospheric consequences of solar activity in geophysical and interplanetary phenomena. Geof. Int. 43:251-257, 2004.

Vallot J., Sardou G., Faure M.: De l'influence des taches solaires: sur les accidents aigus des maladies chroniques. Gazette des Hôpitaux 904-905, 1922.

Verhulst J., Onghena P.: Periodic birth-year pattern of the founders of quantum physics. Psychol. Rep. 78:19-25, 1996.

Villoresi G., Breus T.K., Iucci N. et al.: The influence of geophysical and social effects on the incidences of clinically important pathologies (Moscow 1979-1981). Phys. Med. 10:79-91, 1994a.

Villoresi G., Kopytenko Y.A., Ptitsyna N.G. et al.: The influence of geomagnetic storms and man-made magnetic field disturbances on the incidence of myocardial infarction in St. Petersburg. Phys. Med. 10: 107-117, 1994b.

Villoresi G., Dorman L.I., Ptitsyna N.G. et al.: Forbush decreases as indicators of healthhazardous geomagnetic storms. Proc. 24th International Cosmic Ray Conference, Rome, 1995, Vol. 4, pp. 1106-1109.

von Steiger R. History of the solar wind. In: Schröder W. (ed.): Arbeitskreis Geschichte der Geophysik und Kosmische Physik. Meteorological and Geophysical Field Dynamics (A book to commemorate the centenary of the birth of Hans Ertel). Wilfried Schröder/Science Edition/Arbk. Geschichte Geophysik, Bremen 2004, pp. 75-89.

Watanabe Y., Cornélissen G., Halberg F.: Thousands of blood pressure and heart rate measurements at fixed clock hours may mislead. Neuro Endocrinol. Lett. 24: 339340, 2003.

Watanabe Y., Cornélissen G., Katinas G. et al.: Case report: a drug for damping circannual and transannual amplitudes of blood pressure and heart rate. Abstract, $2^{\text {nd }}$ International Symposium, Problems of Rhythms in Natural Sciences, Moscow, March 1-3, 2004. Russian People's Friendship University, Moscow 2004aI, pp. 18-20.

Watanabe Y., Watanabe F., Cornélissen G., Halberg F.: Infradian aspects of the blood pressure (BP) and heart rate (HR) chronomes during adolescence. Abstract S812, $3^{\text {rd }}$ Int. Congress on Cardiovascular Disease, Taipei, Taiwan, Nov. 26-28, 2004. Int. J. Cardiol. 97 (Suppl. 2): S15, 2004 bI.

Wever R.A.: The Circadian System of Man: Results of Experiments under Temporal Isolation. Springer-Verlag, New York 1979.

Weydahl A., Sothern R.B., Cornélissen G., Wetterberg L.: Geomagnetic activity influences the melatonin secretion at latitude $70^{\circ}$ N. Biomed. Pharmacother. 55:57-62, 2001.

Wohlfahrt J., Melbye M., Christens P. et al.: Secular and seasonal variation of length and weight at birth. Lancet North Am. Ed. 352: 1990, 1998.

Zeman M., Jozsa R., Cornélissen G. et al.: Chronomics: circadian lead of extrapineal vs. pineal melatonin rhythms with an infradian hypothalamic exploration. Biomed. Pharmacother. 59 (Suppl 1):S213-S219, 2005aI.

Zeman M., Stebelova K., Cornélissen G. et al.: Extension of Chossat phenomena to rat plasma melatonin: increase in circadian amplitude during starvation. Abstract, 
Noninvasive Methods in Cardiology, Brno, Czech Republic, Sept. 14, 2005bI, p. 23.

Zigel' F. (Dreier W., Lerche D., Übers., Göring H., Wissenschaftl. Red. der Deutschsprachigen):
Schuld ist die Sonne. Harri Deutsch, Thun/Frankfurt am Main 1979. 215 pp. 